Portland State University

PDXScholar

Summer 7-30-2013

\title{
Perceived Dangerousness of the Job and Well-Being Among Correctional Officers: the Role of Perceived Stress and Family Supportive Supervisor Behaviors (FSSB)
}

David Duane Meier

Portland State University

Follow this and additional works at: https://pdxscholar.library.pdx.edu/open_access_etds

Part of the Psychology Commons

Let us know how access to this document benefits you.

\section{Recommended Citation}

Meier, David Duane, "Perceived Dangerousness of the Job and Well-Being Among Correctional Officers: the Role of Perceived Stress and Family Supportive Supervisor Behaviors (FSSB)" (2013). Dissertations and Theses. Paper 1032.

https://doi.org/10.15760/etd.1032

This Thesis is brought to you for free and open access. It has been accepted for inclusion in Dissertations and Theses by an authorized administrator of PDXScholar. Please contact us if we can make this document more accessible: pdxscholar@pdx.edu. 
Perceived Dangerousness of the Job and Well-Being Among Correctional Officers: The Role of Perceived Stress and Family Supportive Supervisor Behaviors (FSSB)

by

David Duane Meier

A thesis submitted in partial fulfillment of the requirements for the degree of

\author{
Master of Science \\ in \\ Psychology
}

Thesis Committee:

Leslie Hammer, Chair

Charlotte Fritz

Kimberly Kahn

Portland State University

2013 


\begin{abstract}
Occupational stress has become a world-wide epidemic exacting severe tolls on both businesses and employees alike. Of all the workplace stressors, the perceived dangerousness of one's job is ever present within the occupation of corrections. The current study examined the mediating process of perceived stress on the relationship between perceived dangerousness of the job and the negative employee well-being outcomes of work-family conflict and symptoms of psychological distress, as well as the moderating effects of family supportive supervisor behaviors on this process. As part of a larger study, survey data were collected from 1,370 state correctional officers. It was hypothesized that perceived stress would fully mediate the relationship between perceived dangerousness of job and the negative well-being outcomes and that family supportive supervisor behaviors would moderate this mediation such that increased levels of family supportive supervisor behaviors would mitigate the negative well-being outcomes. The mediation hypotheses were not found to be supported. However, family supportive supervisor behaviors were found to moderate the relationship between perceived dangerousness of the job and work-to-family conflict. Additionally, family supportive supervisor behaviors were found to moderate the relationship between perceived stress and physical symptoms of psychological distress.
\end{abstract}


Table of Contents

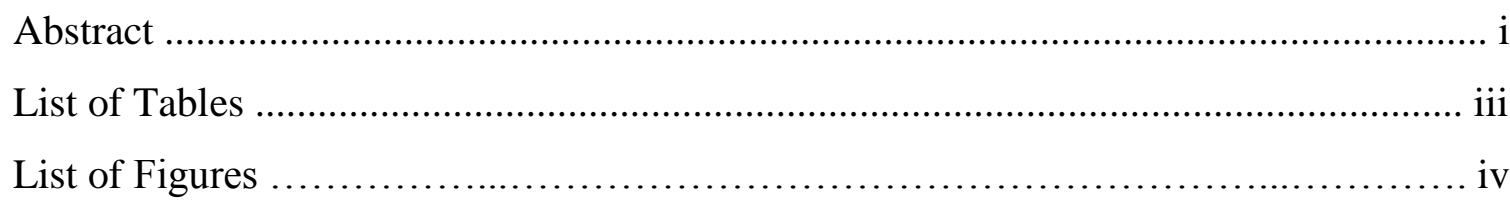

\section{Chapter 1}

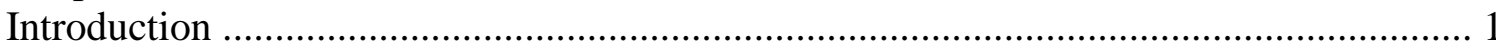

Chapter 2

Method

Chapter 3

Results

Chapter 4

Discussion

References

\section{Appendix}
A. Email of Support: Union Representative I .......................... 101
B. Email of Support: Union Representative II ............................... 102
C. Survey Recruitment Email: Assistant Director of Operations ............... 103
D. Templates for Email Support For Superintendents ...................... 105
E. First Reminder Email ............................................. 107
F. Second Reminder Email ........................................... 108

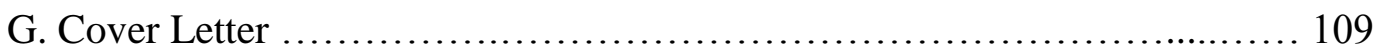
H. Current Study Survey Items ..................................... 110
I. PSU/ODOC Survey ............................................ 116 


\section{List of Tables}

Table 1

Means, Standard Deviations, and Zero-Order Correlations of Study Variables

Table 2

Hierarchical Multiple Regression Analyses Predicting Well-Being From PDJ 75

Table 3

Hierarchical Multiple Regression Analyses Predicting Well-being From PDJ, SRCI .... 76 


\section{List of Figures}

Figure 1

Model of Study Variables

Figure 2

Interaction Between PDJ and FSSB on WFC

Figure 3

Interaction Between Perceived Stress and FSSB on Physical Symptoms............... 79 


\section{Chapter 1 Introduction}

A major source of stress for many people is the workplace. Besides being prevalent, job stress is expensive for employers. The annual costs of employee stress, including costs due to absenteeism, reduced productivity, and health care costs have been estimated to be $\$ 200$ to $\$ 350$ billion in the United States, $\$ 64.8$ to $\$ 66.1$ billion in the United Kingdom, and \$232 billion in Japan (Miree, 2007).

The corrections industry has been argued to be one of the most stressful industries in which to work (Lambert, Hogan, \& Barton, 2002; Rosine, 1992). The overarching goals of the corrections system within the United States are to punish those found guilty of crimes, protect society from criminals, and rehabilitate criminal offenders. Incarceration is the most common form of punishment within our corrections system and the rate of individuals incarcerated within state and federal jurisdiction in the United States has been steadily growing. In 1990 this rate was 297 per 100,000 of the population, while in 2005 this rate had grown to 491 per 100,000 of the population (Glaze, 2010). The overcrowding that has developed as a result of an incarceration rate outpacing facility construction is unarguable. Indeed, in 2005 federal prisons were operating at $37 \%$ above their design capacity and state prisons were operating at $8 \%$ above design capacity (Bureau of Justice Statistics, 1990; 2005).

The daily oversight of inmates is the primary responsibility of correctional officers, who comprise over $60 \%$ of state and federal correctional employees (Bureau of Justice Statistics, 1990; 2005). In 1990 a total of 169,587 correctional officers were employed by state and federal prisons, a number that grew to 295,261 in 2005 (Bureau of 
Justice Statistics, 1990; 2005). Thus, while the number of inmates grew by $99.8 \%$ between 1990 and 2005, the number of correctional officers grew by only $74.1 \%$ during this same time period (Bureau of Justice Statistics, 1990; 2005). As such, the number of inmates per full-time employed correctional officer within state and federal prisons has grown from 4.22 in 1990 to 4.84 in 2005 . This increased ratio of inmates to correctional officers may be a contributing component to the dangerousness of the job perceived by correctional officers and the corresponding perceived stress.

As an occupational group, correctional and law enforcement officers have been found to have lessened life spans. Indeed, Cheek (1984) reported corrections officers to have life spans sixteen years lower than the national average (59 years compared to 75 years). Parker (2011) determined that correctional and law enforcement officers in Florida as a group had life spans nearly twelve years lower than the state general population (62.4 years compared to 74.2 years). Additionally, correctional officers have been found to have elevated rates of suicide (Stack \& Tsoudis, 1997; Task Force on Police Suicide, 2009) and divorce (Cheek \& Miller, 1983; Shawn \& Aamodt, 2010). Despite these observations, empirical studies examining the potential stress related effects on well-being among correctional officers are still scarce.

The current study sought to address this need in the literature utilizing a sample of state correctional officers to examine perceived stress as a mediator of the relationship between perceived dangerousness of the job (PDJ), a particularly salient occupational stressor for correctional officers (Cullen, Link, Wolfe, \& Frank, 1985; Lambert, Hogan, \& Barton, 2002), and the negative well-being outcomes of work-to-family conflict 
(WFC), family-to-work conflict (FWC), and physical symptoms of psychological distress (physical symptoms). The support of one's supervisor in particular has been found to be beneficial in reducing work-family conflict (Eby, Casper, Lockwood, Bordeaux, \& Brinley, 2005). Additionally, in their 2011 article investigating the relationship between work-family conflict and depression among correctional officers, Obidoa and colleagues suggest that information on work-environment factors such as the presence or absence of support in the workplace from coworkers and supervisors will help to provide a more robust explanation of work-family conflict among this occupational group (Obidoa, Reeves, Warren, Reisine, \& Cherniack, 2011). Given this, the current study also investigated the moderating role of family supportive supervisor behaviors (FSSB) on the perceived dangerousness of the job-perceived stress-negative well-being outcome relationship. It was hypothesized that the moderating role of FSSB would mitigate the negative well-being outcomes in question. A theoretical model on which this study is based is shown in Figure 1. The following sections review the study variables with discussion of the constructs and previous related research in addition to a general overview of stress associated with correctional work. I begin with a review of a specific potential source of stress for correctional officers that originates from the work itself and is the independent variable of the current study: perceived dangerousness of the job.

\section{Perceived Dangerousness of the Job}

Many occupations involve tasks or working environments that carry with them the possibility of employees suffering harm or injury. Dangerous aspects of work have been considered in the psychological literature involving many occupations such as 
firefighting (Colquitt, Lepine, Zapata, \& Wild, 2011; Del Ben, 2008; Edge, 2008), direct

medical care (Allen, de Nesnera, Cummings, \& Darling, 2011), mental health (Wilhelm, Kovess, Rios-Seidel, \& Finch, 2004), crisis intervention (Weaver, 1984), construction (Goldenhar, Williams, \& Swanson, 2003), commercial fishing (Gold, Geater, Aiyarak, Wongcharoenyong, Juengprasert, Chuchaisangrat, \& Griffin, 2000), professional driving (Honkasalo, 1992), and game conservation (Walsh \& Donovan, 1984). This said, however, it is mainly within the occupations of policing (Cullen, Link, Travis, \& Lemming, 1983; Cullen, Lemming, Link, \& Wozniak, 1985), corrections (Cullen, Link et al., 1985), and correctional facility support in general (Lambert, Cluse-Tolar, \& Hogan, 2007; Lambert et al., 2002) that the level of occupational danger perceived by the employee has been specifically assessed and studied.

While there are a myriad of potential job characteristic stressors for correctional employees that can be studied, perceived dangerousness of the job is one of the most salient (Lambert et al., 2002). For example, $49 \%$ of a sample of correctional officers defined "danger" as the main "disadvantage" of their jobs (Jacobs \& Retsky, 1975) while another study found that $50 \%$ of the respondents indicated physical danger and mental strain as an unsatisfying aspect of the job (Lombardo, 1981). Additionally, Cullen and Link et al. (1985) found the threat of inmate violence to be the second highest source of stress for their correctional officer sample while interviewees participating in Finn's (1998) study identified the threat of inmate violence as a greater source of stress than any other single feature of their occupation. Despite the self-reported salience of dangerousness associated with the occupation of correctional officer, there is a lack of 
existing research investigating this factor from an industrial and organizational perspective. Additionally, the limited publications of previous research investigating this factor in the criminology literature seldom include an explicit theoretical framework. The current study addresses both of these concerns.

Potential dangers associated with correctional work. Correctional officers have good reason to view their work as dangerous. Only police officers have a higher number of workplace nonfatal violent incidents per 1,000 employees (Finn, 2000). From 1992 to 1996 there were 218 incidents for every 1,000 correctional officers in the United States (Finn, 2000). Correctional officers, however, reported more nonfatal occupational injuries and illnesses that required days away from work in 2010 than any other state government occupation, thus comprising $16 \%$ of the total number of cases (U.S. Bureau of Labor Statistics, 2011). And tragically, as of May 2012, a total number of 585 correctional officers in the United States have been recorded as losing their lives in the line of duty since the year 1971 (National Law Enforcement Officers Memorial Fund, 2012).

The job of a corrections officer is relatively unique in that it requires the monitoring, supervising, and transportation of involuntary clients, and the overcrowding experienced in many correctional facilities can create a degree of disorder and tension that facilitates violence (Gibbons \& Katzenbach, 2006). Compounding these dangerous working conditions, correctional officers often work long shifts without sufficient backup, support, or training (Finn, 2000). Interestingly, the time of day a correctional officer works may impact their perceived dangerousness of the job. Cheek and Miller 
(1983) found that their correctional officer participant group reported experiencing the most "tension" when working the second shift (usually 2:20 P.M through 10:20 P.M.). This was the period of the day when the correctional officers were most directly involved with the individual activities of the inmates and most concerned about inmate-tocorrectional officer problems occurring. Additionally, correctional officers working the third shift (usually 10:20 P.M. through 6:20 A.M.) reported experiencing less tension than those working the second shift and correctional officers working the first shift (usually 6:20 A.M. through 2:20 P.M.) reported experiencing the least tension of all three shifts. Threats of inmate-on-correction officer violence, actual inmate-on-correction officer violence, the breaking up of inmate-on-inmate fights, being taken hostage, riots, escape attempts, and inspecting mail and visitors for prohibited items are all potential dangerous situations that correctional officers may experience every day they show up for work. Sadly, in 1995 alone, the most recent year for which I could find data specific to correctional officer employees, there were a combined total of 14,165 reported inmate attacks on correctional officers in state and federal facilities (Finn, 2000).

Physical violence is not the only source of danger associated with correctional work. The maintaining of order in correctional facilities requires routinely performing pat, strip, and cell searches as well as responding to attempted inmate suicides, medical emergencies, and accidents. The performing of these tasks place correctional officers in situations where they may come into direct contact with sharp objects, blood, and bodily fluids. This element of danger is exacerbated by those inmates who choose to spit and/or throw bodily waste (McIntyre, Marquart, \& Brewer, 1999). Years of poor health care, 
poverty, and substance abuse result in inmates as a group being far less healthy than the general population thus making infectious diseases such as tuberculosis, hepatitis $\mathrm{C}$, and HIV/AIDS potential biological hazards to be faced at work by correctional officers (Gibbons \& Katzenbach, 2006; McIntyre et al., 1999; Wright \& Northrup, 2001). The Bureau of Justice Statistics reported that in 2004 the overall rate of confirmed AIDS cases among inmates at $0.50 \%$ was more than three times higher than that of the general population at $0.15 \%$ (Bureau of Justice Statistics, 2006). Given this, it is not surprising that correctional officers report being fearful of contracting an infectious disease while at work (Freeman \& Johnson, 1982; Mahaffey \& Marcus, 1995).

Outcomes of perceived dangerousness of the job. As a construct, perceived dangerousness of job has been almost exclusively included in studies as an independent variable and has been shown to have a significant negative relationship with job satisfaction (Moon \& Maxwell, 2004; Lambert et al., 2002, Lambert \& Paoline, 2005) and distributive justice (Lambert, Hogan, \& Griffin, 2007). Additionally, significant positive relationships have been found between perceived dangerousness of the job and life and work stress (Castle \& Martin, 2006; Cullen et al., 1983; Cullen, Link et al., 1985; Lambert, Cluse-Tolar et al., 2007; Lambert \& Paoline, 2005; Triplett, Mullings, \& Scarborough, 1999), role ambiguity (Lambert et al., 2002), role conflict (Lambert et al., 2002), the emotional exhaustion dimension of job burnout (Lambert \& Hogan, 2010), and work-to-family conflict (Lambert \& Hogan, 2006). Measurement of perceived dangerousness of the job in these works has been conducted either with Cullen and colleagues' original 1983 five item scale or, more commonly, a reduced scale consisting 
of four of the original five items. With a review of the construct of perceived dangerousness of the job complete, I will now review perceived stress, the mediating variable of the current study.

\section{Perceived Stress}

Stress and its processes have long been of interest to scholars and the layperson alike. As Hobfoll (1989) notes, there are few areas in the study of psychology that have received more attention than stress and its processes. The scientific study of stress has proven to be an arduous task with even a universally accepted definition of the term "stress" yet to be established. Some researchers even claim that it is almost a tradition to point out the difficulties surrounding the different definitions of stress (Dewe \& Trenberth, 2004). Even the terms used to denote the variables associated with the processes of stress have been used in inconsistent and potentially confusing ways (Lazarus, 1993). In the remainder of this section I will overview historical developments in stress research, introduce and outline the transactional model of stress and coping, overview the job demands-resources model of workplace stress, both of which serving as theoretical frameworks for this study, and give a general overview of work stress related to the occupation of correctional officer.

Walter Cannon believed that stress occurred when environmental demands challenged the homeostatic balance of an individual thus placing stress in a stimulusresponse framework in which chronic stress could inhibit homeostatic balance recovery and lead to ill health (Cannon, 1932). Cannon's emphasis on stress as a response to stimuli was continued by Hans Selye who published works in which he presented the idea 
that individuals undergo stages of adaptation to environmental demands or as he phrased them, "noxious agents" as the experience of stress. According to Selye, an individual has a finite capacity for adaptation and if the noxious agent(s) are not countered by an outside force the individual will eventually become exhausted from the effort of adaption and ultimately perish (Ganster \& Perrewe, 2011). Around the same time Selye was working on his stages of adaptation, other investigators were obtaining research results in seeming contradiction to a stimulus-response view of stress. In these studies researchers found that participants did not react in a uniform manner to stressful conditions (Lazarus \& Eriksen, 1952). These studies supported a new and emerging view of stress; that of the stimulusorganism-response (Lazarus, 1993). With the historical developments in stress research broadly reviewed, I will now overview the transactional model of stress and coping which serves as the theoretical framework for this study.

The transactional model of stress and coping. The transactional model of stress and coping has been developed by Richard Lazarus and his colleagues over a number of years and is sometimes referred to as the cognitive theory of psychological stress and coping or the cognitive-relational approach. Throughout the rest of this proposal I will refer to the model as the transactional model of stress and coping despite the continued development of the model over the decades and the variety of titles that have come to be attached to it.

The transactional model of stress and coping views the cognitive processes of the individual as key to the response to external or internal conditions/events or demands (Lazarus, 1999). Given this, "stress is conceptualized as a relationship between the 
person and the environment that is appraised by the person as taxing or exceeding his or her resources and as endangering wellbeing (Folkman, Lazarus, Gruen, \& DeLongis, 1986, p. 993)." Within the transactional model of stress and coping, cognitive appraisal and coping are identified as the mediators of a stressful person-environment relationship and their immediate and long-term outcomes (Folkman, Lazarus, Gruen et al., 1986). According to the model, external or internal demands or events are first appraised by the individual before a response occurs. This appraisal process has two components, primary and secondary appraisal, and is anteceded by environmental and personal variables (Lazarus, 1999).

According to Lazarus (1999), the anteceding environmental variables of the appraisal process include demands, constraints, opportunity, and culture. Lazarus defines demands as consisting of the implicit or explicit pressures an individual perceives from their social environment to act in certain ways and to manifest socially correct attitudes. Constraints, on the other hand, are defined as what an individual perceives from their social environment as what they should not do. Opportunity entails "a combination of luck and positioning oneself to take advantage of an opportunity (Lazarus, 1999, p. 64).” Lastly, Lazarus defines culture as cultural values and meanings that are internalized by the individual and become a part of the individual's goals and beliefs.

The person variables that antecede the appraisal process are goals and goal hierarchies, beliefs about self and world, and personal resources. According to Lazarus (1999), goals and goal hierarchies are what an individual values most and least, along with the probabilities and costs of trying to actualize them. Beliefs about self and world 
refer to how an individual conceives themself and their place in the environment. These beliefs shape expectations about what is likely to happen in an encounter as well as what an individual can hope for and fear (Lazarus, 1999). Lastly, personal resources greatly influence an individual's chances of adaptational success when confronted with an external or internal demand and include intelligence, money, social skills, education, supportive family and friends, physical attractiveness, health and energy, and sanguinity (Lazarus, 1999). These environmental and person variables interact to influence both the appraisal and coping processes.

As mentioned previously, according to the transactional model of stress and coping there are two components to the appraisal process: primary appraisal and secondary appraisal. It is important to note that Lazarus (1999) states that these two components of appraisal work interdependently and despite their qualifying adjectives of "primary" and "secondary" primary appraising does not necessarily occur first. In the primary appraisal process, an individual perceives if the external or internal demand/environmental condition is relevant to their values, goal commitments, beliefs about self and world, and/or situational intentions (Lazarus, 1999). Lazarus states that if the external or internal demand/environmental condition is not perceived to be relevant (i.e., in challenge to) these factors, no stress condition will occur. However, if the external or internal demand/environmental condition is perceived to be relevant then a stress condition will occur in the form of either a harm/loss, threat, and/or challenge appraisal (Lazarus, 1999). A harm/loss condition or appraisal consists of damage, psychological and/or physical, that has already occurred. Threat stress conditions or 
appraisals consist of the perceived possibility or anticipation of such damage in the future while challenge conditions or appraisals are perceived by the individual as opportunities for mastery or gain (Folkman \& Lazarus, 1980; Lazarus, 1999).

The secondary appraisal process is essentially a cognitive evaluation process by the individual regarding what can be done about a stressful condition/appraisal or in other words, an assessment of the controllability of the condition/appraisal by the individual based on available coping resources. It is by this process that an individual evaluates their coping options, decides on which ones to choose, and how to set them in motion (Lazarus, 1999). Thus, "the degree to which a person experiences psychological stress, that is, feels harmed, threatened, or challenged, is determined by the relationship between the person and the environment in that specific encounter as it is defined both by the evaluation of what is at stake and the evaluation of coping resources and options (Folkman \& Lazarus, 1980, p. 223).”

The transactional model of stress and coping defines coping as "the cognitive and behavioral efforts made to master, tolerate, or reduce external and internal demands and conflicts among them (Folkman \& Lazarus, 1980, p. 223)" and posits that there are two coping strategies available to an individual: problem-focused and emotion focused (Folkman \& Lazarus, 1980). Problem-focused coping involves a person obtaining information about what can be done regarding the stress condition/appraisal and then mobilizing actions for the purpose of changing the reality of the stressful personenvironment relationship. Emotion-focused coping, on the other hand, is a function aimed to regulate the emotions associated with the stress condition/appraisal (Lazarus, 1999). 
An example provided by Lazarus of this type of coping process would be attributing a spouse's harsh words to a difficult day at work instead of perceiving it as a manifestation of anger from one spouse to the other. Previous research by Folkman, Lazarus, and colleagues (Folkman, 1984; Folkman, Lazarus, Dunkel-Schetter, DeLongis, \& Gruen, 1986; Folkman, Lazarus, Gruen et al., 1986) has demonstrated that the choice of coping option is largely determined by the individual's perceived controllability of the stress condition/appraisal. When the stress condition/appraisal is perceived as changeable, or within the individual's control, problem-focused coping has been found to predominate. However, when the stress condition/appraisal is perceived as unchangeable or not within the individual's control, emotion-focused coping tends to be the predominant coping choice (Lazarus, 1999). It is important to note that coping choice can change if one strategy is found to be ineffective or the stress condition/appraisal changes (Lazarus, 1999). Lastly, the transactional model of stress and coping posits that if coping resources prove inadequate to counter the stress condition/appraisal or choice of coping strategy is inefficient then negative outcomes with regards to an individual's subjective well-being, social and work function, and/or somatic health can ensue (Lazarus, 1999).

The job demands-resources model. The job demands-resources model (JD-R) is another transactional model of stress and pertains specifically to the workplace (Demerouti, Bakker, Nachreiner, \& Schaufeli, 2001). Working conditions are grouped into one of two categories within the JD-R: job demands and job resources. Job demands are defined as physical, social, or organizational aspects of one's work that require efforts and thus have physical and mental costs associated with them. Job resources, on the other 
hand, are defined as physical, psychological, social, or organizational aspects of one's work that help with the achievement of work goals, reduce demands, or stimulate growth and development (Demerouti et al., 2001). According to the JD-R model, demanding and resource providing work conditions influence key processes involved in health impairment as well as motivation. A critical assumption of the model is that job stress or burnout develop when job demands are high and job resources low (Demerouti et al., 2001).

The JD-R model is considered to be a heuristic, overarching model of job stress that can be applied to any occupational setting without regard to the particular demands or resources contained within (Llorens, Bakker, Schaufeli, \& Salanova 2006). Previous research utilizing a JD-R theoretical framework has shown it to predict outcomes such as job satisfaction (Lewig \& Dollard, 2003), work engagement (Bakker, Hakanen, Demerouti, \& Xanthopoulou, 2007), and burnout (Demerouti et al., 2001). Additionally, many different resources may act as a buffer to the effect of many different demands on stress related outcomes (Bakker, Demerouti, \& Euwema, (2005).

With the transactional model of stress and coping and the job demands-resources model reviewed, I will now provide a brief overview of potential sources and negative outcomes of occupational stress associated with the occupation of correctional officer. These sources of stress can be understood as potential stimuli in the stimulus-organismresponse view of stress while the negative outcomes constitute potential negative responses within this view. 
Correctional officer stress. Correctional work has been described as an occupation that is more stressful than most (Lambert et al., 2002; Rosine, 1992) and this is partially due to the fact that correctional officers perform their work roles in environments filled with hostility, disrespect, isolation, and confinement (Cheek \& Miller, 1983). Potential stress stimuli originating from the organization, the work itself, and from outside the corrections system all combine to create an occupation potentially fraught with stress (Finn, 1998; Moon \& Maxwell, 2004).

Organizational sources of stress or stress related stimuli for correctional officers can include understaffing, overtime, shift work, role conflict, and role ambiguity (Dowden \& Tellier, 2004; Lambert, Hogan, Camp, \& Ventura, 2006; Lambert \& Paoline, 2005; Swenson, Waseleski, \& Hartl, 2008). Sources originating from performing the work itself include threats and actual inmate violence, inmate demands and attempts at manipulation, and problems with coworkers (Cullen, Link et al., 1985; Finn, 1998; Lambert, Cluse-Tolar et al., 2007). Finally, poor public image and low pay are two additional reported sources of stress for correctional officers that originate from outside the corrections system. According to Van Fleet, negative images are regularly reflected in the media portraying correctional officers as "stupid, animalistic, and senseless abusers of socially wronged individuals (Van Fleet, 1992)." Additionally, in 2010 the median pay for a correctional officer in the United States was $\$ 39,020$ per year, or $\$ 18.76$ an hour while the median pay for police officers and detectives was $\$ 55,010$ per year, or $\$ 26.45$ an hour (U.S. Bureau of Labor Statistics, 2012a, b). This discrepancy in pay between law 
enforcement occupations may be just one contributor to the reports of correctional officers citing low pay as a source of stress (Stohr, Lovrich, \& Wilson, 1994).

According to Lazarus and Folkman, excessive demands and/or a lack of adequate coping resources to counter workplace stressors or stimuli can potentially lead to ill effects or negative responses with regard to an employee's well-being (Lazarus, 1999). The negative well-being outcomes or responses associated with occupational stressors or stimuli for correctional officers can be broadly classified into four categories: workrelated, psychological and emotional, physical, and maladaptive behavioral outcomes. With regard to work-related outcomes, job stress has been negatively associated with job satisfaction, organizational commitment, and workplace safety among correctional officers (Finn, 2000; Lambert, 2004; Lambert, Cluse-Tolar et al., 2007) and positively related to the use of sick time and turnover (Finn, 1998), as well as burnout (Lambert \& Hogan, 2010). Psychological and emotional outcomes related to job stress among correctional officers include increased tension, fatigue, irritability, excitability, and depression (Lambert et al., 2006; Obidoa et al., 2011). It is interesting to note here that a meta-analysis conducted by Dowden and Tellier (2004) regarding the predictors of workrelated stress in correctional officers indicated that officers who were minorities experienced significantly less job stress than Caucasian officers. For example, Britton (1997) found that African American correctional officers reported lower levels of job stress utilizing a six item job stress scale assessing the degree to which the participants believed that the job was hardening them emotionally and whether they felt strain, were drained emotionally, or fatigued by their work. In a review of the correctional officer 
stress literature from 1977 to 2007, Morgan found heart disease, poor circulation, highblood pressure, teeth grinding, and aches and pains of the hands, neck, or back to be physical outcomes or negative responses associated with occupational stress for correctional and police officers (Morgan, 2009).

Potential maladaptive behavioral outcomes of occupational stress for correctional officers often touch the lives of their loved ones. A Governor's Task Force in New Jersey found that for the years 2003 to 2007 , for males ages 25 to 64 , per 100,000 the suicide rate for correctional officers in that state was 34.8 compared to their police force with a suicide rate of 15.1 and the general state population at a rate of 14.0 (Task Force on Police Suicide, 2009). These results are similar to those found by Stack and Tsoudis (1997). Utilizing multivariate logistic regression analysis with data from 21 states, Stack and Tsoudis found the risk of suicide among correctional officers to be $39 \%$ higher than that of the rest of the working age population. In addition to this alarming statistic, Cheek and Miller (1983) found the divorce rate of their sample of 143 correctional officers to be 20.9\%. Indeed, in an analysis of U.S. Census data from the year 2000, Shawn and Aamodt (2010) found the divorce rate for corrections officers to be $21.54 \%$ and $19.58 \%$ for corrections supervisors, both of which being higher than the national average of $16.35 \%$ for all census occupations at that time. Additionally, correctional officers experiencing excessive occupational stress may weaken their family relationships by displacing frustrations onto spouses and children (Finn, 1998; 2000). Correctional officers are required to learn roles at work, such as barking orders at or questioning the activities of others, that are not necessarily appropriate in everyday social and family life 
(Lambert et al., 2006). Taking these factors as well as the need to perform shift work and overtime into account, it is not surprising that job stress has been found to be positively related to work-to-family conflict, an outcome variable in the current study, among correctional officers (Lambert \& Hogan, 2006).

With perceived dangerousness of the job and perceived stress discussed, I will now overview physical symptoms of psychological distress, an outcome variable of the proposed study.

\section{Physical Symptoms of Psychological Distress}

Studies of job stress often involve investigating relationships between workplace stressors and their impact on employees. Many theoretical models for this process exist, however, most of them propose that the employee is exposed to stressful working conditions, the conditions are then perceived by the employee, and then the employee exhibits a reaction to the stressor(s) or "strains" (Spector \& Jex, 1998). The transactional model of stress and coping is one such model. Strains, or negative responses to stressful stimuli can include maladaptive behaviors, physical illness, and psychological distress (Spector \& Jex, 1998). Psychological distress has been broadly defined as a nonspecific term that encompasses sadness, frustration, anxiety, depression, and a number of other negative mood states. Psychological distress includes mild, moderate, and severe forms of these mood states, as well as both transient and persistent ones. Finally, psychological distress also refers to symptoms of psychiatric disorders as well as normal emotional responses to stress (Addonizio, 2012). Psychological distress can have somatic symptoms, which are manifestations of physical strain (Nixon, Mazzola, Bauer, Krueger, 
$\&$ Spector, 2011). Some of the somatic symptoms of psychological distress that have been investigated in previous research include headache, nausea, sweaty palms (Ganster, Fusilier, \& Mayes, 1986), sleep problems, heart symptoms (Hurrell \& Lindstrom, 1992), backache, eye strain, fatigue (Spector, Dwyer, \& Jex, 1988), skin rash, shortness of breath, chest pain, fever, acid indigestion or heartburn, diarrhea, stomach cramps, constipation, loss of appetite, and dizziness (Spector \& Jex, 1998). Interpersonal conflict, organizational constraints, workload, role ambiguity, number of hours worked, lack of control (Hurrell \& Lindstrom, 1992; Nixon et al., 2011; Spector 1987, Spector et al., 1988), work under-load (Ganster et al., 1986), lack of job clarity, and limited promotion opportunities (Hurrell \& Lindstrom, 1992) have all been found to be workplace stressors positively related to physical symptoms of psychological distress.

As mentioned earlier, irritability and depression (Lambert et al., 2006; Obidoa et al., 2011) are two common forms of psychological distress experienced by correctional officers. Indeed, in a study assessing the impact of work-family conflict on depression among a sample of 220 correctional officers from two prisons in the northeastern United States, Obidoa, Reeves, Warren, Reisine, and Cherniack (2011) found 31\% of their participants to have ratings of depression above the cutoff for serious psychological distress. Using a transactional model of stress and coping framework, the current study views physical symptoms of psychological distress as outcomes or responses derived from an individual's inability to successful cope with the perceived stress resulting from the perceived dangerousness of the job. In the next section I will discuss the construct of work-family conflict, the predictors and outcomes associated with work-family conflict, 
and previous research involving correctional officers and work-family conflict, a major outcome examined in the current study.

\section{Work-Family Conflict}

Work-family conflict is a form of interrole conflict in which the role demands stemming from either the work or family domains are incompatible with role demands stemming from the other (Greenhaus \& Beutell, 1985; Parasuraman \& Greenhaus, 2002). While early work-family research during the 1980s conceptualized work-family conflict as a unidimensional construct (e.g., Bedeian, Burke, \& Moffett, 1988; Cooke \& Rousseau, 1984: Kopelman, Greenhaus, \& Connolly, 1983), it has now come to be generally viewed and researched as two dimensional (Frone, Russell, \& Cooper, 1992a, 1992b; Kelloway, Gottlieb, \& Barham, 1999; Williams \& Alliger, 1994). These two dimensions are work interfering with family, or work-to-family conflict (WFC), and family interfering with work, or family-to-work conflict (FWC), and are distinct and reciprocal constructs that have independent antecedents and outcomes (e.g., Anderson, Coffey, \& Byerly, 2002; Carlson \& Kacmar, 2000; Frone, Yardley, \& Markel, 1997; Grandey \& Cropanzano, 1999). Evidence has been found, however, suggesting that WFC is more prevalent than FWC (Eagle, Miles, \& Icenogle, 1997; Gutek, Searle, \& Klepa, 1991).

The need for work-family conflict research. Changes in the composition of the labor pool have prompted an increase in research over the last four decades investigating the relationship between individuals' work and family lives (Eby et al., 2005). The proportion of women in the labor force has been steadily increasing. In 2010, $47.2 \%$ of 
the U.S. workforce over the age of 16 was comprised of women (U.S. Census Bureau, 2012) compared to $43.7 \%$ in 1983 (U.S. Census Bureau, 2001). This influx of women into the labor force has also increased the number of dual-earner couples (Offermann \& Gowing, 1990). The proportion of married couples in the U.S. with both husband and wife in the labor force was $49.9 \%$ in 1986 (U.S. Census Bureau, 2004) compared to $54.2 \%$ in 2010 (U.S. Census Bureau, 2012). The world population is aging as well with the population of persons 65 and over in the U.S. increasing at a faster rate than any other sector and in 2011, 17.9\% of this age group was employed (U.S. Bureau of Labor Statistics, 2012c).

In addition to these changes in the labor pool, the U.S. population has begun a trend of delaying childbearing until later in life (Hammer \& Zimmerman, 2011). With the population living longer and women postponing childbearing, many families find themselves in the position of having to provide both child and elder parent care simultaneously (Hammer \& Zimmerman, 2011). This situation can be particularly challenging for couples who are both in the labor force and in 2010, $64.3 \%$ of married couples with their own children under the age of 18 were both working (U.S. Census Bureau, 2012). The condition of being generationally "sandwiched" is and will continue to be a concern for a large percentage of employees and employers alike well into the foreseeable future (Neal \& Hammer, 2007).

The changes in the labor pool and the phenomenon of the "sandwiched generation" have the potential of making the fulfillment of work and family roles more difficult. There has been an increase in the number of three-generation households and as 
more and more women enter the work force they, and men, may find themselves with increased responsibilities that are often in contradiction to traditional gender roles (Offermann \& Gowing, 1990). The conflict that can arise from competing work and family role expectations has been the source of much empirical investigation (see Allen, Herst, Bruck, \& Sutton, 2000; Byron, 2005; Greenhaus \& Beutell, 1985; Kossek \& Ozeki, 1999 for meta-analyses and reviews).

Most individuals spend the majority of their lives striving to meet the expectations and demands required to fulfill their roles within the work and family domains. Employees have long been aware that the complete separation of the work and family domains is nearly impossible (Hammer \& Zimmerman, 2011). Even when one works far away from the home thoughts of upcoming family events or sudden family emergencies can intrude into the work domain. Additionally, when at home one may worry over unfinished projects at work or receive communications from the workplace. Rosabeth Kanter's 1977 book titled, "Men and women of the corporation", has helped greatly to dispel the "myth of separate worlds" held by many organizations that work and family domains are mutually exclusive (Hammer \& Zimmerman, 2011; Higgins \& Duxbury, 1992). Work-family research increased drastically during the 1980's (Eby et al., 2005), as academics and practitioners began to investigate and seek methods of mitigating the negative outcomes that can stem from the interaction of work and family domains. Although numerous theories have been employed in the endeavor of hypothesis generation and testing within work-family research, Role Theory, developed by Kahn and 
colleagues, has been one considered to be of critical importance (Hammer \& Zimmerman, 2011).

Role theory. In their seminal work on organizational stress, Kahn and colleagues posited that roles are the result of expectations of others regarding appropriate behaviors in a particular position (Kahn, Wolfe, Quinn, Snoek, \& Rosenthal, 1964). Within this role theory, role conflict can be defined as the "simultaneous occurrence of two (or more) sets of pressures such that compliance with one would make more difficult compliance with the other" (Kahn et al., 1964, p. 19). Pressures can stem from within and between roles making multiple role conflict situations possible. Within a single role, intrarole conflict occurs when one experiences pressure in the form of incompatible demands from two or more expectation senders. Interrole conflict, in contrast, occurs between roles when pressures stemming from one role are incompatible with pressures stemming from one or more other roles. Given this, work-family conflict is a form of interrole conflict.

The study of the effects of simultaneously occupying multiple roles has been largely guided by the scarcity and enhancement hypotheses (Hammer \& Zimmerman, 2011). The scarcity hypothesis posits that individuals have limited time and energy and that the opportunity for role conflict increases with the number of roles an individual occupies (Goode, 1960). In response to the scarcity hypothesis, the enhancement or expansion hypothesis posits that the engagement in multiple roles can produce positive outcomes. This hypothesis argues that multiple roles can be associated with various rewards such as role privileges, status security, resources, personality enrichment, and ego gratification that can not only offset the costs of engaging in multiple roles 
simultaneously but even lead to better role functioning (Marks, 1977; Sieber, 1974). As such, the enhancement hypothesis serves as the basis for work-family positive spillover and enrichment research (Hammer \& Zimmerman, 2011). It is important to note that some researchers have argued that the engagement in multiple roles simultaneously can be both a source of role enhancement and role conflict at the same time (Crouter, 1984; Gerson, 1985; Tiedje et al, 1990). While in contrast with one another, both the scarcity and enhancement hypotheses stem from social identity theory (Mead, 1934; Stryker, 1968) which posits that the self is comprised of social identities that are determined by both the individual and others who send role expectations.

Predictors of work-family conflict, WFC, and FWC. Previously investigated predictors of work-family conflict include family and background characteristics, work and job attributes, employee behaviors, coping, and child and parenting variables (Eby et al., 2005). Work-related antecedents tend to have a stronger relationship with WFC whereas family antecedents tend to have a stronger relationship with FWC (Hammer \& Zimmerman, 2011).

Within the family domain, single parents have been found to generally report higher levels of work-family conflict thus indicating marital status as a predictor of workfamily conflict in general (Duxbury, Higgins, \& Lee, 1994; Eagle, Icenogle, Maes, \& Miles, 1998) in addition to having children at home (Behson, 2002; Carlson, 1999; Grzywacz \& Marks, 2000). Additionally, having children at home (Grandey \& Cropanzano, 1999) has been shown to be positively related to FWC in particular. 
There have been numerous studies investigating the characteristics of the work domain as predictors of work-family conflict. Working nonstandard workdays (Staines \& Pleck, 1984) has been found to have a negative relationship with WFC in particular. Having more conflict, pressure, and stress at work (Carlson, 1999; Carlson \& Perrewe, 1999; Fox \& Dwyer, 1999; Greenhaus, Bedeian, \& Mossholder, 1987; Grzywacz \& Marks, 2000; Shamir, 1983; Wallace, 1997), the number of hours worked and length of work shift (Carlson \& Perrewe, 1999; Greenhaus et al., 1987; Nielson, Carlson, \& Lankau, 2001; Shamir, 1983), unpredictable and/or inflexible work schedules (Fox \& Dwyer, 1999; Hammer, Allen, \& Grigsby, 1997), and working weekends and rotating shifts (Shamir, 1983) have all been found to be positively related to work-family conflict in general. Additionally, job stress (Byron, 2005), time spent at work (Byron, 2005; Parasuraman, Purohit, Godshalk, \& Beutell, 1996), role ambiguity, and perceived dangerousness of the job (Lambert \& Hogan, 2006) have been found to be positively related to WFC in particular.

Supervisor and organizational support has been shown to be beneficial in reducing work-family conflict. Work support (Carlson \& Perrewe, 1999; Greenhaus et al., 1987; Thompson, Beauvais, \& Lyness, 1999), having a mentor who is perceived as having similar work-family values (Nielson et al., 2001), and having a family specific supportive supervisor (Breaugh \& Frye, 2008; Kossek, Pichler, Bodner, \& Hammer, 2007) have all been found to be related to lower levels of work-family conflict in general. Not surprisingly it has been found that experiencing abusive supervision relates positively to work-family conflict in general (Tepper, 2000). 
Previous work-family conflict research and correctional officers. As

previously mentioned, existing empirical studies investigating work-family conflict among correctional officers are scarce. Additionally, of the fourteen previous studies that I have been able to locate that included the measurement of work-family conflict with a sample including correctional officers, only five have utilized work-family conflict as a dependent or outcome variable (Dollard \& Winefield, 1998; Lambert, 2008; Lambert, Altheimer, Hogan, \& Barton-Bellessa, 2011; Lambert \& Hogan, 2006; Lambert, Hogan, $\&$ Barton, 2004). Outcome variables investigated within the other fourteen studies included burnout (Lambert \& Hogan, 2010; Lambert, Hogan, \& Altheimer, 2010; Shamir \& Drory, 1982), job stress (Griffin, 2006; Lambert et al., 2006; Lambert et al, 2007; Triplett et al., 1999), job satisfaction (Lambert et al., 2002; Lambert et al., 2006), organizational commitment (Lambert et al., 2006), and depression (Obidoa et al., 2011). As the current study utilizes WFC and FWC as outcome variables, I will now review these previous published works.

In 1998 Dollard and Winefield tested the demand-control/support model of work stress (Johnson \& Hall, 1988; Karasek, 1979) among 419 Australian correctional officers (Dollard \& Winefield, 1998), demonstrating a link between high demands, low control, and low support and WFC. The study results suggested that an additive combination of high demands, low control, and low support lead to the highest levels of strain, including WFC, among correctional officers. Additionally, shift workers showed significantly higher levels of WFC than non-shift workers. WFC, referred to as work-home conflict by the authors, was measured with seven items based off of Holahan and Gilbert's (1979) 
previous work. These items were designed to assess the degree to which the job impacts upon and/or disrupts the individual's home life and included the impression partners had about the employee's WFC. This study was important as it tested a model of occupational stress within a correctional officer sample in relation to, among other outcomes, WFC and included partner perceptions in the measurement of the construct.

Lambert and various colleagues have published four studies (Lambert, 2008; Lambert et al., 2011; Lambert \& Hogan, 2006; Lambert et al., 2004) assessing workfamily conflict as an outcome variable among correctional employees including correctional officers utilizing the same data set. Lambert, Hogan, and Barton (2004) assessed the relationship between personal characteristics such as age, tenure, position, education, and ethnicity and work-family conflict. Utilizing a sample of 272 correctional staff (50\% correctional officers) from a maximum security prison in the midwestern United States, the authors found work-family conflict to be a significant stressor for many correctional staff, with correctional officers in general experiencing more WFC than other correctional staff members. Additionally, results of the study indicated that younger correctional officers (i.e. under 40) experienced more WFC than older correctional officers.

Lambert and Hogan (2006) investigated the relationship between 16 independent variables, nine of which were work environment variables and seven were personal characteristics, and work-family conflict. The results of their analyses indicated that, again, correctional officers on average reported higher levels of WFC than non-custody staff. Of the nine work environment measures in the study, only three had significant 
effects on WFC. Perceived dangerousness of the job and role ambiguity were positively related to WFC and organizational fairness was negatively related to WFC. It is also worthy to note here that supervisor support, one of the work environment variables, did not have a significant relationship with WFC. This finding is not overly surprising, however, given that the three items in the scale were used to measure a person's perception of accessibility, fairness, and candidness of the relationship with his/her supervisor and did not reflect a level of perceived support from one's supervisor for the fulfilling of both work and family role expectations. This study moved the correctional officer work-family conflict literature forward by specifically investigating possible workplace antecedents of WFC. For the first time, perceived dangerousness of the job, the independent variable of the current study, had been empirically shown to be positively related to WFC among correctional officers and staff.

Lambert (2008) assessed the effect of job involvement on correctional staff. Job involvement and seven personal characteristics were used as independent variables while FWC and WFC, among other constructs, served as the dependent variables. Work-family conflict was measured in this study broadly with nine items measuring WFC and two items measuring FWC. After controlling for gender, age, tenure, position, educational level, race, and supervisory status, Lambert conducted a multivariate analysis which indicated that job involvement had a statistically significant positive relationship with both forms of work-family conflict. Consistent with previous studies, Lambert found that correctional officers generally reported greater levels of WFC than did non-custody workers. This study contributed to the correctional officer work-family conflict literature 
by introducing job involvement as a construct significantly and positively related to both dimensions of work-family conflict among correctional officers and other staff.

Lambert, Altheimer, Hogan, and Barton-Bellessa (2011) investigated the relationship between correctional staff orientation (support for punishment or support for treatment) and various outcomes including WFC. Correctional orientation refers to the views of individual correctional staff on the functions of prisons and it should be noted here that participants worked at a treatment-oriented state prison. Support for punishment orientation was found to be significantly and positively associated with WFC, whereas support for treatment was found to be not significantly related to WFC. The authors posit that their study results suggest that efforts should be made to increase the likelihood that employee values and objectives are congruent with those of the organization. This, the most recently published work by Lambert and colleagues involving work-family conflict and correctional officers and staff to be reviewed here introduced a new and salient variable, correctional orientation, to the relevant literature.

The five works reviewed above constitute the previous published empirical studies utilizing work-family conflict as an outcome variable among correctional officers that I have been able to locate. In summation, these studies found job involvement to be positively and significantly related to both WFC and FWC (Lambert, 2008), high demands, low control, low support, shift-work (Dollard \& Winefield, 1998), perceived dangerousness of the job, role ambiguity (Lambert \& Hogan, 2006), and support for punishment orientation (Lambert et al., 2011) to be significantly and positively related to WFC, and age (Lambert et al., 2004) and organizational fairness (Lambert \& Hogan, 
2006) to be significantly and negatively related to WFC. In common with these studies, the current study utilizes work-family conflict as an outcome variable. Within the framework of the transactional model of stress and coping, the proposed study model views WFC and FWC to be potential responses among correctional officers to the stimulus of the perceived dangerousness of the job. Next, I will discuss family supportive supervisor behaviors, the moderating variable in the current study and a theoretical source of additional coping resources for correctional officers.

\section{Family Supportive Supervisor Behaviors (FSSB)}

The changes in the composition of the labor pool previously mentioned have helped to encourage employers to adopt policies and practices that directly support working families (Brough, O’Driscoll, \& Kalliath, 2005). However, the actual employee utilization of available workplace supports, for example those regarding work hours, scheduling, and flexibility, can be argued to be influenced by the informal discretion of one's supervisor who Hammer and colleagues consider the "linking pins" between formal workplace organizational supports and their usage (Hammer, Kossek, Zimmerman, \& Daniels, 2007). Additionally, Breaugh and Frye (2008) suggest that for their sample of participants, informal actions taken by the supervisor to accommodate family responsibilities may have greater influence on work-family conflict than the use of formal workplace organizational supports. Thus it can be seen that supervisors are not only an influential factor in an employee's work domain, but their influence can extend into their lives outside of the workplace as well. In the remainder of this section I will overview social support, general supervisor support, family supportive supervision, and the 
construct of FSSB which the current study hypothesizes will moderate the relationships between PDJ, perceived stress, and the negative well-being outcomes of WFC, FWC, and physical symptoms.

Social support has been defined to be a transaction between individuals that includes emotional expressions of concern, instrumental assistance, and/or information sharing (House, 1981). In the workplace these transactions can occur between employees and their coworkers as well as between employees and their supervisors. Previous research involving social support, especially from one's supervisor, has found it to be significantly associated with strain (Ganster et al., 1986). In their study, Ganster and colleagues found that significant amounts of the variance in life dissatisfaction, depression, and somatic complaints were explained by social support. Karasek and colleagues proposed social support to have a buffering effect on negative work outcomes (Karasek et al., 1998). Humphrey, Nahrgang, and Morgeson (2007) found support for this buffering effect on stress, role overload, and burnout demonstrated in their meta-analysis.

General supervisor support has been conceptualized to involve emotional support in the form of general expressions of concern and instrumental support in the form of tangible assistance by the supervisor (Hammer, Kossek, Yragui, Bodner, \& Hanson, 2009). However, in their meta-analysis Kossek and colleagues indicate that general supervisor support focuses on support for personal effectiveness at work (Kossek, Pichler, Bodner, \& Hammer, 2011). Indeed, utilizing a measure of general supervisor support, Brough and Pears (2004) demonstrated that support received from supervisors positively predicted levels of job satisfaction among their participant pool of public sector 
human service workers in Australia. Additionally, general supervisor support has been found to be negatively correlated with work stress (Van Voorhis, Cullen, Link, \& Wolfe, 1991; Kobasa \& Puccetti, 1983).

Family supportive supervision. Supervisor work-family support facilitates an employee's ability to successfully manage work and family domain role expectations (Kossek et al., 2011). Hammer and colleagues (2009) have defined supervisor workfamily support as perceptions that one's supervisor cares about their work-family wellbeing as demonstrated by helping behaviors designed to resolve work-family conflicts. Given the lack of conceptual clarity in measuring informal supervisor support for the resolving of work-family conflicts for employees however, Hammer and colleagues developed and validated a measure of FSSB (Hammer et al., 2009).

Expanding on general supervisor support and grounded in social support theory, FSSB are behaviors exhibited by supervisors that acknowledge and are supportive of employees' family role demands (Hammer et al., 2009). Hammer and colleagues (2009) view FSSB as a multidimensional construct with four subordinate categories: emotional support, role modeling, instrumental support, and creative work-family management. Emotional support concerns the perceptions of the subordinate that they are being cared for by their supervisor, that their feelings are being considered, and that they feel comfortable communicating with their supervisors when needed. Role modeling refers to the demonstration of supervisors of how to integrate work and family thorough their behaviors on the job. Instrumental support is reactive and pertains to the supervisor support as they respond to an employee's work and family needs in the form of day-to- 
day management transactions. Lastly, creative work-family management behaviors are proactive, strategic, and innovative supervisor initiated behaviors with the aim to restructure work to facilitate an employee's effectiveness both on and off the job and can include factors such as the time, place, and way in which work is done (Hammer et al., 2009).

While empirical work-family conflict research involving correctional officers is scarce, research involving FSSB in particular and correctional officers is non-existent. From a transactional model of stress and coping view, FSSB can be viewed as additional and/or more effective coping resources that correctional employees can utilize in efforts to mitigate the negative responses of WFC, FWC, and physical symptoms of psychological distress. With the main variables of the proposed study discussed, I will now provide the specific hypotheses of the current study.

\section{Hypotheses}

As previously mentioned, perceived dangerousness of one's job has been shown to be a job characteristic predictive of increased WFC (Lambert \& Hogan, 2006). Additionally, the behaviors required for the successful fulfillment of a work role with an inherent component of dangerousness are most likely to be in conflict with the required behaviors to fulfill the expectations of one's family roles. Thus, with Lambert and Hogan's previous research, role theory, and the scarcity hypothesis in support, the following is hypothesized:

Hypothesis 1a: Perceived dangerousness of the job will be positively related to work-to-family conflict. 
Furthermore, because of the reciprocal nature of work-family conflict dimensions, it is expected that:

Hypothesis $1 \mathrm{~b}$ : Perceived dangerousness of the job will be positively related to family-to-work conflict.

As previously mentioned, the perceived dangerousness of the job has been identified by correctional officers as a salient stressor at work (Cullen, Link et al., 1985; Lambert et al., 2002). Given this and the results of previous studies that have found a positive relationship between workplace stressors and physical symptoms of psychological distress (Ganster et al., 1986; Hurrell \& Lindstrom, 1992; Nixon et al., 2011; Spector 1987, Spector et al., 1988), the following is hypothesized:

Hypothesis 1c: Perceived dangerousness of the job will be positively related to physical symptoms of psychological distress.

The three relationships involved within this first hypothesis are all hypothesized to be positive. However, given that WFC has been found to be more prevalent than FWC (Eagle, Miles, \& Icenogle, 1997; Gutek, Searle, \& Klepa, 1991) and that work related antecedents tend to have a stronger relationship with WFC than FWC (Hammer \& Zimmerman, 2011), it is anticipated that the strongest magnitude of these three positive relationships will be between PDJ and WFC.

According to the transactional model of stress and coping, stress is conceptualized as a relationship between the person and the environment that is appraised by the person as taxing or exceeding his or her resources and as endangering wellbeing (Folkman, Lazarus, Gruen et al., 1986). Within the framework of this model, perceived dangerous of 
the job may translate into a threat appraisal of the working environment. The model also posits that if coping resources prove inadequate to counter the stress condition appraisal or choice of coping strategy is inefficient then negative outcomes with regards to an individual's subjective well-being, social and work function, and/or somatic health can ensue (Lazarus, 1999). Based on this, it is possible that coping resources for countering the threat appraisal of the perceived dangerousness of the job are inadequate or coping strategy utilized inefficient thus resulting in decreased social function (i.e., WFC and FWC) and somatic health (i.e., physical symptoms of psychological distress). Given this, the following is hypothesized:

Hypothesis 2a: Perceived stress will mediate the relationship between perceived dangerousness of job and work-to-family conflict.

Hypothesis $2 b$ : Perceived stress will mediate the relationship between perceived dangerousness of job and family-to-work conflict.

Hypothesis 2c: Perceived stress will mediate the relationship between perceived dangerousness of job and physical symptoms of psychological distress.

Within the framework of the transactional model of stress and coping FSSB can be viewed as workplace coping resources that employees could utilize in either problemfocused or emotion-focused coping strategies mobilized to master, tolerate, or reduce stress from perceived dangerousness of the job. In essence FSSB could act as a moderator of the PDJ - perceived stress relationship, buffering correctional officers to a degree from the full effects of PDJ on their level of perceived stress. Additionally, from a JD-R model perspective, PDJ can be seen as a workplace demand requiring effort from correctional 
officers and as such also being capable of having a mental cost associated with it. From this perspective FSSB can be seen as a social job resource that may act as a buffer to the effect of PDJ on correctional officers' perceived stress. Finally, as previously mentioned, social support has been defined as transactions between individuals that include emotional expressions of concern, instrumental assistance, and/or information sharing (House, 1981). These social transactions can occur between coworkers as well as between employees and their supervisors. Thus from a social support theory lens, FSSB can be viewed as specific, social, and supportive transactions that may assist in buffing the strain experienced by correctional officers and subsequently reduce their perceived stress. Given this the following is hypothesized:

Hypothesis 3: FSSB will moderate the effect of perceived dangerousness of job on perceived stress, such that the positive relationship between perceived dangerousness of job and perceived stress will be weaker when FSSB is high. Having a family specific supportive supervisor has been found to be related to lower levels of work-family conflict (Breaugh \& Frye, 2008; Kossek et al., 2007). As previously stated, FSSB can be viewed as additional coping resources from a transactional model of stress and coping lens that correctional officers can utilize thus potentially reducing WFC, FWC, psychological distress and the associated physical symptoms. This potential buffering effect of FSSB on the PDJ - WFC, FWC, and physical symptoms relationships can also be viewed from the lens of the JD-R model. From this perspective, FSSB can again be seen as a social job resource that may mitigate or buffer the physical and mental costs associated with the job demand of PDJ. This 
buffering effect would translate to lower levels of WFC, FWC, and physical symptoms. And as previously mentioned, research involving social support, especially from one's supervisor, has found it to be significantly associated with strain (Ganster et al., 1986). In their study, Ganster and colleagues found that significant amounts of the variance in somatic complaints were explained by social support. As such, the following is hypothesized:

Hypothesis 4a: FSSB will moderate the effect of perceived dangerousness of job on work-to-family conflict, such that the positive relationship between perceived dangerousness of job and work-to-family conflict will be weaker when FSSB is high.

Hypothesis 4b: FSSB will moderate the effect of perceived dangerousness of job on family-to-work conflict, such that the positive relationship between perceived dangerousness of job and family-to-work conflict will be weaker when FSSB is high.

Hypothesis 4c: FSSB will moderate the effect of perceived dangerousness of job on physical symptoms of psychological distress, such that the positive relationship between perceived dangerousness of job and physical symptoms of psychological distress will be weaker when FSSB is high.

Given that PDJ is a workplace stressor/demand, it is anticipated that the buffering effect of FSSB will be greatest on the PDJ - WFC and PDJ - physical symptoms relationships. 
From a transactional theory of stress and coping framework FSSB can be viewed as workplace resources that employees can utilize to restructure their previous unsuccessful coping efforts in attempts to master, tolerate, or reduce stress related to perceived dangerousness of the job that has already occurred. Thus, the following is hypothesized:

Hypothesis 5a: FSSB will moderate the effect of perceived stress on work-tofamily conflict, such that the positive relationship between perceived stress and work-to-family conflict will be weaker when FSSB is high.

Hypothesis 5b: FSSB will moderate the effect of perceived stress on family-towork conflict, such that the positive relationship between perceived stress and family-to-work conflict will be weaker when FSSB is high.

Hypothesis 5c: FSSB will moderate the effect of perceived stress on physical symptoms of psychological distress, such that the positive relationship between perceived stress and physical symptoms of psychological distress will be weaker when FSSB is high.

As complex study models may more accurately reflect relationships among variables, an overall moderated mediation framework will be examined. The following is thus hypothesized:

Hypothesis 6a: FSSB will moderate the mediating effects of perceived stress on the perceived dangerousness of the job-WFC relationship, such that the mediating effect will be weakened under high levels of FSSB. 
Hypothesis $6 b$ : FSSB will moderate the mediating effects of perceived stress on the perceived dangerousness of the job-FWC relationship, such that the mediating effect will be weakened under high levels of FSSB.

Hypothesis $6 c$ : FSSB will moderate the mediating effects of perceived stress on the perceived dangerousness of the job-physical symptoms of psychological distress relationship, such that the mediating effect will be weakened under high levels of FSSB. 


\section{Chapter 2}

Method

\section{Participants and Procedure}

This study is part of a larger study being conducted by Portland State University (PSU) and the Oregon Department of Corrections (ODOC) to examine the relationship between work stress, work-family conflict, and employee well-being among correctional officers employed by the ODOC. The PSU/ODOC study was initiated by ODOC research unit members who contacted researchers at PSU. The ODOC personnel expressed an interest in inviting academic researchers from outside their institution to conduct research focusing on their correctional officer employees. The ODOC personnel are concerned about this population of employees due to the higher than average number of domestic abuse incidents, psychological distress, and suicides among the correctional officers within the last decade. Senior management within the ODOC, their internal research unit, and leaders of the two employee unions are in full support of the study. It should be noted here that I am a member of the PSU team of researchers involved in the larger study along with Dr. Leslie Hammer, Dr. Charlotte Fritz, and Frankie Guros.

Correctional facilities/institutions. As of August 2012, the ODOC operates 14 correctional facilities across the state housing approximately 14,200 inmates. Of the 14 facilities, eight currently house only minimum security level inmates, three house both minimum and medium security level inmates, two house only medium security level inmates, and only one, the Oregon State Penitentiary, holds maximum security level inmates. Of the current inmate population in Oregon, roughly 25 percent (3550 inmates) 
are classified as minimum security level, 58 percent (8236 inmates) as medium security level, and 17 percent (2414 inmates) as maximum security level.

Correctional officers. The ODOC currently employs approximately 2,460 correctional officers to supervise and monitor the state's inmate population. All 14 of the ODOC facilities are unionized. There are two unions active within the ODOC with correctional officer membership. The first, the Association of Oregon Corrections Employees has union representation within four facilities and the second, the American Federation of State, County, and Municipal Employees has union representation within 11 facilities. The current reported population of correctional officers employed by the ODOC is from 21 to 71 years of age $($ mean $=44), 82 \%$ male, and $88 \%$ Caucasian.

Recruitment and data collection. Participants for the current study were correctional officers employed by the ODOC. Data for the current study was collected as part of the larger PSU/ODOC study. Members of the PSU research team conducted preliminary visits of three of the ODOC facilities to make firsthand observations of the work environment to assist in survey construction. Given that the study was to be conducted among all 14 ODOC facilities, a minimum security facility (Columbia River correctional Institution), a medium security facility (Coffee Creek Correctional Facility), and the one maximum security facility (Oregon State Penitentiary) were selected for the visits. Facility visits were guided by members of the facility administration and the corresponding union. Research design meetings with two correctional officers from each of the visited facilities were also conducted by Dr. Charlotte Fritz and Frankie Guros. 
This larger study survey was made available online and, if requested, in paper format. Surveys were made available to all 14 ODOC facilities over a period of several months by staggering the availability of the survey to groups of two or three facilities at a time. Participants were informed within the survey that their responses would be anonymous and both the online and paper versions of the survey contained the same items. The paper survey packets included one survey as well as a stamped envelope addressed to Dr. Charlotte Fritz. The online survey was conducted utilizing the online survey software Qualtrics with responses being sent directly to the researchers. For each facility, an email invitation was sent to all correctional officers by the superintendent of the facility, a union representative, and a member of the ODOC research department, demonstrating support for the study by all levels. These emails contained directions for taking the survey and included both a web-link to the online version and directions for how to acquire a paper and pencil version of the study if preferred. Participants were informed that a survey was being conducted to examine work stress and strain among correctional officers. Participants were told that the survey would be available for them to take for a two week time period. After the first week, the superintendent of the facility sent a reminder email out to their facility with an emphasis of how valuable each correctional officer's response was (see Appendices A through F for all study related emails).

The PSU Human Subjects Research Review Board (HSRRB) gave approval for the larger PSU/ODOC study as well as the current study. Informed consent was obtained from participants on both the online and written forms of the survey. The first page of the 
survey contains information about the survey, including resources available to the participants, contact information for the HSRRC and the Principal Investigator, an explanation of the purpose of the study, and a reminder that participation is strictly voluntary and anonymous. A statement follows this information advising the participant that by filling out the survey they are indicating that they understand their rights as a participant, are 18 years of age or older, and are consenting to participate (see Appendix $\mathrm{G}$ for cover letter). Printing of the paper surveys was the responsibility of the ODOC research unit and the maintenance of the online version was the responsibility of the PSU researchers utilizing a PSU Qualtrics account.

Of the 2,460 correctional officers employed by the ODOC, a total of 1,370 took the survey, yielding an initial response rate of 54\%. Respondents who indicated they did not work as security staff and members of the ODOC Transportation Team were removed for the purposes of the current study resulting in a sample base sample size of $\mathrm{N}=1317$.

\section{Measures}

The current study inserted its measures into the larger PSU/ODOC study survey. The six measures are all in a five point Likert format and, with the exception of FSSB, are prefaced with instructions for the participant to reflect on the last month when responding. The response option category label wording was altered for some of the measures for consistency within the larger PSU/ODOC study survey (see Appendix H for current study items and measures and Appendix I for the entire PSU/ODOC survey).

Perceived dangerousness of the job (PDJ). PDJ was measured using a six item modified version of the five item perceived dangerousness of job scale developed by 
Cullen et al. (1983) which had a reported alpha of .64. The original scale was modified by myself and my advisor, Dr. Leslie Hammer, to make responses more proximal to the participant and to better capture a sense of required alertness and the potential for violent confrontations at work. Directionality of possible responses was reversed and the number of possible responses shortened from seven points to five with higher scores indicating a greater degree of the construct. The original scale has been reworded into the past tense as participants are being asked to reflect upon the last month when responding to the modified scale. The first two items of the modified scale only changed the tense of their original counterparts. Specifically, "I work in a dangerous job" was changed to "I worked in a dangerous job." and "My job is a lot more dangerous than other kinds of jobs." was changed to "My job has been much more dangerous than other kinds of jobs." The third question of the modified scale, "In my job, a person stands a good chance of getting hurt." was changed to "In my job, I stood a good chance of getting hurt." Besides altering the original item to the past tense, replacing "a person" with "I" makes the context of the item more proximal. The fourth item was modified from "A lot of people I work with get physically injured in the line of duty." to "People I work with were at risk of getting physically injured on the job.”, as participants are asked to reflect on the last month when responding. Item five, "While at work I had to maintain a high level of alertness due to the potential for dangerous situations.", was added to the original scale in an attempt capture the participant's sense of required alertness or vigilance while at work due to their perceived potential for dangerous situations to occur. Item six was added to the original scale as well and reads, "While at work I have been concerned that I may be 
involved in a violent confrontation." The intent of this item is to capture a participant's level of concern over possible violent confrontations. One item from the original scale, "There is really not much chance of getting hurt in my job.", was discarded for space considerations and the fact that it is essentially the reverse of the third item. The overarching aim of this modified scale is to measure the extent to which a participant perceives his/her job as being dangerous in general, in regards to becoming physically injured, and the degree to which they feel they must be alert for potentially dangerous situations to arise while they are at work.

Items on this modified scale were rated on a scale from 1 (Not at all) to 5 (Very much), with higher scores indicating greater perceived dangerousness of job. Since this was be the first time the modified scale has been used it had no previous reliability to report.

Perceived stress. Perceived stress was measured using the four item short form of the Perceived Stress Scale (PSS) developed and validated by Cohen, Kamarck, and Mermelstein (1983) which has a reported alpha of .72. Items on the PSS are all prefaced with "In the past month, how often have you felt..." and were rated on a scale of 1 (none of the time) to 5 (all of the time) with lower scores indicating a greater degree of perceived stress. Item number one, "That you were unable to control the important things in your life?', and item number four, "Difficulties were pilling up so high that you could not overcome them?" were reverse coded. As a subjective and global measure, the PSS items are designed to assess the degree to which a participant finds their life unpredictable, uncontrollable, and overloading. 
Work-to-family conflict (WFC). WFC conflict was measured using the workfamily conflict scale developed and validated by Netemeyer, Boles, and McMurrian (1996) which consists of five items (alpha $=.88$ ). These items were worded in the past tense and prefaced with "To what extent do you agree with the following statements? In the past month..." and rated on a scale from 1 (Not at all) to 5 (very much) with higher scores indicating a greater degree of the construct. This scale assesses general demands as well as time and strain-based conflict between work and family roles stemming from work role pressures. "The demands of my work interfered with my home and family life." is an example of one item within the scale.

Family-to-work conflict (FWC). FWC conflict was measured using the familywork conflict scale developed and validated by Netemeyer et al. (1996) which consists of five items (alpha $=.86)$. These items were worded in the past tense and prefaced with "To what extent do you agree with the following statements? In the past month..." and rated on a scale from 1 (Not at all) to 5 (very much) with higher scores indicating a greater degree of the construct. This scale assesses general demand as well as time and strainbased conflict between work and family roles stemming from family role pressures. "I had to put off doing things at work because of demands on my time at home." is an example from this scale.

Physical symptoms of psychological distress (Physical Symptoms). Physical symptoms were measured using the 12 item short form of the Physical Symptom Inventory (PSI) developed by Spector and Jex (1998). Items on the PSI were all prefaced with "Over the past month, how often have you experienced each of the following 
symptoms?" and were rated on a scale of 1 (not at all) to 5 (every day) with higher scores indicating greater frequency of symptoms. Example items are trouble sleeping, eye strain, constipation, and loss of appetite. The PSI assesses physical, somatic health symptoms thought by stress researchers to be associated with psychological distress (Spector \& Jex, 1998) and each is a condition or state of which an individual would likely be aware. The PSI is a causal indicator and therefore coefficient alpha is irrelevant (Spector \& Jex, 1998).

Family supportive supervisor behaviors (FSSB). FSSB was measured using a four item short form scale developed and validated by Hammer, Kossek, Bodner, and Crain (2013) with a reported alpha of .88. Items were rated on a scale from 1 (Not at all) to 5 (Very much), with higher scores indicating greater FSSB. The scale consists of one item from each of the four subordinate dimensions identified in the original 14 item scale (Hammer et al., 2009). These four subordinate dimensions are: emotional support, role modeling behaviors, instrumental support, and creative work-family management. "Your supervisor" was changed from the original scale to "My Officer in Charge (OIC)" and "company" was changed to "agency" to reflect job titles and language specific to this group of participants.

Control variables. Several control variables were initially considered for use in this study based on previous empirical research findings. These control variables included age, education, tenure, gender, number of children living with the participant, marital status, ethnicity, shift worked, and average number of hours worked per week. Age and education were to be considered as control variables as they were found by Lambert and 
Paoline (2012) to be significantly and negatively correlated with perceived dangerousness of the job. These investigators also found tenure to be significantly and positively correlated with perceived dangerousness of the job as well. Studies investigating gender in relation to work-family conflict have yielded mixed results. Eagle, Miles, and Icenogle (1997) found that women did not report higher levels of FWC than men and that men did not report higher levels of WFC than women. Conversely, Gutek, Searle, and Klepa (1991) found that women reported higher levels of WFC than men. Additionally, Parasuraman and Simmers (2001) found that men reported higher levels of time and strained based WFC and FWC than women. Despite the inconsistencies in previous research findings, some relationship between gender and work-family conflict has been identified and gender was initially to be considered as a control variable in the current study. The number of children living with the participant was to be considered as a control variable as Eagle and colleagues (1998) found that their respondents with children reported higher levels of time-based FWC than their respondents without children. Marital status was to be considered as a control variable as Byron (2005) found evidence in her meta-analytic review of more than 60 work-family conflict studies that single parents reported more WFC and FWC than married parents with children. The decision to consider ethnicity as a control variable was made based on the findings of Dowden and Tellier's 2004 meta-analysis regarding the predictors of work-related stress in correctional officers which indicated that officers who were minorities experienced significantly less job stress than Caucasian officers. Shift worked was to be considered as a control variable for this study given the research findings of Cheek and Miller (1983) 
who found that their correctional officer participant group reported experiencing the most "tension" when working the second shift (usually 2:20 P.M through 10:20 P.M.). In addition to the initially considered control variables reviewed above, understaffing and resource inadequacy and lack of opportunity to participate in decision making as sources of work stress were to be considered as control variables as well given that they have been identified as job characteristic stressors for correctional employees (Dowden \& Tellier, 2004; Brough \& Williams, 2007).

Once data collection and cleaning were completed, WFC was regressed on the considered control variables outlined above. This analysis found age, tenure, hours worked per week, understaffing and resource inadequacy, and lack of opportunity to participate in decision making to be significant. Next, FWC was regressed on the considered control variables outlined above. This analysis found age, marital status, and understaffing and resource inadequacy to be significant. Finally, physical symptoms was regressed on the considered control variables outlined above. This analysis found understaffing and resource inadequacy as well as lack of opportunity to participate in decision making to be significant. Given the results of these three regressions, age, tenure, hours worked per week, marital status, understaffing and resource inadequacy, and lack of opportunity to participate in decision making were used as control variables for the current study. Understaffing and resource inadequacy and lack of opportunity to participate in decision making were measured with one item each. These two items are included in the larger PSU/ODOC study survey within the correctional officer job demands scale (Brough \& Williams, 2007). 


\section{Chapter 3 \\ Results}

All analyses were conducted using Statistical Packages for the Social Sciences (SPSS) software owned by International Business Machines (IBM). Table 1 shows means, standard deviations, reliabilities, and intercorrelations of all study variables.

\section{Preliminary Analyses}

Missing data. Listwise deletion was used where appropriate in analyses to address missing data. As such, sample size for each analysis varied depending on how many participants responded to the variables included in the analysis.

PDJ scale dimensionality. Factor analyses were conducted on the modified perceived dangerousness of the job scale as this was the first time this modified version had been used. First, a principle components analysis was conducted to assess the dimensionality of the measure. Kaiser's criterion and a scree plot both indicated that a one-factor solution would fit the data. This single factor accounted for $68.62 \%$ of the variance in responses. Second, an exploratory factor analysis with principle axis factoring was conducted to assess the dimensionality of the measure. Here again, a scree plot indicated a single factor within the measure and this single factor accounted for $62.66 \%$ of the variance in responses.

Variable descriptives. PDJ $(M=4.08, S D=.84)$ was significantly and positively correlated with WFC $(M=3.11, S D=1.16), \operatorname{FWC}(M=1.80, S D=.82)$, physical symptoms $(M=25.65, S D=7.71)$, and perceived stress. The strongest of these correlations was between PDJ and WFC $(r=.31, p<.01)$. PDJ was also significantly and negatively correlated with FSSB $(r=-.13, p<.01)$. FSSB $(M=2.78, S D=1.16)$ was 
significantly and negatively correlated with WFC, FWC, physical symptoms, PDJ, and perceived stress. The strongest of these correlations was between FSSB and WFC ( $r=$ $.27, p<.01)$. Perceived stress $(M=2.53, S D=.72)$ was significantly and positively related to WFC, FWC, physical symptoms, and PDJ. The strongest of these correlations was between perceived stress and physical symptoms $(r=.51, p<.01)$. Perceived stress was also significantly and negatively correlated with FSSB $(r=-.23, p<.01)$. Please see Table 1 for means, standard deviations, and correlations of all study variables.

\section{Hypothesis Testing}

Hypothesis 1a - c. To test hypothesis 1 (that PDJ was positively related to wellbeing) a series of three hierarchical regression analyses were conducted. For all three regressions, the control variables (age, tenure, hours worked per week, marital status, understaffing/resource inadequacy, and lack of opportunity to participate in decision making) were entered into the first step of the regression equation followed by the wellbeing indicator of interest (WFC, FWC, and physical symptoms). Results indicated that PDJ was significantly and positively related to WFC $\left(\Delta R^{2}=.04, F(1,691)=38.49, p\right.$ $<.01)$, FWC $\left(\Delta R^{2}=.01, F(1,691)=10.72, p<.01\right)$, and physical symptoms $\left(\Delta R^{2}=.03\right.$, $F(1,643)=19.36, p<.01)$. Thus, PDJ was significantly and positively related to wellbeing and hypothesis 1 was supported. Results of these analyses can be found in Table 2 .

Hypothesis 2a - c. Baron and Kenny's (1986) casual steps approach of mediation was utilized to test hypothesis 2 (that perceived stress mediates the relationship between PDJ and well-being). The casual steps approach to mediation consists of four steps and stipulates that all for steps must be successfully completed in order to conclude that 
mediation is present. In step one it must be shown through hierarchical regression that the independent variable significantly predicts the dependent variable. In step two it must be shown that the independent variable significantly predicts the mediating variable. In step three is must be shown that the mediating variable significantly predicts the dependent variable. Finally, in step four it must be shown that the independent variable significantly predicts the dependent variable when controlling for the mediating variable. The value of $\beta$ for the mediating variable in the fourth step is examined to see if it is significant at $\alpha=$ .05. If value of $\beta$ for the mediating variable is non-significant in this step then a fully mediated relationship is indicated between the independent variable and the dependent variable. Partial mediation is indicated if the value of $\beta$ for the mediating variable is significant but lower than it was in step one.

To test hypothesis 2, three mediation analyses were needed (PDJ - WFC, mediated by perceived stress; PDJ - FWC, mediated by perceived stress; PDJ - physical symptoms, mediated by perceived stress). Step one of the causal steps approach to mediation were conducted and found to be significant for all three analyses when testing hypothesis 1 . When conducting step two of the casual steps approach it was found that PDJ was not significantly related to perceived stress when including the control variables (age, tenure, hours worked per week, marital status, understaffing/resource inadequacy, and lack of opportunity to participate in decision making; $\Delta R^{2}=.00, F(1,690)=3.25, p$ $=.07)$. Given this, it was not possible to find mediation within any of the three analyses needed to test hypothesis 2 and no further steps were attempted. Thus, hypothesis 2 was not supported. 
Hypothesis 3. Hierarchical regression analyses were performed to test hypothesis 3 (that FSSB would moderate the effect of PDJ on perceived stress such that the positive relationship between PDJ and perceived stress would be weaker when FSSB is high). Interaction terms were created using the product of the centered predictor (PDJ) and centered moderator (FSSB) to alleviate issues of muticollinearity. In step one of the hierarchical regressions, the control variables (age, tenure, hours worked per week, marital status, understaffing/resource inadequacy, and lack of opportunity to participate in decision making) were entered as predictor variables and perceived stress was entered as a dependent variable. In step two the centered predictor variables (PDJ and FSSB) were entered. In step three, the interaction term (PDJ x FSSB) was entered as a predictor variable. In the final step of the first regression analysis, the interaction between PDJ and FSSB did not explain significant incremental variance in perceived stress $\left(\Delta R^{2}=.00\right.$, $F(1,686)=.00, p=.95)$. Given this, hypothesis 3 was not supported.

Hypothesis $4 \mathbf{a}-\mathbf{c}$. Three hierarchical regression analyses were performed to test hypothesis 4 (that FSSB would moderate the effect of PDJ on well-being such that the positive relationship between PDJ and well-being would be weaker when FSSB is high). Interaction terms were created using the product of the centered predictor (PDJ) and centered moderator (FSSB) to alleviate issues of muticollinearity. In step one of the hierarchical regressions, the control variables (age, tenure, hours worked per week, marital status, understaffing/resource inadequacy, and lack of opportunity to participate in decision making) were entered as predictor variables and (a) WFC, (b) FWC, and (c) physical symptoms were entered as a dependent variable. In step two the centered 
predictor variables (PDJ and FSSB) were entered. In step three, the interaction term (PDJ $\mathrm{x}$ FSSB) was entered as a predictor variable. In the final step of the first regression analysis (H4a), the interaction between PDJ and FSSB explained significant incremental variance in WFC $\left(\Delta R^{2}=.01, F(1,687)=4.56, p<.05\right)$. A test of simple slopes indicated that the slopes for low FSSB $(t=7.31, p<.01)$ and the slopes for high FSSB were significant $(t=3.35, p<.01)$. Thus, FSSB significantly moderated the PDJ to WFC relationship. The PDJ to WFC relationship was strongest in the case of low FSSB and weakest in the case of high FSSB. Individuals of different levels of FSSB did not differ in WFC under conditions of low PDJ, however, differences were noted under conditions of high PDJ: individuals reporting high levels of FSSB reported lower levels of WFC than individuals reporting low levels of FSSB. Figure 2 presents a graphical representation of this interaction.

In the final step of the second regression analysis $(\mathrm{H} 4 \mathrm{~b})$, the interaction between PDJ and FSSB did not explain significant incremental variance in FWC $\left(\Delta R^{2}=.00\right.$, $F(1,687)=.37, p=.54)$. In the final step of the third regression analysis $(\mathrm{H} 4 \mathrm{c})$, the interaction between PDJ and FSSB did not explain significant incremental variance in physical symptoms $\left(\Delta R^{2}=.00, F(1,639)=.57, p=.45\right)$. Given this, hypothesis 4 was partially supported.

Hypothesis 5a-c. Three hierarchical regression analyses were performed to test hypothesis 5 (that FSSB would moderate the effect of perceived stress on well-being such that the positive relationship between perceived stress and well-being would be weaker when FSSB is high). Interaction terms were created using the product of the centered 
predictor (perceived stress) and centered moderator (FSSB) to alleviate issues of muticollinearity. In step one of the hierarchical regressions, the control variables (age, tenure, hours worked per week, marital status, understaffing/resource inadequacy, and lack of opportunity to participate in decision making) were entered as predictor variables and (a) WFC, (b) FWC, and (c) physical symptoms were entered as a dependent variable. In step two the centered predictor variables (perceived stress and FSSB) were entered. In step three, the interaction term (perceived stress x FSSB) was entered as a predictor variable. In the final step of the first regression analysis (H5a), the interaction between perceived stress and FSSB did not explain significant incremental variance in WFC $\left(\Delta R^{2}\right.$ $=.00, F(1,686)=2.44, p=.12)$. In the final step of the second regression analysis $(\mathrm{H} 5 \mathrm{~b})$, the interaction between perceived stress and FSSB did not explain significant incremental variance in FWC $\left(\Delta R^{2}=.00, F(1,686)=1.10, p=.29\right)$. In the final step of the third regression analysis $(\mathrm{H} 5 \mathrm{c})$, the interaction between perceived stress and FSSB explained significant incremental variance in physical symptoms $\left(\Delta R^{2}=.01, F(1,638)=4.44, p\right.$ $<.05)$. A test of simple slopes indicated that the slopes for low FSSB $(t=12.95, p<.01)$ and the slopes for high FSSB were significant $(t=7.83, p<.01)$. Thus, FSSB significantly moderated the perceived stress to physical symptoms relationship. The perceived stress to physical symptoms relationship was strongest in the case of low FSSB and weakest in the case of high FSSB. Individuals of different levels of FSSB did differ slightly in physical symptoms under conditions of low perceived stress: individuals reporting high levels of FSSB reported slightly higher levels of physical symptoms. Differences were greater under conditions of high perceived stress: individuals reporting 
high levels of FSSB reported lower levels of physical symptoms than individuals reporting low levels of FSSB. Figure 3 presents a graphical representation of this interaction. Given this, hypothesis 5 was partially supported.

Hypothesis 6a - c. Hypothesis 6 was that FSSB would moderate the mediating effects of perceived stress on the PDJ - well-being relationships such that the mediating effects would be weaker under high levels of FSSB. To test this hypothesis, three tests of conditional indirect effects would be required. A conditional indirect effect is the magnitude of an indirect effect at a particular value of a moderator variable (Preacher, Rucker, \& Hayes, 2007). No indirect effects were found in the testing of hypothesis 2 , and as such, no testing of hypothesis 6 could be performed. Therefore, hypothesis 6 was not supported.

\section{Additional Analyses: Testing of Hypotheses Using a Single Facility}

Participants from 14 facilities provided data for the current study. In interest of considering the effects of possible nesting of data (i.e., differential effects of findings by facility), all hypotheses were additionally tested utilizing only responses from the facility with the largest number of survey responses. This facility was the Snake River Correctional Institution (SRCI), a multi-security level facility employing 552 correctional officers and housing 3075 inmates at the time of data collection. SRCI is the largest inmate capacity facility operated by the ODOC and has special inmate housing units including a disciplinary segregation unit and an intensive management unit.

Facility and security level (minimum, medium, or maximum) of inmates worked with most in the last 30 days were examined within the dataset of all 14 facilities and 
both were found to be non-significantly related to WFC, FWC, or physical symptoms. Security level of inmates most worked with in the last 30 days was also not significantly related to WFC, FWC, or physical symptoms within the SRCI only dataset as well. Only hypothesis 1a and 1c were supported when utilizing only the SRCI responses. It should be noted that this facility had a maximum sample size for analyses of $\mathrm{N}=124$.

Hypothesis 1a - c SRCI only. To test hypothesis 1 (that PDJ was positively related to well-being) a series of three regression analyses were conducted. For all three regressions, the control variables (age, tenure, hours worked per week, marital status, understaffing/resource inadequacy, and lack of opportunity to participate in decision making) were entered into the first step of the regression equation followed by the wellbeing indicator (WFC, FWC, and physical symptoms). Results indicated that PDJ was positively and significantly related to $\mathrm{WFC}\left(\Delta R^{2}=.04, F(1,108)=6.14, p<.05\right)$ and physical symptoms $\left(\Delta R^{2}=.06, F(1,100)=8.20, p<.01\right)$. PDJ was not significantly related to FWC $\left(\Delta R^{2}=.00, F(1,108)=.26, p=.61\right)$, Thus, hypothesis 1 was partially supported. Results of these analyses can be found in Table 3. In comparison, when this hypothesis was tested within the dataset of all 14 facilities, PDJ was found to be positively and significantly related to WFC, FWC, and physical symptoms.

Hypothesis 2a - c SRCI only. Step one of the causal steps approach to mediation were conducted and found to be significant for only PDJ - WFC (H2a) and PDJ physical symptoms (H2c) when testing hypothesis 1 . When conducting step two of the casual steps approach $\mathrm{H} 2 \mathrm{a}$ and $\mathrm{H} 2 \mathrm{c}$ it was found that PDJ was not significantly related to perceived stress $\left(\Delta R^{2}=.03, F(1,107)=3.35, p=.07\right)$. Given this, it was not possible to 
find mediation within either of the two possible analyses needed to test $\mathrm{H} 2 \mathrm{a}$ and $\mathrm{H} 2 \mathrm{c}$. As such, no further steps were attempted. Thus, hypothesis 2 was not supported. This result is the same as when this hypothesis was tested using data from all 14 of the ODOC facilities in aggregate.

Hypothesis 3 SRCI only. Hierarchical regression analyses were performed to test hypothesis 3 (that FSSB would moderate the effect of PDJ on perceived stress such that the positive relationship between PDJ and perceived stress would be weaker when FSSB is high). Interaction terms were created using the product of the centered predictor (PDJ) and centered moderator (FSSB) to alleviate issues of muticollinearity. In step one of the hierarchical regressions, the control variables (age, tenure, hours worked per week, marital status, understaffing/resource inadequacy, and lack of opportunity to participate in decision making) were entered as predictor variables and perceived stress was entered as a dependent variable. In step two the centered predictor variables (PDJ and FSSB) were entered. In step three, the interaction term (PDJ x FSSB) was entered as a predictor variable. In the final step of the regression analysis, the interaction between PDJ and FSSB did not explain significant incremental variance in perceived stress $\left(\Delta R^{2}=.01\right.$, $F(1,105)=.86, p=.36)$. Given this, hypothesis 3 was not supported. Again, this result is the same as when this hypothesis was tested using data from all 14 facilities.

Hypothesis 4a-c SRCI only. Three hierarchical regression analyses were performed to test hypothesis 4 (that FSSB would moderate the effect of PDJ on wellbeing such that the positive relationship between PDJ and well-being would be weaker when FSSB is high.) Interaction terms were created using the product of the centered 
predictor (PDJ) and centered moderator (FSSB) to alleviate issues of muticollinearity. In step one of the hierarchical regressions, the control variables (age, tenure, hours worked per week, marital status, understaffing/resource inadequacy, and lack of opportunity to participate in decision making) were entered as predictor variables and (a) WFC (b) FWC and (c) physical symptoms were entered as a dependent variable. In step two the centered predictor variables (PDJ and FSSB) were entered. In step three, the interaction term (PDJ $\mathrm{x}$ FSSB) was entered as a predictor variable. In the final step of the first regression analysis (H4a), the interaction between PDJ and FSSB did not explain significant incremental variance in WFC $\left(\Delta R^{2}=.00, F(1,106)=.01, p=.91\right)$. In the final step of the second regression analysis (H4b), the interaction between PDJ and FSSB did not explain significant incremental variance in FWC $\left(\Delta R^{2}=.00, F(1,106)=.48, p=.49\right)$. In the final step of the third regression analysis $(\mathrm{H} 4 \mathrm{c})$, the interaction between PDJ and FSSB did not explain significant incremental variance in physical symptoms $\left(\Delta R^{2}=.00, F(1,98)=.35\right.$, $p=.55)$. Given this, hypothesis 4 was not supported. In comparison, when this hypothesis was tested with the data from all 14 facilities in aggregate, FSSB was found to moderate the relationship between PDJ and WFC but not the relationships between PDJ and FWC and PDJ and physical symptoms.

Hypothesis 5a - c SRCI only. Three hierarchical regression analyses were performed to test hypothesis 5 (that FSSB would moderate the effect of perceived stress on well-being such that the positive relationship between perceived stress and well-being would be weaker when FSSB is high). Interaction terms were created using the product of the centered predictor (perceived stress) and centered moderator (FSSB) to alleviate 
issues of muticollinearity. In step one of the hierarchical regressions, the control variables (age, tenure, hours worked per week, marital status, understaffing/resource inadequacy, and lack of opportunity to participate in decision making) were entered as predictor variables and (a) WFC, (b) FWC, and (c) physical symptoms were entered as a dependent variable. In step two the centered predictor variables (perceived stress and FSSB) were entered. In step three, the interaction term (perceived stress x FSSB) was entered as a predictor variable. In the final step of the first regression analysis (H5a), the interaction between perceived stress and FSSB did not explain significant incremental variance in WFC $\left(\Delta R^{2}=.00, F(1,105)=1.06, p=.31\right)$. In the final step of the second regression analysis (H5b), the interaction between perceived stress and FSSB did not explain significant incremental variance in FWC $\left(\Delta R^{2}=.00, F(1,105)=.16, p=.69\right)$. In the final step of the third regression analysis $(\mathrm{H} 5 \mathrm{c})$, the interaction between perceived stress and FSSB did not explain significant incremental variance in physical symptoms $\left(\Delta R^{2}=.00\right.$, $F(1,97)=.64, p=.43)$. Given this, hypothesis 5 was not supported. In comparison, when this hypothesis was tested using the data from all 14 facilities in aggregate, FSSB was found to moderate the relationship between perceived stress and physical symptoms but not the relationships between perceived stress and WFC and perceived stress and FWC.

Hypothesis 6a-c SRCI only. Hypothesis 6 was that FSSB would moderate the mediating effects of perceived stress on the PDJ - well-being relationships such that the mediating effects would be weaker under high levels of FSSB. To test this hypothesis, three tests of conditional indirect effects would be required. A conditional indirect effect is the magnitude of an indirect effect at a particular value of a moderator variable 
(Preacher et al., 2007). No indirect effects were found in the testing of hypothesis 2, and as such, no testing of hypothesis 6 could be performed. Therefore, hypothesis 6 was not supported. This was the same result as when this hypothesis was addressed for all facilities in aggregate.

To summarize, when the hypotheses were tested using the data from all 14 of the facilities in aggregate, $\mathrm{H} 1 \mathrm{a}, \mathrm{H} 1 \mathrm{~b}, \mathrm{H} 1 \mathrm{c}, \mathrm{H} 4 \mathrm{a}$, and $\mathrm{H} 5 \mathrm{c}$ were found to be supported. Thus, PDJ was found to be positively and significantly related to WFC, FWC, and physical symptoms. Additionally, FSSB was found to moderate the relationships between PDJ and WFC and perceived stress and physical symptoms. In comparison, when the hypotheses were tested using only data from SRCI only H1a and H1c were found to be supported. Thus, PDJ was found to be significantly and positively related to WFC and physical symptoms.

\section{Additional Analyses: PDJ and Security Level of Inmates Most Worked With}

A one-way analysis of variance was conducted to evaluate the effect of security level of inmates most worked with in the last 30 days on PDJ. The independent variable was security level of inmates most worked with and had three levels (minimum, medium, and maximum), while the dependent variable was PDJ score, where higher scores indicated higher levels of PDJ. The results were significant, $F(2,774)=20.94, p<.01, \eta^{2}$ $=.05$. Participants working with maximum security level inmates the most over the last 30 days scored highest on PDJ $(M=4.26, S D=.75, N=158)$, participants working with medium security level inmates the most over the last 30 days scored slightly lower on PDJ $(M=4.15, S D=.75, N=385)$, and participants working with minimum security level 
inmates the most over the last 30 days scored the lowest on PDJ $(M=3.78, S D=.95$, $N=234)$.

Post hoc analyses were conducted to assess further differences among the three groups. Pairwise comparisons among the three groups were conducted using a GamesHowell test. Based on the test results, participants working with maximum $(p<.01)$ and medium $(p<.01)$ security level inmates the most in the last 30 days scored significantly higher on PDJ than participants working with minimum security level inmates the most in the last 30 days. No significant differences were found between those participants who worked with maximum security level inmates the most in the last 30 days and those who worked with medium level security inmates the most in the last 30 days $(p=.26)$. 


\section{Chapter 4}

Discussion

The purpose of the current study was to investigate the relationship between perceived dangerousness of the job (PDJ) and well-being among correctional officers. Indicators of well-being in the current study were measures of work-to-family conflict (WFC), family-to-work conflict (FWC), and physical symptoms of psychological distress (physical symptoms). Additionally, these relationships were examined for mediation by perceived stress and moderation by family supportive supervisor behaviors (FSSB). While adding to the existing literature regarding PDJ and work-family conflict among correctional officers, this study also was the first to examine the moderating role of FSSB within this occupation.

The examination of these relationships is especially important for this occupational group. As stated previously, correctional officers have been found to have life spans 12 to 16 years lower than average (Cheek 1984; Parker 2011). This occupational group also has been found to have elevated rates of suicide (Stack \& Tsoudis, 1997; Task Force on Police Suicide, 2009), divorce (Cheek \& Miller, 1983; Shawn \& Aamodt, 2010), and depression (Obidoa et al., 2011). Additionally, the ODOC initially contacted PSU researchers out of concern for the well-being of their correctional officer staff. The ODOC reported to the PSU researchers that their correctional officers had suicide and domestic violence rates that were higher than the occupational national average. The examination of the relationships between a specific and salient workplace stressor for correctional officers, PDJ, and WFC, FWC, and physical symptoms may prove to be crucial in efforts to better understand the contributing factors of, and the 
successful implementation of, interventions aimed to lessen the rates of suicide and domestic violence among correctional officers in Oregon.

Results of the current study supported the proposed direct positive relationship between PDJ and the well-being indicators. Specifically, it was hypothesized that PDJ would have positive relationships with WFC, FWC, and physical symptoms. The finding that PDJ was positively related to WFC is consistent with previous research (Lambert \& Hogan, 2006). The positive relationship between PDJ and physical symptoms found by the current study is also consistent with previous research involving other occupations that have found a positive relationship between workplace stressors and physical symptoms (Ganster et al., 1986; Hurrell \& Lindstrom, 1992; Nixon et al., 2011; Spector 1987, Spector et al., 1988).

The current study also hypothesized a mediating role of perceived stress on the relationships between PDJ and the well-being indicators of WFC, FWC, and physical symptoms. No support for this hypothesis could be found, however, utilizing a Baron and Kenny (1986) causal steps approach to mediation due to the non-significant relationship between PDJ and perceived stress. Sobel's (1982) test of these three models also found no evidence of significant indirect effects. It is possible that the global nature (life in general) of the perceived stress scale used in this study (PSS; Cohen et al., 1983) may be capturing perceived stress originating from sources too distal to the workplace to be a significant mediator of these particular relationships. Utilizing a stress measure with a workplace frame of reference, as opposed to general perceived stress, may have improved the likelihood of finding a significant relationship between PDJ and stress. 
Additionally, the workplace culture of this sample may have heavily influenced the results of this theoretically-driven hypothesis. From our research design meetings with correctional officers employed by the ODOC, we learned that there is a stigma attached to correctional officers by their peers when they seek help for stress-related concerns. The fear of potential ostracizing by their peers may have been powerful enough for some participants to even influence their responses to the items of the PSS.

Finally, the construct of perceived stress used in the current study may have been a theoretically less than perfect choice. Perhaps instead of perceived stress, measures of primary and secondary appraisals and problem focused and emotion focused coping efforts with regards to PDJ as mediating variables would have found the mediating hypotheses to be supported.

The moderating role of FSSB on three different sets of relationships was also investigated within the current study. The first of these, the interaction between PDJ and FSSB (when including control variables) was not found to explain significant incremental variance in perceived stress. Here again, the perceived stress scale used may be inappropriate for the study model. Additionally, it is possible that the two job characteristic items of understaffing and lack of adequate resources and lack of opportunity to participate in decision making that were included as controls are too strongly correlated with perceived stress $(r=.25, p<.01$ and $r=.24, p<.01$ respectively). In comparison, the correlation of PDJ, which is also a job characteristic, and perceived stress was weaker $(r=.11, p<.01)$. 
The second set of moderations to be tested was the interaction between PDJ and FSSB on the well-being indicators of WFC, FWC, and physical symptoms. The interaction between PDJ and FSSB did explain significant incremental variance in WFC. Thus, FSSB significantly moderated the PDJ to WFC relationship. The PDJ to WFC relationship was strongest in the case of low FSSB and weakest in the case of high FSSB. Individuals with different levels of FSSB did not differ in WFC under conditions of low PDJ, however, differences were noted under conditions of high PDJ: individuals reporting high levels of FSSB reported significantly lower levels of WFC than individuals reporting low levels of FSSB. The buffering effect of FSSB for correctional officers high in PDJ is in agreement with previous studies that have found having a family specific supportive supervisor to be related to lower levels of work-family conflict (Breaugh \& Frye, 2008; Hammer et al., 2009; Kossek et al., 2007). Additionally, this finding is supported by the transactional model of stress and coping in which FSSB can be viewed as a toolkit of additional coping resources that correctional officers can utilize thus potentially reducing WFC. This finding is also consistent with a JD-R model of workplace stress in which FSSB can be seen as a social job resource that may mitigate or buffer the physical and mental costs associated with the job demand of PDJ.

No support of moderation was found when testing the interaction of PDJ and FSSB on FWC or physical symptoms. It is possible that PDJ is such a strong workplace stressor that FSSB may not be able to mitigate the effects of family domain role expectations conflicting with those of the work domain for correctional officers. The interaction of PDJ and FSSB was also not found to explain significant incremental 
variance in physical symptoms. This again seems counter to the transactional model of stress and coping as well as the JD-R model and social support theory.

The last test of moderations within the current study investigated the moderating role of FSSB on the relationship between perceived stress and well-being. The interaction of perceived stress and FSSB did explain significant incremental variance in physical symptoms but not in WFC or FWC. Thus, FSSB significantly moderated the perceived stress to physical symptoms relationship. The perceived stress to physical symptoms relationship was strongest in the case of low FSSB and weakest in the case of high FSSB. Individuals of different levels of FSSB did differ slightly in physical symptoms under conditions of low perceived stress: individuals reporting high levels of FSSB reported slightly higher levels of physical symptoms. Differences were greater under conditions of high perceived stress: individuals reporting high levels of FSSB reported lower levels of physical symptoms than individuals reporting low levels of FSSB. This finding is supported by the transactional model of stress and coping in which FSSB can be viewed as workplace resources that employees could utilize to restructure their previous unsuccessful coping efforts in attempts to master, tolerate, or reduce stress.

In summation, the current study found support for the positive relationship between PDJ and well-being among correctional officers and that FSSB can be beneficial in reducing WFC for those experiencing high levels of PDJ and physical symptoms of psychological distress for those experiencing high levels of perceived stress. Additionally, the current study found that the mean levels of PDJ increased as the security level of inmates most worked with increased. 


\section{Contributions}

A call has been made for examination of more mediated relationships in workfamily research (Eby et al., 2005). The current study attempted to address this methodological need within the field by investigating the perceived stress mediated relationship between PDJ and the well-being indicators of WFC, FWC, and physical symptoms of psychological distress, however, no significant indirect effects were found. This study also represents the first time a version of a FSSB scale (Hammer et al., 2009; Hammer et al., 2013) and the PSI (Spector \& Jex, 1998) have been utilized with a correctional officer sample. Additionally, in their 2011 article investigating the relationship between work-family conflict and depression among correctional officers, Obidoa and colleagues suggested that information on work-environment factors such as the presence or absence of support in the workplace from coworkers and supervisors would help to provide a more robust explanation of work-family conflict among this occupational group (Obidoa et., 2011). The current study examined the potentially moderating role of FSSB, a form of supervisor social and instrumental support, and thus contributes to the body of knowledge regarding correctional officers and work-family conflict. Finally, PDJ is an especially salient workplace stressor for correctional officers (Cullen et al., 1985; Lambert et al., 2002) that has largely been reported specifically in the criminology literature and seldom investigated in relation to work-family conflict (see Lambert \& Hogan, 2006; 2010 for exceptions). The current study contributes to the existing literature by having investigated the relationship between the specific workplace 
stressor of PDJ and measures of both WFC and FWC as well as physical symptoms of psychological distress.

Practical implications. Results of the current study indicate that PDJ does have a significant and positive relationship with WFC, FWC, and physical symptoms. Given the very nature of the work, the element of danger associated with the occupation of correctional officer is not only necessary for the safety of correctional officers themselves, but also for the safety of the inmates in their charge. Attempts to lessen the PDJ of correctional officers would therefore not only be extremely problematic but potentially unethical as well. What should be pursued, however, are investigations of potential constructs that could buffer the effects of PDJ on correctional officer wellbeing. In the current study, FSSB were found to act as a buffer both to the effects of PDJ on WFC and perceived stress on physical symptoms. The current study results indicate that those correctional officers rating high in PDJ and perceived stress could benefit the most from a family supportive supervisor behavior workplace intervention such as that outlined by Hammer, Kossek, Anger, Bodner, and Zimmerman (2011). It should also be noted that correctional officers within the current study sample do not have the same supervisor consistently. The majority of correctional officers and Corporals employed by the ODOC are supervised by a variety of Captains and Lieutenants. Assignments are also bid upon every six months within the ODOC meaning that during every six month time period a correctional officer is likely to work for multiple, different supervisors. Additionally, correctional officers and Corporals may work more in proximity to a Sergeant who is not an official supervisor but a "lead worker" who directs the daily work 
of the correctional officers and Corporals but has no authority over their schedules. Given this situation, it would be critical that an FSSB intervention within this occupational setting include all employees that have any supervisory position whatsoever. This intervention should include a group level orientation to the construct and practice of FSSB as well as individual computer-based training. It would also be recommended that the training of FSSB be conducted in the future for supervisor position new hires as well as those promoted to such a status from within the organization. An initial FSSB intervention and sustained incorporation of its fundamental tenets by the ODOC could improve the well-being of their correctional officers by potentially lessening the WFC and physical symptoms of psychological distress they experience.

\section{Limitations and Future Research}

No research endeavor is without potential limitations. The proposed study is cross-sectional by design and as such it is impossible to infer causality among the variables. Additionally, the rank or position of the respondents was not asked on the survey. Specifically, it is unknown which respondents are correctional officers, Corporals, Sergeants, Captains, or Lieutenants. All that is known is that all respondents included in the current study analyses indicated that they were security staff. Specific rank or position of respondents was not inquired on the survey as the research department of the ODOC and the broad literature on correctional officers both indicated that correctional officers as an occupational group are suspicious of upper level management within their organizations and may be less willing to complete the survey if rank or position was asked. These issues of course mean that the analyses involving FSSB in the 
current study should be interpreted with caution as the optimum sampling method of matching subordinates to their supervisors was unable to be performed.

The current study utilized a modified version of the PDJ scale (Cullen et al., 1983) that was developed using a sample of police officers and then later used with correctional officers and correctional facility staff (Lambert \& Hogan, 2006; Moon \& Maxwell, 2004). Future research should investigate whether the current study results, using the same modified version of this scale as well the overall study model, are replicated with samples from other occupations such as private, corporate, and military security personnel. Additionally, the current study utilized outcome variables that are negative indicators of well-being. That is, with regard to WFC, FWC, and physical symptoms of psychological distress, less of the constructs are actually better for an individual's well-being. Future studies could build on this work by utilizing the model with positive indicators of well-being outcome variables such as life satisfaction and positive work-to-family spillover and a mediator variable such as peer support. The investigation of not only strain reactions to PDJ but also effects of enhancement to positive well-being by FSSB could further increase the understanding of the larger relationship of work and well-bring among correctional officers. Also, assessing and analyzing work-family conflict by the individual sources of time-based, strain-based, and behavior-based conflict was beyond the scope of the current study, however, future research utilizing the current study model and including measurement of these individual sources could increase understanding of the more precise impact of the workplace stressor of PDJ. From our research design meetings with correctional officers employed 
by the ODOC and the fact that the average number of hours worked per week among the current study's participants was 43, I would hypothesize that behavior and strain based sources of WFC would be found to be more prominent. Finally, a longitudinal study utilizing the current study model is another potential avenue for future research. As the correctional officers employed by the ODOC bid on shifts and working assignments every six months, measuring the study variables, especially perceived stress, at six month intervals may prove to be very informative.

\section{Conclusion}

The current study adds to the work-family literature in general and the workfamily literature as it pertains to correctional officers specifically by examining the relationship between a salient workplace stressor, PDJ, and WFC and FWC.

Additionally, the current study adds to the stress literature by investigating the relationships between PDJ and perceived stress and physical symptoms of psychological distress. PDJ was found have a significant and positive relationship with WFC, FWC, and physical symptoms among ODOC correctional officers. Additionally, FSSB were found to moderate the relationship between PDJ and WFC and perceived stress and physical symptoms. From a transactional model of stress and coping lens, FSSB represent potential problem focused and emotion focused coping resources that correctional officers can employ in their efforts of reducing strain derived from PDJ and perceived stress. From a JD-R model perspective, FSSB provide a social job resource that may buffer the WFC experienced by correctional officer due in part to the job demand of PDJ. This study lays important groundwork for future studies to continue investigating the 
potential of FSSB to improve employee well-being as well as helping to inform potential workplace interventions. The results of this study have value for correctional organizations directly as well. The supported hypotheses indicate that the perceived dangerousness of the job is a real and salient workplace stressor for their correctional officer employees and is associated with measures of their well-being. With such knowledge and scientific support in hand, it is hoped that upper level management of correctional organizations will be better able to take real and concerted action in efforts of improving the well-being of this most deserved population of workers. 


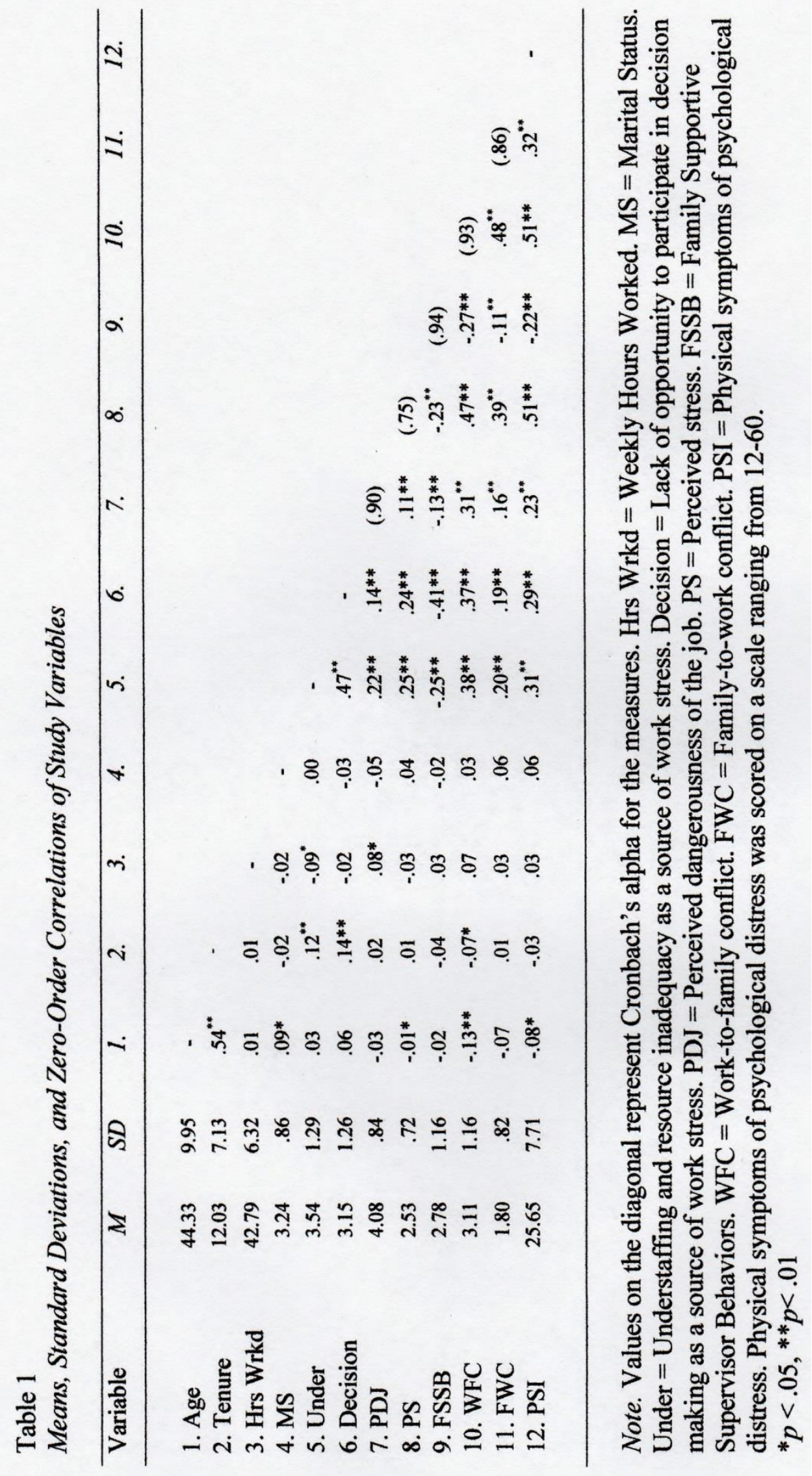




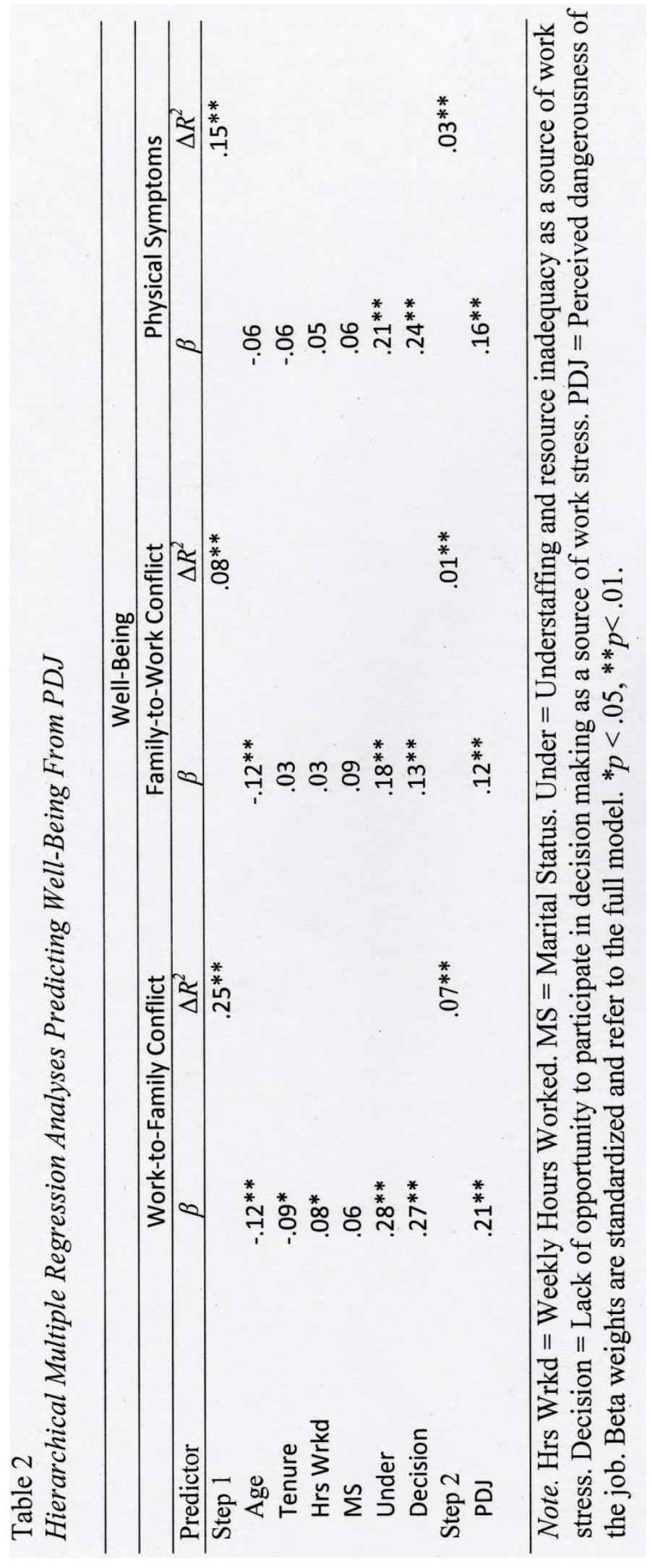




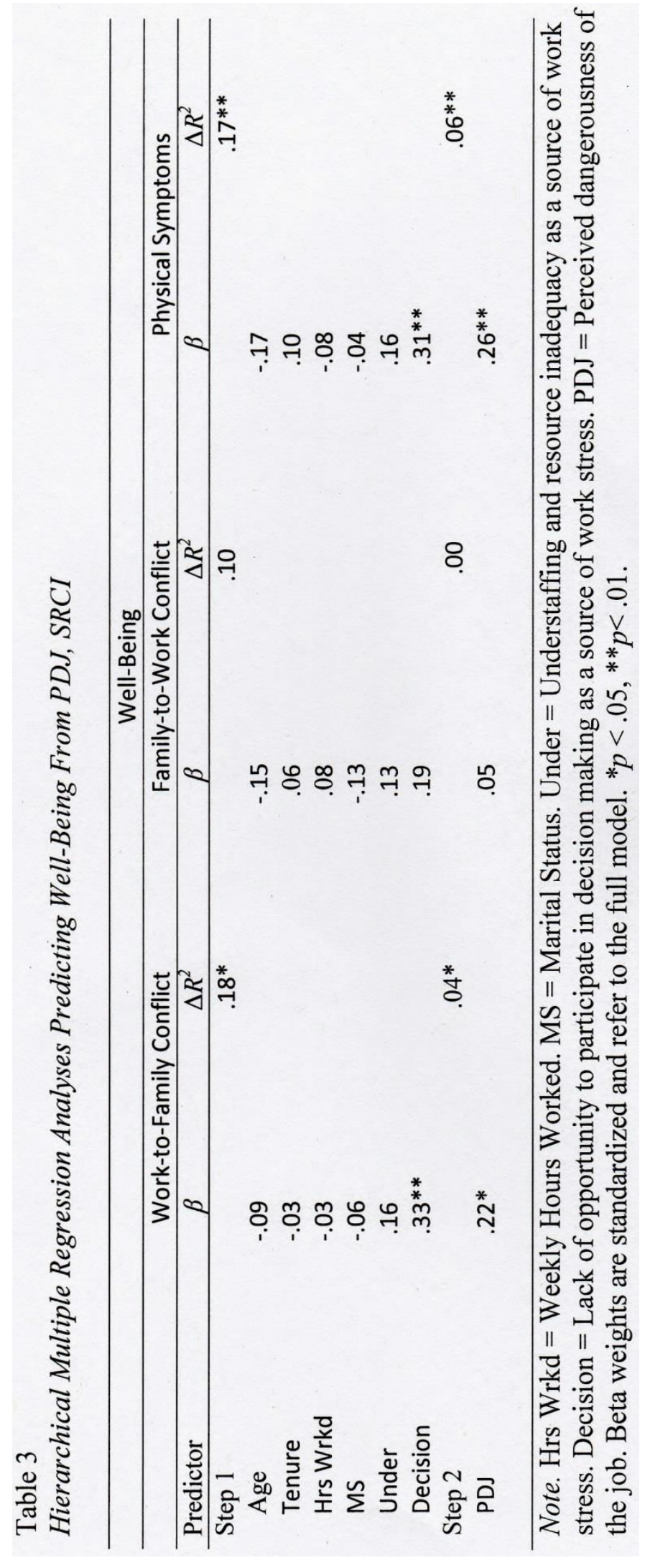




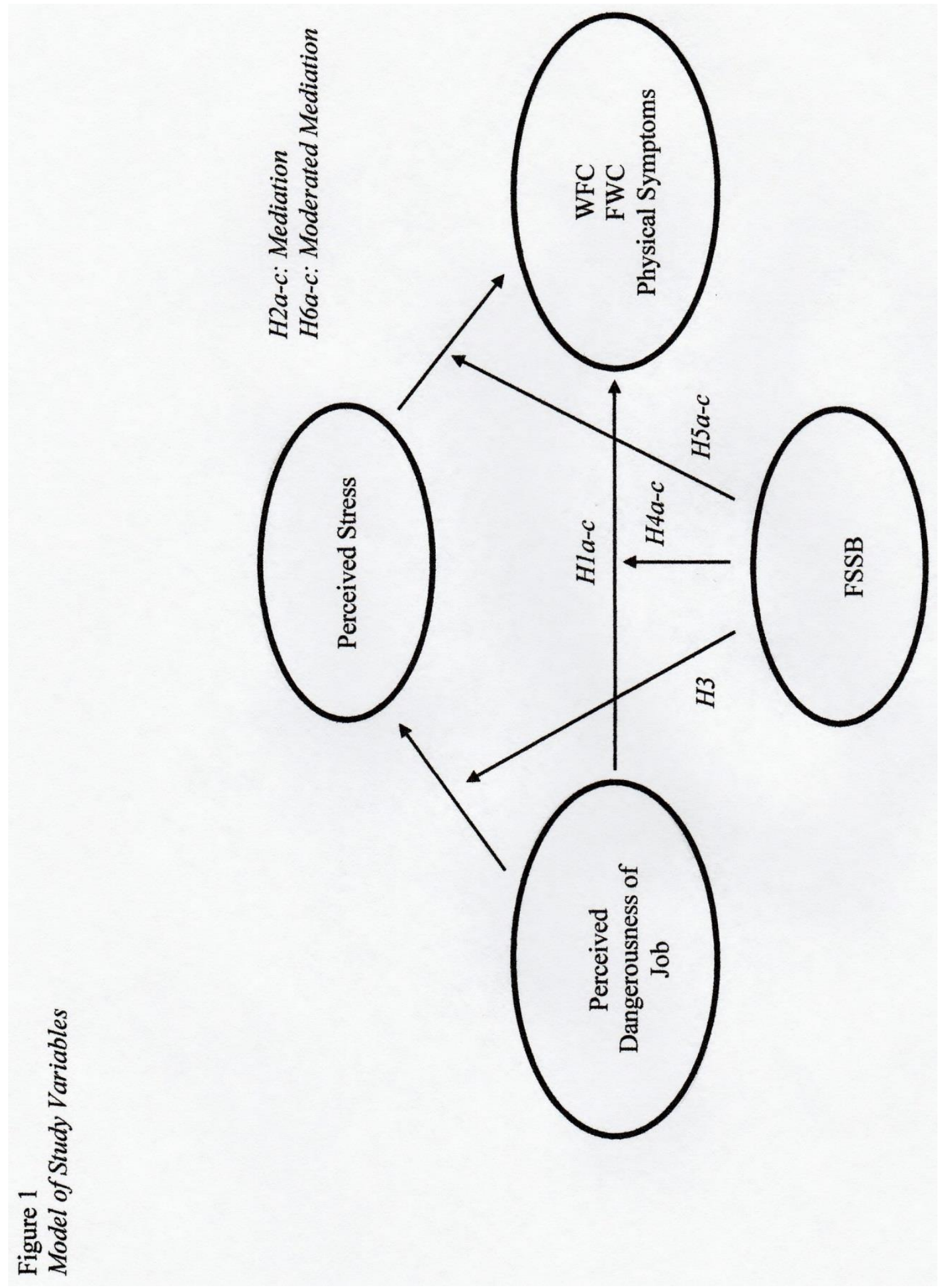


Figure 2

Interaction between PDJ and FSSB on WFC

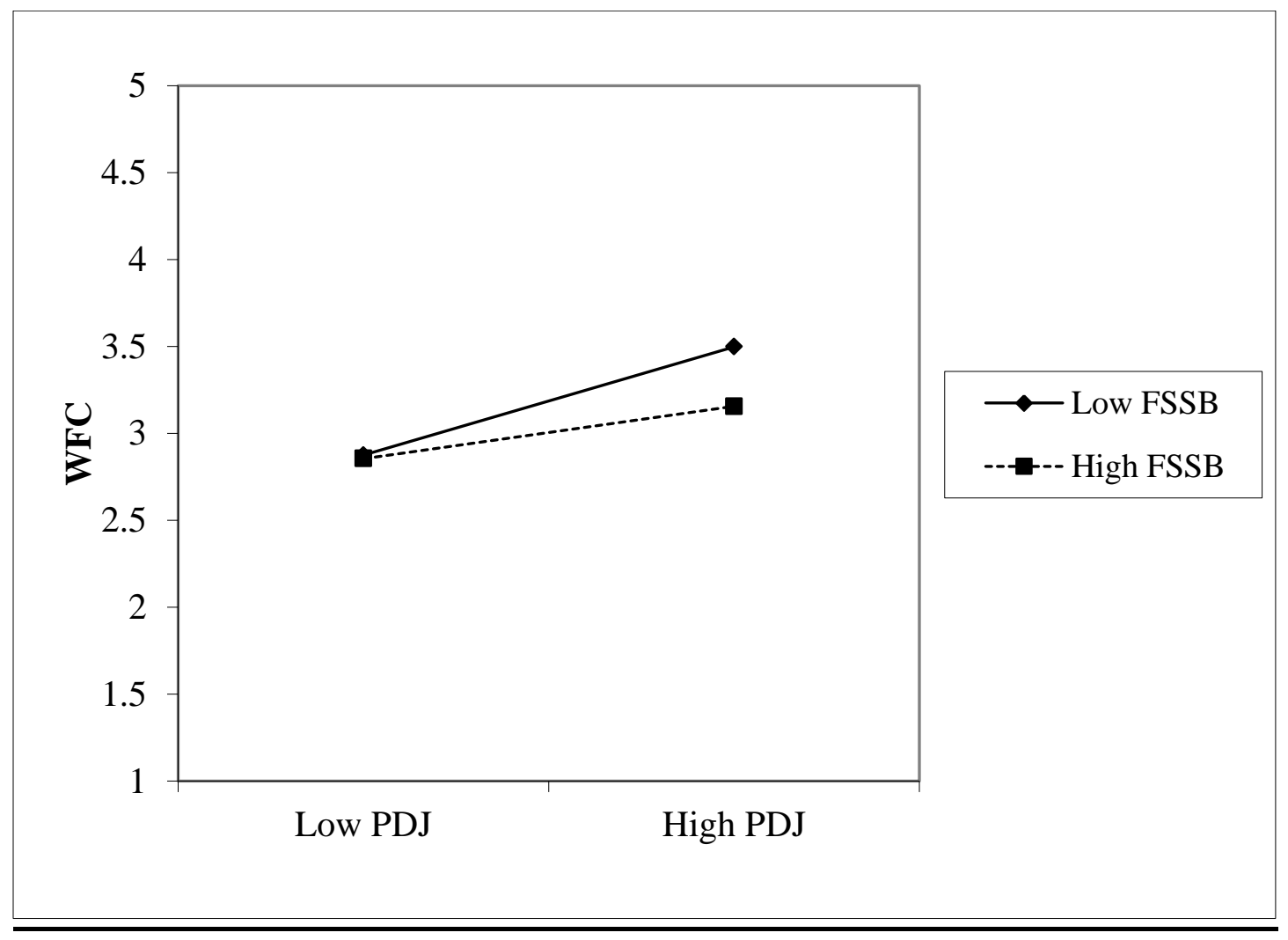


Figure 3

Interaction between perceived stress and FSSB on physical symptoms

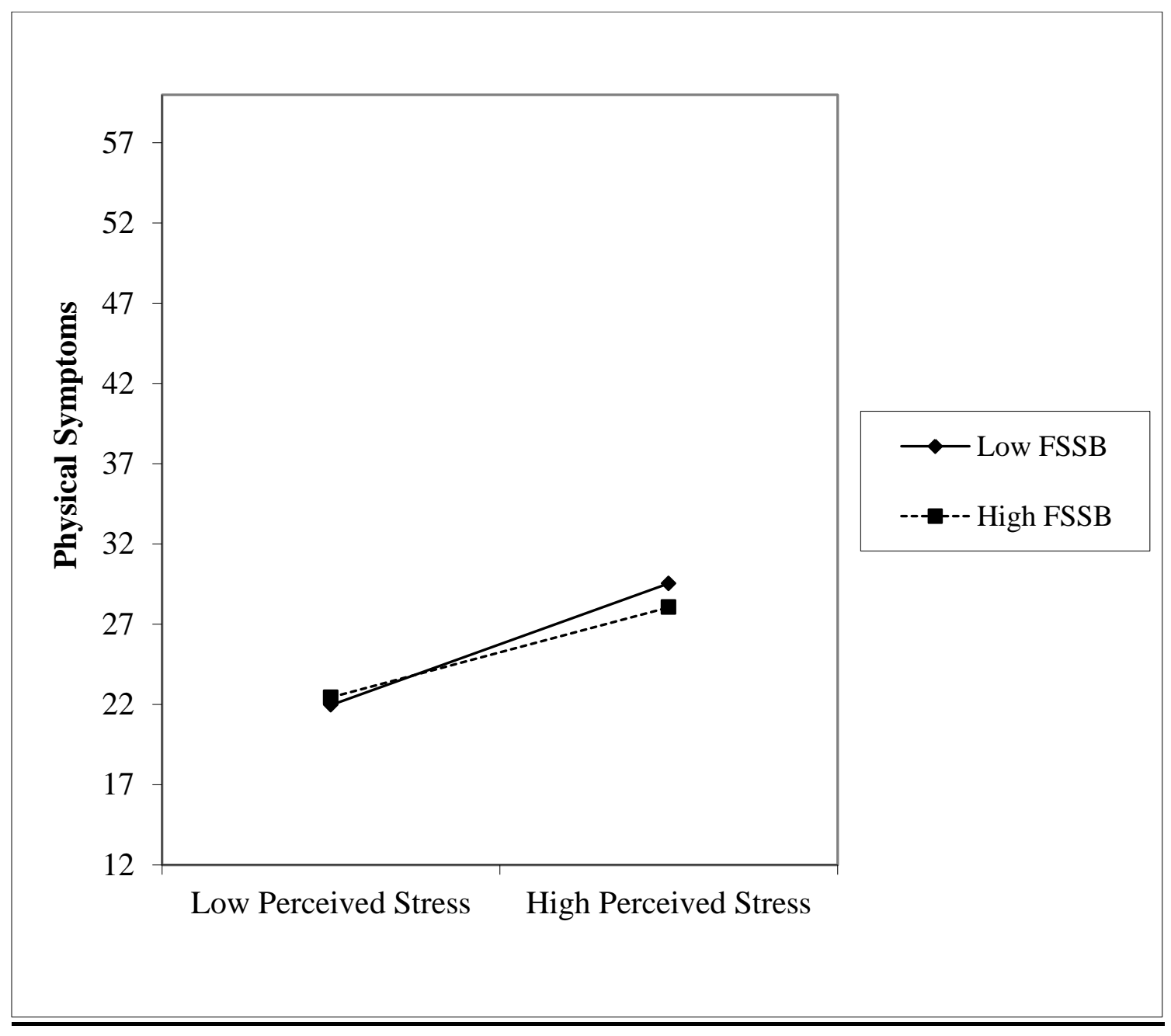




\section{References}

Addonizio, F. P. (2012). Stress, coping, social support, and psychological distress among MSW students. Dissertation Abstracts International: Section A: Humanities and Social Sciences, 73(2-A), 764.

Allen, D. E., de Nesnera, A., Cummings, K, \& Darling, F. E. III. (2011). Transforming the culture of caring: Getting hurt is not part of the job. Journal of Psychosocial Nursing and Mental Health Services, 49(1), 45-49.

Allen, T. D., Herst, D. E., Bruck, C.S., \& Sutton, M. (2000). Consequences associated with work-to-family conflict: A review and agenda for future research. Journal of Occupational Health Psychology, 5, 278-308.

Anderson, S. E., Coffey, B. S., \& Byerly, R. T. (2002). Formal organizational initiatives and informal workplace practices: Links to work-family conflict and job-related outcomes. Journal of Management, 28, 787-810.

Bakker, A.B., Demerouti, E., \& Euwema, M.C. (2005). Job resources buffer the impact of job demands on burnout. Journal of Occupational Health Psychology, 10, 17080.

Bakker, A. B., Hakanen, J. J., Demerouti, E., \& Xanthopoulou, D. (2007). Job resources boost work engagement, particularly when job demands are high. Journal of Educational Psychology, 99, 274-284.

Baron, R. M., \& Kenny, D. A. (1986). The moderator-mediator variable distinction in social psychological research: Conceptual, strategic, and statistical considerations. Journal of Personality and Social Psychology, 51(6), 1173-1182. 
Bedeian, A. G., Burke, B. G., \& Moffett, R. G. (1988). Outcomes of work-family conflict among married male and female professionals. Journal of Management, $14,475-491$.

Behson, S. J. (2002). Coping with family-to-work conflict: The role of informal work accommodations to family. Journal of Occupational Health Psychology, 7, 324341.

Breaugh, J. A., \& Frye, N. K. (2008). Work-family conflict: The importance of familyfriendly employment practices and family-supportive supervisors. Journal of Business and Psychology, 22, 345-353.

Britton, D. M. (1997). Perceptions of the work environment among correctional officers: Do race and sex matter? Criminology, 35, 85-105.

Brough, P., O'Driscoll, M. P., \& Kalliath, T. J. (2005). The ability of "family friendly" organizational resources to predict work-family conflict and job and family satisfaction. Stress and Health, 21, 223-234.

Brough, P., \& Pears, J. (2004). Evaluating the influence of the type of social support on job satisfaction and work related psychological well-being. International Journal of Organisational Behaviour, 8, 472-485.

Brough, P., \& Williams, J. (2007). Managing occupational stress in a high-risk industry: Measuring the job demands of correctional officers. Criminal Justice and Behavior, 34(4), 555-567. 
Bureau of Justice Statistics. (1990). Census of state and federal correctional facilities, 1990. Washington, DC: U.S. Department of Justice. http://bjs.ojp.usdoj.gov/content/pub/pdf/csfcf90.pdf

Bureau of Justice Statistics. (2005). Census of state and federal correctional facilities, 2005. Washington, DC: U.S. Department of Justice. http://bjs.ojp.usdoj.gov/content/pub/pdf/csfcf05.pdf

Bureau of Justice Statistics. (2006). HIV in prisons 2004. Washington, DC: U.S. Department of Justice. http://bjs.ojp.usdoj.gov/content/pub/ascii/hivp04.txt

Byron, D. (2005). A meta-analytic review of work-family conflict and its antecedents. Journal of Vocational Behavior, 67, 169-198.)

Cannon, W. B. (1932). The wisdom of the body. Second Edition. New York, NY. Norton.

Carlson, D. S. (1999). Personality and role variables as predictors of three forms of work-family conflict. Journal of Vocational Behavior, 55, 236-253.

Carlson, D. S., \& Kacmar, K. M. (2000). Work-family conflict in the organization: Do life role values make a difference? Journal of Management, 26, 1031-1054.

Carlson, D. S., \& Perrewe, P. L. (1999). The role of social support in the stressor-strain relationship: An examination of work-family conflict. Journal of Management, $25,513-540$.

Castle, T. L., \& Martin, J. S. (2006). Occupational hazard: Predictors of stress among jail correctional officers. American Journal of Criminal Justice, 31(1), 65-80.

Cheek, F. E. (1984). Stress management for correctional officers and their families. College Park, MD: American Correctional Association. 
Cheek, F. E., \& Miller, M. (1983). The experience of stress for correction officers: A double-bind theory of correctional stress. Journal of Criminal Justice, 11, 105120.

Cohen, S., Kamarck, T., \& Mermelstein, R. (1983). A global measure of perceived stress. Journal of Health and Social Behavior, 24, 385-396.

Colquitt, J. A., Lepine, J. A., Zapata, C. P., \& Wild, E. R. (2011). Trust in typical and high-reliability contexts: Building and reacting to trust among firefighters. Academy of Management Journal, 55(5), 999-1015.

Cooke, R. A., \& Rousseau, D. M. (1984). Stress and strain from family roles and workrole expectations. Journal of Applied Psychology, 69, 252-260.

Crouter, A. C. (1984). Spillover from family to work: The neglected side of the workfamily interface. Human Relations, 37(6), 425-442.

Cullen, F. T., Lemming, T., Link, B. G., \& Wozniak, J. F. (1985). The impact of social supports on police stress. Criminology, 23, 503-522.

Cullen, F. T., Link, B. G., Travis, L. F. III, \& Lemming, T. (1983). Paradox in policing: a note on perceptions of danger. Journal of Police Science and Administration, 11(4), 457-462.

Cullen, F. T., Link, B. G., Wolfe, N. T., \& Frank, J. (1985). The social dimensions of correctional officer stress. Justice Quarterly, 2(4), 505-533.

Del Ben, K. S. (2008). Posttraumatic stress disorder in firefighters: A proposed model of mediators and moderators. Dissertation Abstracts International: Section B: The Sciences and Engineering, 68(8-B), 5563. 
Demerouti, E., Bakker, A.B., Nachreiner, F. \& Schaufeli, W.B. (2001). The job demandsresources model of burnout, Journal of Applied Psychology, 86, 499-512.

Dewe, P., \& Trenberth, L. (2004). Work stress and coping: drawing together theory and practice, British Journal of Guidance \& Counseling, 32, 143-156.

Dollard, M. F., \& Winefield, A. H. (1998). A test of the demand-control/support model of work stress in correctional officers. Journal of Occupational Health Psychology. 3, 243-264.

Dowden, C., \& Tellier, C. (2004). Predicting work-related stress in correctional officers: A meta-analysis. Journal of Criminal Justice, 32, 31-47.

Duxbury, L., Higgins, C., \& Lee C. (1994). Work-family conflict: A comparison by gender, family type, and perceived control. Journal of Family Issues, 15, 449-466.

Eagle, B., Icenogle, M. L., Maes J. D., Miles, E. W. (1998). The importance of employee demographic profiles for understanding experiences of work-family interrole conflicts. Journal of Social Psychology, 138, 690-709.

Eagle, B. W., Miles, E. W., \& Icenogle, M. L. (1997). Interrole conflicts and the permeability of work and family domains: Are there gender differences? Journal of Vocational Behavior, 50, 168-184.

Eby, L. T., Casper, W. J., Lockwood, A., Bordeaux, C., \& Brinley, A. (2005). Work and family research in IO/OB: Content analysis and review of the literature (19802002). Journal of Vocational Behavior, 66, 124-197. 
Edge, T. F. (2008). Adult attachment and emotion: An examination of work-stress spillover in firefighter couples. Dissertation Abstracts International: Section B: The Sciences and Engineering, 68(9-B), 6300.

Finn, P. (1998). Correctional officer stress: A cause for concern and additional help. Federal Probation, 62, 65-74.

Finn, P. (2000). Addressing Correctional Officer Stress: Programs and Strategies. Washington, D.C.: National Institute of Justice, 2000. https://www.ncjrs.gov/pdffiles1/nij/183474.pdf

Folkman, S. (1984). Personal control and stress and coping processes: A theoretical analysis. Journal of Personality and Social Psychology, 46, 829-852.

Folkman, S., \& Lazarus, R. S. (1980). An analysis of coping in a middle-aged community sample. Journal of Health and Social Behavior, 21, 219-239.

Folkman, S., Lazarus, R. S., Dunkel-Schetter, C., DeLongis, A., \& Gruen, R. (1986). Dynamics of a stressful encounter: Cognitive appraisal, coping, and encounter outcomes. Journal of Personality and Social Psychology, 50, 992-1003.

Folkman, S., Lazarus, R. S., Gruen, R. J., \& DeLongis, A. (1986). Appraisal, coping, health status, and psychological symptoms. Journal of Personality and Social Psychology, 50(3), 571-579.

Fox, M. L., \& Dwyer, D. J. (1999). An investigation of the effects of time and involvement in the relationship between stressors and work-family conflict. Journal of Occupational Health Psychology, 4, 164-174.

Freeman, R., \& Johnson, L. (1982). Health-related knowledge, attitudes, and practices 
PERCEIVED DANGEROUSNESS AND WELL-BEING

of correctional officers. Journal of Prison and Jail Health, 2, 125-138.

Frone, M. R., Russell, M., \& Cooper, M. L. (1992a). Antecedents and outcomes of workfamily conflict: Testing a model of the work-family interface. Journal of Applied Psychology, 77, 65-78.

Frone, M. R., Russell, M., \& Cooper, M. L. (1992b). Prevalence of work-family conflict: Are work and family boundaries asymmetrically permeable? Journal of Organizational Behavior, 13, 723-729.

Frone, M. R., Yardley, J. K., \& Markel, K. S. (1997). Developing and testing an integrative model of the work-family interface. Journal of Vocational Behavior, $50,145-167$.

Ganster, D. C., Fusilier, M. R., \& Mayes, B. T. (1986). Role of social support in the experience of stress at work. Journal of Applied Psychology, 71(1), 102-110.

Ganster, D.C., \& Perrewe, P. L. (2011). Theories of Occupational Stress. In J. C. Quick and L. E. Tetrick (Eds.), Handbook of Occupational Health Psychology. Second Edition. Washington, DC: American Psychological Association.

Gibbons, J. J., \& Katzenbach, N. B. (2006). Confronting confinement: A report of the commission on safety and abuse in America's prisons. Journal of Law \& Policy, $28,385-562$.

Gerson, J. M. (1985). Women returning to school: The consequences of multiple roles. Sex Roles, 13, 77-91. 
Glaze, M. E. (2010). Correctional populations in the United States, 2009. Retrieved December 20, 2012 from U.S. Bureau of Justice Statistics online report: http://bjs.ojp.usdoj.gov/index.cfm?ty=pbdetail\&iid=2316

Gold, D., Geater, A., Aiyarak, S., Wongcharoenyong, S., Juengprasert, W., Chuchaisangrat, B., \& Griffin, M. (2000). The indigenous fisherman divers of Thailand: Attitiudes toward and awareness of hazards. Journal of Safety Research, 31(1), 17-28.

Goldenhar, L. M., Williams, L. J., \& Swanson, N. G. (2003). Modelling relationships between job stressors and injury and near-miss outcomes for construction labourers. Work \& Stress, 17(3), 218-240.

Goode, W. J. (1960). A theory of role strain. American Sociological Review, 25, 483-496.

Grandey, A. A., \& Cropanzano, R. (1999). The Conservation of Resources model applied to work-family conflict and strain. Journal of Vocational Behavior, 54, 350-370.

Greenhaus, J. H., Bedeian, A. G., \& Mossholder, K. W. (1987). Work experiences, job performance, and feelings of personal and family well-being. Journal of Vocational Behavior, 31, 200-215.

Greenhaus, J. H., \& Beutell, N. J. (1985). Sources of conflict between work and family roles. Academy of Management Review, 10(1), 76-88.

Griffin, M. (2006). Gender and stress: A comparative assessment of sources of stress among correctional officers. Journal of Contemporary Criminal Justice, 22, 4-25.

Grzywacz, J. G., \& Marks, N. F. (2000). Reconceptualizing the work-family interface: An ecological perspective on the correlates of positive and negative spillover 
PERCEIVED DANGEROUSNESS AND WELL-BEING

between work and family. Journal of Occupational Health Psychology, 5, 111126.

Gutek, B. A., Searle, S., \& Klepa, L. (1991). Rational versus gender role explanations for work-family conflict. Journal of Applied Psychology, 7, 560-568.

Hammer, L. B., Allen, E., \& Grigsby, T. D. (1997). Work-family conflict in dual-earner couples: Within-individual and crossover effects of work and family. Journal of Vocational Behavior, 50, 185-203.

Hammer, L. B., Kossek, E. E., Anger, W. K., Bodner, T., \& Zimmerman, K. (2011). Clarifying work-family intervention processes: The roles of work-family conflict and family supportive supervisor behaviors. Journal of Applied Psychology, 96, 134-150.

Hammer, L. B., Kossek, E. E., Bodner, T., \& Crain, T. (2013, June 3). Measurement development and validation of the family supportive supervision behavior shortform (FSSB-SF). Journal of Occupational Health Psychology. Advance online publication. doi: 10.1037/a0032612

Hammer, L. B., Kossek, E. E., Yragui, N. L., Bodner, T. E., \& Hanson, G. C. (2009). Development and validation of a multidimensional measure of family supportive supervisor behaviors (FSSB). Journal of Management, 35(4), 837-856.

Hammer, L. B., Kossek, E. E., Zimmerman, K.., \& Daniels, R. (2007). Clarifying the Construct of Family-Supportive Supervisory Behaviors (FSSB): A Multilevel Perspective. In P.L. Perrewe, \& D. C. Ganster (Eds.). Exploring the Work and Non-work Interface (pp. 165-204). Oxford, UK: Elsevier Ltd. 
Hammer, L.B., \& Zimmerman, K. L. (2011). Quality of Work Life. In S. Zedeck (Ed.), APA Handbook of Industrial and Organizational Psychology, Vol. 3, (pp. 399431). Washington, DC: American Psychological Association.

Higgins, C. A., \& Duxbury, L. E. (1992). Work-family conflict: A comparison of dualcareer and traditional-career men. Journal of Organizational Behavior, 13, 389411.

Hobfoll, A. E. (1989). Conservation of resources: A new attempt at conceptualizing stress. American Psychologist, 44(3), 513-524.

Holahan, C. K., \& Gilbert, L. A. (1979). Conflict between major life roles: Women and men in dual-career couples. Human Relations, 32, 451-467.

Honkasalo, A. (1992). Finnish drivers' view of occupational risks and risk taking. Applied Ergonomics, 23(3), 202-206.

House, J. S. (1981). Work stress and social support. Reading, MA: Addison-Wesley.

House, J. S., Landis, K. R., \& Umberson, C. (1988). Social relationships and health. American Association for the Advancement of Science, 241, 540-545.

Humphrey, S. E., Nahrgang, J. D., \& Morgeson, F. P. (2007). Integrating motivational, social, and contextual work design features: A meta-analytic summary and theoretical extension of the work design literature. Journal of Applied Psychology, $92,1332-1356$.

Hurrell, J. J., \& Lindstrom, K. (1992). Comparison of job demands, control, and psychosomatic complaints at different career stages of managers in Finland and 
PERCEIVED DANGEROUSNESS AND WELL-BEING

the United States. Scandinavian Journal of Work, Environment and Health, 18, 11-13.

Jacobs, A. B., \& Retsky, H. G. (1975). Prison guard. Urban Life, 4, 5-29.

Johnson, J. V., \& Hall, E. M. (1988). Job strain, work place social support, and cardiovascular disease: A cross-sectional study of a random sample of the Swedish working population. American Journal of Public Health, 78, 1336-1342.

Kahn, R. L., Wolfe, D. M., Quinn, R., Snoek, J. D., \& Rosenthal, R. A. (1964). Organizational Stress. New York: Wiley.

Karasek, R. A. (1979). Job demands, decision latitude, and mental strain: Implications for job redesign. Administrative Science Quarterly, 24, 285-307

Karasek, R., Brisson, C., Kawakami, N., Houtman, I., Bongers, P., \& Amick, D. (1998). The Job Content Questionnaire (JCQ): An instrument for internationally comparative assessments of psychosocial job characteristics. Journal of Occupational Health Psychology, 3(4), 322-355.

Kelloway, E. K., Gottlieb, B. H., \& Barham, L. (1999). The source, nature, and direction of work and family conflict: A longitudinal investigation. Journal of Occupational Health Psychology, 4, 337-346.

Kobasa, S. C., \& Puccetti, M. C. (1983). Personality and social resources in stress resistance. Journal of Personality and Social Psychology, 45, 839-850.

Kopelman, R. E., Greenhaus, J. H., \& Connolly, T. F. (1983). A model of work, family, and interrole conflict: A construct validation study. Organizational Behavior and Human Decision Processes, 32, 198-215. 
Kossek, E. E., \& Ozeki, C. (1999). Bridging the work-family policy and productivity gap: A literature review. Community, Work and Family, 2, 7-32.

Kossek, E., Pichler, S., Bodner, T., \& Hammer, L. (2007). Contextualizing Workplace Supports for Family: An Integrative Meta- Analysis of Direct and Moderating Linkages to Work-Family Conflict. Paper presented at National Meetings of the Society of Industrial \& Organizational Psychology, NY.

Kossek, E. E., Pichler. S., Bodner, T., \& Hammer, L. B. (2011). Workplace social support and work-family conflict: A meta-analysis clarifying the influence of general and work-family-specific supervisor and organizational support. Personnel Psychology, 64, 289-313.

Lambert, E. (2004). The impact of job characteristics on correctional staff. Prison Journal, 84, 208-227.

Lambert, E. (2008). The effect of job involvement on correctional staff. Professional Issues in Criminal Justice, 3(1), 57-76.84, 208-227.

Lambert, E. G., Altheimer, I., Hogan, N. L., \& Barton-Bellessa, S. M. (2011). Correlates of correctional orientation in a treatment oriented prison: A partial test of personenvironment fit theory. Criminal Justice and Behavior, 38(5), 453-470.

Lambert, E. G., Cluse-Tolar, T., \& Hogan, N. L. (2007). This job is killing me: The impact of job characteristics on correctional staff job stress. Applied Psychology in Criminal Justice, 3(2), 117-142. 
Lambert, E. G., \& Hogan, N. L. (2006). Possible antecedents of correctional staff work on family conflict. Professional Issues in Criminal Justice: A Professional Journal, 1(2), 17-34.

Lambert, E. G., \& Hogan, N. L. (2010). Work-family conflict and job burnout among correctional staff. Psychological Reports, 106(1), 19-26.

Lambert, E. G., Hogan, N. L., \& Altheimer, I. (2010). The Association Between WorkFamily Conflict and Job Burnout among Correctional Staff: A Preliminary Study. American Journal of Criminal Justice, 35(1), 37-55.

Lambert, E. G., Hogan, N. L., \& Barton, S. M. (2002). The impact of work-family conflict on correctional staff job satisfaction: An exploratory study. American Journal of Criminal Justice, 27(1), 35-52.

Lambert, E. G., Hogan, N. L., \& Barton, S. M. (2004). The nature of work-family conflict among correctional staff: An exploratory examination. Criminal Justice Review, 29(1), 145-172.

Lambert, E. G., Hogan, N. L., Camp, S. D., \& Ventura, L. A. (2006). The impact of work-family conflict on correctional staff: A preliminary study. Criminology \& Justice, 6(4), 371-387.

Lambert, E. G., Hogan, N. L., \& Griffin, M. L. (2007). The impact of distributive and procedural justice on correctional staff job stress, job satisfaction, and organizational commitment. Journal of Criminal Justice, 35, 644-656. 
Lambert, E., \& Paoline, E. (2005). The impact of jail medical issues on the job stress and job satisfaction of jail staff: An exploratory study. Punishment and Society: The International Journal of Penology, 7, 259-275.

Lambert, E. G., \& Paoline, E. A. (2012). Exploring potential antecedents of job involvement: An exploratory study among jail staff. Criminal Justice and Behavior, 39(3), 264-286.

Lazarus, R. S. (1993). From psychological stress to the emotions: A history of changing outlooks. Annual Review of Psychology, 44, 1-21.

Lazarus, R. S. (1999). Stress and emotion. New York, NY. Springer.

Lazarus, R. S., \& Eriksen, C. W. (1952). Effects of failure stress upon skilled performance. Journal of Experimental Psychology, 43, 100-105.

Lewig, K.A., \& Dollard, M.F. (2003). Emotional dissonance, emotional exhaustion, and job satisfaction in call centre workers. European Journal of Work and Organizational Psychology, 12, 366-392.

Lombardo, L. X. (1981). Guards imprisoned: Correctional officers at work. New York, NY. Elsevier.

Llorens, S., Bakker, A.B., Schaufeli, W., \& Salanova, M. (2006). Testing the robustness of the job demands-resources model. International Journal of Stress Management, 13, 378-391.

Mahaffey, K., \& Marcus, D. (1995). Correctional officers' attitudes towards AIDS. Criminal Justice and Behavior, 22, 91-105. 
Marks, S. R. (1977). Multiple roles and role strain: Some notes on human energy, time, and commitment. American Sociological Review, 42, 921-936.

McIntyre, J., Marquart, J. W., \& Brewer, V. (1999). Toward an understanding of the perception of HIV/AIDS-related risk among prison officers. Journal of Criminal Justice, 22(6), 525-538.

Mead, G. H. (1934). Mind, Self, and Society. Chicago: University of Chicago Press.

Miree, L. F. (2007). Financial implications of employee job stress. Research presented at the Annual Student/Faculty Research Conference, American University of Bulgaria.

Moon, B., \& Maxwell, S. R. (2004). The sources and consequences of corrections officers' stress: A South Korean example. Journal of Criminal Justice, 32, 359370.

Morgan, W. J. Jr. (2009). Correctional officer stress: A review of the literature 19772007. American Jails, 23(2), 33-42.

National Law Enforcement Officers Memorial Fund (2012). Law enforcement facts. Retrieved September 9, 2012 from: http://www.nleomf.org/facts/enforcement/ Neal, M.B., \& Hammer, L.B. (2007). Working couples caring for children and aging parents: Effects on work and well-Being. Mahwah, NJ: Lawrence Erlbaum Associates.

Netemeyer, R. G., Boles, J. S., \& McMurrian, R. (1996). Development and validation of work-family conflict and family-work conflict scales. Journal of Applied Psychology, 81(4), 400-410. 
Nielson, T. R., Carlson, D. S., \& Lankau, M. J. (2001). The supportive mentor as a means of reducing work-family conflict. Journal of Vocational Behavior, 59, 364-381.

Nixon, A. E., Mazzola, J. J., Bauer, J., Krueger, J. R., \& Spector, P. E. (2011). Can work make you sick? A meta-analysis of the relationships between job stressors and physical symptoms. Work \& Stress, 25(1), 1-22.

Obidoa, C., Reeves, D., Warren, N., Reisine, S., \& Cherniack, M. (2011). Depression and work family conflict among corrections officers. Journal of Occupational and Environmental Medicine, 53(11), 1294-1301.

Offermann, L.R., \& Gowing, M.K. (1990). Organizations of the future: Changes and challenges. American Psychologist, 45, 95 - 108.

Parasuraman, S., \& Greenhaus, J.H. (2002). Toward reducing some critical gaps in workfamily research. Human Resource Management Review, 12(3), p. 299-312.

Parasuraman, S., Purohit, Y. S., Godshalk, V. M., \& Beutell, N. J. (1996). Work and family variables, entrepreneurial career success, and psychological wellbeing. Journal of Vocational Behavior, 48, 275-300.

Parasuraman, S., \& Simmers, C. A. (2001). Type of employment, work-family conflict and well being: A comparative study. Journal of Organizational Behavior, 22, $551-568$.

Parker, J. R. (2011). Florida mortality study: Florida law enforcement and correctional officers compared to Florida general population. Retrieved December 27, 2012 from: http://www.floridastatefop.org/pdf_files/floridamortalitystudy.pdf 
Preacher, K.J., Rucker, D.D., \& Hayes, A.F. (2007). Addressing moderated mediation hypotheses: Theory, methods, and prescriptions. Multivariate Behavioral Research, 42, 185-227.

Rosine, L. (1992). Exposure to critical incidents: What are the effects on Canadian correctional officers? Forum on Corrections Research, 4, 3 1-36.

Shamir, B. (1983). Some antecedents of work-nonwork conflict. Journal of Vocational Behavior, 23, 98-111.

Shamir, B., \& Drory, A. (1982). Occupational tedium among prison officers. Criminal Justice and Behavior, 9, 79-99.

Shawn, P. M., \& Aamodt, M. G. (2010). A comparison of law enforcement divorce rates with those of other occupations. Journal of Police and Criminal Psychology, 25, $1-16$.

Sieber, S. D. (1974). Toward a theory of role accumulation. American Sociological Review. 39, 567-578.

Sobel, M.E. (1982). Asymptotic confidence intervals for indirect effects in structural equation models. In S. Leinhardt (Ed.), Sociological methodology (pp. 290-321). Washington, D. C.: Sociological Association.

Spector, P. E. (1987). Interactive effects of perceived control and job stressors on affective reactions and health outcomes for clerical workers. Work and Stress, 1 , $155-162$. 
Spector, P. E., Dwyer, D. J., \& Jex, S. M. (1988). Relation of job stressors to affective, health, and performance outcome: A comparison of multiple data sources. Journal of Applied Psychology, 73(1), 11-19.

Spector, P. E., \& Jex, S. M. (1998). Development of four self-report measures of job stressors and strain: Interpersonal conflict at work scale, organizational constraints scale, quantitative workload inventory, and physical symptoms inventory. Journal of Occupational Health Psychology, 32(4), 356-367.

Stack, S. J., \& Tsoudis, O. (1997). Suicide risk among correctional officers: A logistic regression analysis. Archives of Suicide Research, 3, 183-186.

Staines, G. L., \& Pleck, J. H. (1984). Nonstandard work schedules and family life. Journal of Applied Psychology, 69, 515-523.

Stohr, M. K., Lovrich, N. P., \& Wilson, G. L. (1994). Staff stress in contemporary jails: Assessing problem severity and the payoff of progressive personnel practices. Journal of Criminal Justice, 22(4), 313-327.

Stryker, S. (1968). Identity salience and role performance: The relevance of symbolic interaction theory for family research. Journal of Marriage and the Family, 30, $558-564$.

Swenson, D. X., Waseleski, D., \& Hartl, R. (2008). Shift work and correctional officers: Effects and strategies for adjustment. Journal of Correctional Health Care, 14(4), 299-310.

Tabachnick, B. G., \& Fidell, L. S. (2007). Using multivariate statistics. Fifth Edition. Boston, MA: Pearson Education. 
Task Force on Police Suicide (2009). New Jersey Police Suicide Task Force report.

Retrieved November 1, 2009 from

http://www.state.nj.us/lps/library/NJPoliceSuicide TaskForceReport-January-302009-Final(r2.3.09).pdf

Tepper, B. J. (2000). Consequences of abusive supervision. Academy of Management Journal, 43, 178-190.

Thompson, C. A., Beauvais, L. L., \& Lyness, K. S. (1999). When work-family benefits are not enough: The influence of work-family culture on benefit utilization, organizational attachment, and work-family conflict. Journal of Vocational Behavior, 54, 392-415.

Tiedje, L. B., Wortman, C. B., Downey, G., Emmons, C, Biernat, M., \& Lang, E. (1990). Women with multiple roles: Role-compatibility perceptions, satisfaction, and mental health. Journal of Marriage and the Family. 52, 63-72.

Triplett, R., Mullings, J. L., \& Scarborough, K. E. (1999). Examining the effect of workhome conflict on work-related stress among correctional officers. Journal of Criminal Justice, 27(4), 371-384.

U.S. Bureau of Labor Statistics, (2011). Number, incidence rate, and median days away from work for nonfatal occupational injuries and illnesses involving days away from work by selected detailed occupation and private industry, state government, and local government, 2010. Retrieved September 9, 2012 from the U.S. Bureau of Labor Statistics online news release: http://www.bls.gov/news.release/osh2.t04.htm 
U.S. Bureau of Labor Statistics. (2012a). U.S. Department of Labor, Occupational Outlook Handbook, 2012-13 Edition, Correctional Officers. Retrieved November 2, 2012 from: http://www.bls.gov/ooh/protective-service/correctional-officers.htm U.S. Bureau of Labor Statistics. (2012b). U.S. Department of Labor, Occupational Outlook Handbook, 2012-13 Edition, Police and Detectives. Retrieved November 2, 2012 from: http://www.bls.gov/ooh/protective-service/correctional-officers.htm U.S. Bureau of Labor Statistics, (2012c). Employment status of the civilian noninstitutional population by age, sex, and race. Retrieved July 18, 2012 from the U.S. Bureau of Labor Statistics online report: http://www.bls.gov/cps/cpsaat03.htm

U.S. Census Bureau (2001). Statistical abstract of the United States: 2001 (121st ed.). Washington, DC: US Census Bureau.

U.S. Census Bureau, (2004). Married Couples by Labor Force Status of Spouses: 1986 to Present. Retrieved July 18, 2012 from the U.S. Census Bureau online report: http://www.census.gov/population/socdemo/hh-fam/tabMC-1.pdf

U.S. Census Bureau (2012). Statistical abstract of the United States: 2012 (132nd ed.). Washington, DC: US Census Bureau.

Van Fleet, F. (1992). Correctional officers and their families: Dealing with stress. In American Correctional Association, The effective correctional officer (pp. 37-44). Laurel, MD: Author. 
Van Voorhis, IP., Cullen, F., Link, B., \& Wolfe, N. (1991). The impact of race and gender on correctional officers' orientation to the integrated environment. Journal of Research in Crime and Delinquency, 28, 472-500.

Wallace, J. E. (1997). It's about time: A study of hours worked and work spillover among law firm lawyers. Journal of Vocational Behavior, 50, 227-248.

Walsh, W. F., \& Donovan, E. J. (1984). Job stress in game conservation officers. Journal of Police Science \& Administration, 12(3), 333-338.

Weaver, J. D. (1984). Work-related stressors and means of coping among crisis intervention workers and their spouses. Emotional First Aid: A Journal of Crisis Intervention, 1(4), 14-24.

Wilhelm, K., Kovess, V., Rios-Seidel, C., \& Finch, A. (2004). Work and mental health. Social Psychiatry and Psychiatric Epidemiology, 39(11), 866-873.

Williams, K., \& Alliger, G. M. (1994). Role stressors, mood spillover, and perceptions of work-family conflict in employed parents. Academy of Management Journal, 37, $837-868$.

Wright, L.N., \& Northrup, M. K. (2001) 'Examining the health risks for corrections professionals'. Corrections Today, 63(6), 106-109.

Zahrly, J., \& Tosi, H. (1989). The differential effect of organizational induction process on early work role adjustment. Journal of Organizational Behavior, 10, 59-74. 
Appendix A

\section{Sample email from Mike VanPatten, AOCE Leadership:}

Everyone,

We have been working on and supporting the PSU / DOC survey that will help to examine the work stress, possible imbalances and wellness that our minds and bodies go through. The survey data collected is confidential and will be utilized to improve our over occupational health and work environment.

By volunteering to participate in the survey is your chance to honestly document the demands and effects on your physical and mental wellbeing at work and at home. There are critical situations and sometimes even the inmate culture itself that can leave long lasting traumatic, emotional, and physical health effects on us and then transition to our family life. Watching the backs of your fellow staff is not just for the physical assault anymore, it also should incorporate the verbal, mental, and traumatic aspect of our careers as Correctional Professionals, this is the first step in calibrating for the future.

If you should have any questions please feel free to contact me also by e-mail or on my cell 503-507-6992.

Be safe and support each other

Sgt. Michael Van Patten, Special Operations Sergeant Oregon State Penitentiary (503) 378-4063

AOCE President 
Appendix B

\section{Sample email from Tim Woolery AFSCME Leadership:}

Correctional Professionals at X \& X,

I realize that you have seen a couple communications that have been sent to you regarding the Portland State University Correctional Officer Stress and Well-being study (included below). But I felt the obligation to encourage those of you who have not yet participated to do so at this time.

As Mr. Gower outlined, this is an independent study that is NOT related to PEBB or HEM or several other studies that may have been conducted recently. This is a research project that is genuinely designed and for the sole purpose of gathering information that will lead to a better understanding of your issues and concerns both on and off the job. It is my hope that will create data and justifications that will lead to making improvements in working conditions for people in this challenging career field as well as off duty life. The survey is anonymous and only the aggregate data will be published or shared once complete.

If there are any operational roadblocks to being able to complete the survey, please contact your Superintendent in order to see if there is a way to help facilitate as many people participating as possible.

ONLINE SURVEY:

https://portlandstate.qualtrics.com//SE/?SID=SV_1QRwxtE0KyNobWI

Tim Woolery

Staff Representative

Oregon AFSCME Council 75

Salem Office

1400 Tandem Avenue NE

Salem, Oregon 97301

Office 503-370-2522 Ext 232 or 800-521-5954

Fax 503-370-7725 


\author{
Appendix C \\ Survey Recruitment Email From Assistant Director of Operations \\ $<$ Date $>$ \\ To: $\mathrm{X}$ and $\mathrm{X}$ Security Staff \\ From: Michael Gower, Assistant Director of Operations \\ RE: Portland State University Correctional Officer Stress and Well-being Survey \\ Without a doubt, correctional officers in Oregon work very hard to maintain the security \\ of our institutions and to ensure the safety of both inmates and coworkers. Unfortunately, \\ our work can be very stressful and sometimes that stress spills over into our personal \\ lives. The demands of our profession can create an imbalance between our work and \\ home lives, and that imbalance can sometimes have negative effects on our overall \\ happiness and wellbeing.
}

ODOC wants to combat these negative effects and help staff feel better in their jobs and at home. In order to do that, we are partnering with researchers at Portland State University (PSU) on a survey to help us examine work stress and work-life balance in correctional staff. Responses to this survey will help us improve the work environment of correctional staff.

There are a few things you should know about the survey:

$\bigcirc$ The survey is anonymous. The survey is voluntary, but we hope that all security staff will participate. The more staff participate, the better picture we will have of work stress and work-life balance among Oregon correctional officers.

- The data obtained from the survey will only be used for research purposes and to inform the development of recommendations to improve correctional officers' work environment.

O The survey is NOT associated with PEBB's Health Engagement Model (HEM).

O The survey is not associated with Desert Waters Correctional Outreach (DWCO).

$\bigcirc$ The survey is also not associated with the OHSU Health Promotion and Protection Study that is ongoing at a few institutions.

$\bigcirc$ Both AFSCME and AOCE are in full support of this project. ODOC's Research \& Evaluation unit and the group of researchers from PSU have been working closely with representatives from both labor organizations since the start of the project.

The survey will go out to security staff at ALL institutions, two-three facilities at a time (in no particular order). 
Although it may seem lengthy, the survey only takes about 25 minutes to complete.

Please consider participating in this important survey. You can complete the survey on paper or online using the link below. Paper copies of the survey, along with stamped envelopes to return completed surveys to the researchers at PSU, are available at your institution. Please watch your email for a message from your institution leadership about where you can pick up a paper copy of the survey.

\section{ONLINE SURVEY:}

https://portlandstate.qualtrics.com//SE/?SID=SV_1QRwxtE0KyNobWI

If you have questions about the survey, you may contact the principal investigator at PSU, Dr. Charlotte Fritz, at fritzc@ pdx.edu or (503) 725-3980. You may also contact Margaret Braun in the ODOC Research \& Evaluation Unit at margaret.j.braun@ doc.state.or.us or (503) 945-9001.

Take care,

Michael F. Gower-Assistant Director

Operations Division

2575 Center St.

Salem, OR. 97301

Office (503) 945-7144 
Appendix D

\section{PSU Occupational Health Survey Email Template For Superintendents}

\section{OPTION 1:}

It is clear, the work you do in corrections has an impact on the overall public safety of our communities. Through national studies it is also clear that corrections work is stressful and impacts all of us in many ways, unfortunately these impacts are often manifested in subtle ways while other times in not so subtle ways. Regardless of how stress presents itself it takes its toll on our health, our personal lives, and our families. To better understand the impacts and help address this issue the department has teamed up with Portland State University to gain a better understanding of how Oregon corrections work impacts our Oregon corrections professionals, starting with those in the security series.

$<$ INSERT STAFF MEMBERS' NAMES HERE $>$ are leading the effort at $<$ INSTITUTION> to help PSU hear from each of you individually regarding how your job impacts your life through a confidential survey that you can complete either electronically or on paper. Taking the survey is voluntary but I encourage each of you to anonymously and confidentially voice how corrections work has and is impacting your life. We can collectively better understand and address the needs of our corrections professionals if we have information germane to Oregon rather than a national perspective.

I hope you all will join in the department's effort to better understand and deal with the impacts of Oregon corrections work on you and your coworkers.

If you would rather do the survey on paper instead of electronically please get with $<$ INSERT STAFF MEMBERS' NAMES $>$. If you have any questions or concerns feel free to contact $<$ INSERT STAFF MEMBERS' NAMES $>$, or myself.

\section{OPTION 2:}

As you can see from the email below, Portland State is going to conduct a survey to examine work stress and work life balance for correctional series staff. At this time the survey has been targeted at the correctional series at the institutions. This survey is an excellent opportunity for all of us to understand potential difficulties in our work situation and how they may be affecting our personal lives. As stated it is anonymous. I highly encourage all staff to participate, the information collected will help both staff presently working and those that will come after us. It is not often that researchers have made themselves available to collect data on correctional officers, it is a stressful job and 
we are largely ignored as public safety officers. I hope you will all engage and complete the survey; any information collected that can affect us positively should be embraced.

If you are not comfortable with completing the survey on line please contact <INSERT STAFF MEMBERS' NAMES $>$ and they will work with you to get you a hard copy and envelope. $<$ INSERT STAFF MEMBERS' NAMES > will also have paper copies available at briefings.

The survey will take a bit of your time, I encourage you to work with the OIC if you require uninterrupted time to complete it.

If you have any questions or concerns please to not hesitate to contact me or any of the contacts listed below.

Thank you all in advance for your participation. 
Appendix E

First reminder email (Send one week after initial email from Central Office)

Dear X and X Security staff,

We have had a great response to the PSU Correctional Officer Stress and Well-being Survey so far. Thank you so much to everyone who has already participated. The more people who respond, the better equipped our agency will be to make changes that will improve the overall health and well-being of our valued staff.

If you have not had time to complete a survey but would like to participate, there is still time. The deadline for online or paper completion of the survey for security staff at $X$ and $\mathrm{X}$ is $\langle$ Date $\rangle$. Please complete the survey one time only, either online or on paper, by $<$ Date $>$.

ONLINE SURVEY:

https://portlandstate.qualtrics.com//SE/?SID=SV 10RwxtE0KyNobWI

As always, if you have questions about the survey you may contact the principal investigator at PSU, Dr. Charlotte Fritz, at fritzc@pdx.edu or (503) 725-3980. You may also contact me directly in the ODOC Research \& Evaluation Unit at margaret.j.braun@doc.state.or.us or (503) 945-9001.

Take care and be well!

Margaret J. F. Braun, PhD

Research Analyst

Oregon Dept. of Corrections

2575 Center St. NE

Salem, OR. 97301

503.945.9001 
Appendix F

\section{Second reminder email (Send two weeks after initial email from Central Office)}

Hello again $\mathrm{X}$ and $\mathrm{X}$ Security staff,

If you have not yet had time to participate in the PSU Correctional Officer Stress and Well-being survey, I am happy to inform you that the deadline has been extended to next <Day, Date>. If you would like to take the survey, please click on the link below or approach the designated staff member(s) in your institution for a paper copy and pre-paid envelope. Each and every person's responses are extremely valuable. The more people respond, the better/more solid answers PSU researchers will have to the questions they ask and the better we can make plans for changes in the future that may help reduce work stress and increase work-life balance.

If you have not yet filled out a survey, please click here: https://portlandstate.qualtrics.com//SE/?SID=SV 10RwxtE0KyNobWI

Thank you very much to those of you who have already participated! We greatly appreciate you taking the time to respond.

If you have questions you may contact the principal investigator at PSU, Dr. Charlotte Fritz, at fritzc@ pdx.edu or (503) 725-3980. You may also contact Margaret Braun in the ODOC Research \& Evaluation Unit at margaret.j.braun@ doc.state.or.us or (503) 9459001.

Margaret J. F. Braun, PhD

Research Analyst

Oregon Dept. of Corrections

2575 Center St. NE

Salem, OR. 97301

503.945.9001 


\section{Appendix G}

\section{Cover Letter}

Thank you for participating in this survey. The purpose of this study is to examine work stress and work-life balance in correctional staff. This survey will help the ODOC and the researchers at Portland State University better understand the life of a correctional officer in Oregon. Responses will be used by the ODOC to help improve the work environment of correctional staff.

The researchers and the ODOC are only interested in the information about participants as a group. Questions that ask for age and gender, for example, are being collected to better understand how the results of the survey questions relate to participants of certain groups, and not to identify individual participants. Some of the questions being asked may make you remember events that may cause slight discomfort. If you feel as though you need to speak with someone about this, please contact your facility Emergency Staff Services (ESS) or the services available through your Employee Assistance Program at 1800-433-2320. If you wish to contact a service not provided by your employer, you can call 1-800-273-8255 to speak with someone at a national talk hotline at no charge.

The survey should take about 20 minutes to complete. Participation in this study is voluntary. At any point you can stop taking the survey. You may contact the Human Subjects Research Review Committee at Portland State University at 503-725-4288 (1877-480-4400) for questions about your rights as a research participant. For other questions about the survey you may contact the Principal Investigator, Dr. Charlotte Fritz, through the Portland State University Department of Psychology at 503-725-3980.

By filling in the following survey, I certify that I am older than 18 years of age and I consent to participate in the survey. 


\author{
Appendix $\mathrm{H}$
}

Current Study Survey Items

\title{
Demographics
}

These final questions ask about your background. These questions are not being asked in order to identify you as an individual. Responses will be compiled in order to look at groups of participants, not individual responses.

206. What is your age? years

207. What is your gender? (Circle one)
a. Male
b. Female

208. What is your marital status? (Circle one)
a. Single, never married
d. Living with a partner
b. Dating someone
e. Divorced
c. Married
f. Widowed

209. What is your ethnicity? (Circle all that apply)
a. White (non-Hispanic)
e. Native American
b. Hispanic/Latino
f. Native Alaskan or Pacific Islander
c. African American g.
Other (please specify:
d. Asian

210. What is the highest level of education you have completed? (Circle one) (Bachelor's)
a. High school/GED
d. 4-year college degree

other)
b. Some college
e. Advanced degree (Master's or

specify:

c. 2-year college degree (Associate's)

f. Other (please

211. How many children do you have that are living with you at least half time?

212. How many minutes to you spend traveling to and from work per day?

213. At which facility do you currently work?

214. What is the security level of inmates you've worked with the most in the past month?
a. Minimum
b. Medium 
c. Maximum

215. Which best describes the shift you work?

a. Day shift

b. Swing shit

c. Night shift

216. How long have you been working as a correctional officer? years

217. How long have you been working at your current facility? years

218. Have you ever served on active duty in the U.S. Armed Forces? (Circle one)

a. Yes

b. No

219. On average in the past month, how many hours did you work per week?

\title{
Job Demands
}

How much has each of the following contributed to stress you have

experienced in the past month?

\section{Not at}

all

Very

much
4. Understaffing and resource inadequacy.
5. Lack of consultation or opportunity to participate in decision-making.
1
2
3
4
5
1
2
3
4
5

\section{Perceived Dangerousness of the Job}

To what extent do you agree with the

\section{Not at}

all

Very
much

following statements? In the past month...

27. I worked in a dangerous job.

\section{1}

\begin{abstract}
2
\end{abstract}
3

4

5

28. My job has been much more 1

2

3

4

5 dangerous than other kinds of jobs. 
29. In my job, I stood a good chance of getting hurt.

30. People I work with were at risk of getting physically injured on the job.

31. While at work I had to maintain a high level of alertness due to the potential for dangerous situations.

32. While at work I have been concerned that I may be involved in a violent confrontation.

12

2

3

3

4

5

1

2

3

4

5

1

1

\section{2}

3

4

5

$\begin{array}{llll}2 & 3 & 4 & 5\end{array}$

\section{Perceived Stress}

In the past month, how often have you felt...

$\begin{array}{lllll}\begin{array}{l}\text { None } \\ \text { of the }\end{array} & \begin{array}{l}\text { A little } \\ \text { of the } \\ \text { time } \\ \text { time }\end{array} & \begin{array}{l}\text { Some the } \\ \text { time }\end{array} & \begin{array}{l}\text { Most } \\ \text { of the } \\ \text { time }\end{array} & \begin{array}{l}\text { All of } \\ \text { the } \\ \text { time }\end{array} \\ & & & \end{array}$

165. That you were unable to control the important things in your life?

$\begin{array}{lllll}1 & 2 & 3 & 4 & 5\end{array}$

166. Confident about your ability to handle your personal problems?

167. That things were going your way?

168. Difficulties were piling up so high that you could not overcome them?

$\begin{array}{lllll}1 & 2 & 3 & 4 & 5 \\ 1 & 2 & 3 & 4 & 5 \\ 1 & 2 & 3 & 4 & 5\end{array}$

\section{Work-to-Family Conflict}

To what extent do you agree with the Not at

following statements regarding the past

month?

33. The demands of my work interfered with my home and family life.

34. The amount of time my job took up
1

2

3

4

5

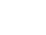

1

1

2

3

4

5 
made it difficult to fulfill family responsibilities.

35. Things I wanted to do at home did not get done because of the demands my job put on me.

36. My job produced strain that made it difficult to fulfill family duties.

37. Due to work-related duties, I had to make changes to my plans for family activities.

\section{Family-to-Work Conflict}

To what extent do you agree with the following statements regarding the past

Not at all
Very

much month?

38. The demands of my family or spouse/partner interfered with work-related activities.

39. I had to put off doing things at work because of demands on my time at home.

40. Things I wanted to do at work didn't get done because of the demands of my family or spouse/partner.

41. My home life interfered with my responsibilities at work such as getting to work on time, accomplishing daily tasks, and working overtime.

42. Family-related strain interfered with my ability to perform job-related duties.

$\begin{array}{lllll}1 & 2 & 3 & 4 & 5\end{array}$

1

2

3

4

5

1

2

3

4

5

2

3

4

5

1

2

3

4

5 


\section{Physical Symptoms of Psychological Distress}

Over the past month, how often have you

experienced each of the following symptoms?

$\begin{array}{lllll}\text { Not } & \text { Once } & \text { Once } & \text { Most } & \text { Every } \\ \text { at all } & \text { or } & \text { or } & \text { days } & \text { day } \\ & \text { twice } & \text { twice } \\ & \text { per } & \\ & & \text { week }\end{array}$

175. An upset stomach or nausea

176. Trouble sleeping

177. Headache

178. Acid indigestion or heartburn

179. Eye strain

180. Diarrhea

181. Stomach cramps (Not menstrual)

182. Constipation

183. Ringing in the ears

184. Loss of appetite

185. Dizziness

186. Tiredness or fatigue $\begin{array}{lllll}1 & 2 & 3 & 4 & 5\end{array}$

$\begin{array}{lllll}1 & 2 & 3 & 4 & 5\end{array}$

$\begin{array}{lllll}1 & 2 & 3 & 4 & 5\end{array}$

$\begin{array}{lllll}1 & 2 & 3 & 4 & 5\end{array}$

$\begin{array}{lllll}1 & 2 & 3 & 4 & 5\end{array}$

$\begin{array}{lllll}1 & 2 & 3 & 4 & 5\end{array}$

$\begin{array}{lllll}1 & 2 & 3 & 4 & 5\end{array}$

$\begin{array}{lllll}1 & 2 & 3 & 4 & 5\end{array}$

$\begin{array}{lllll}1 & 2 & 3 & 4 & 5\end{array}$

$\begin{array}{lllll}1 & 2 & 3 & 4 & 5\end{array}$

$\begin{array}{lllll}1 & 2 & 3 & 4 & 5\end{array}$

$\begin{array}{lllll}1 & 2 & 3 & 4 & 5\end{array}$

5
5
5
5
5
5
5
5
5
5
5

\section{Family Supportive Supervisor Behaviors}

To what extent do you agree with the following statements about your OIC in general?

94. My OIC makes me feel comfortable talking to him or her about
Not at

all
Very

much 
my conflicts between work and nonwork.

95. My OIC works effectively with workers to creatively solve conflicts between work and nonwork.

96. My OIC demonstrates effective behaviors in how to juggle work and nonwork balance.

97. My OIC thinks about how the work 1 12

3

4

5

in my department can be organized to jointly benefit employees and the company.

1

2

3

4

5

(1)

2

3

4

5 


\section{Appendix I}

\section{PSU/ODOC Survey}

Thank you for participating in this survey. The purpose of this study is to examine work stress and work-life balance in correctional staff. This survey will help ODOC and researchers at Portland State University better understand the life of a correctional officer in Oregon. Responses will be used by ODOC to help improve the work environment of correctional staff.

Your participation in this study will remain anonymous. However, as the researchers are hoping to conduct follow-up research, you will have the option of creating a 5-character code that will be used to link your answers on this survey with answers on future surveys. Please write this code in the space provided at the bottom of the page. We recommend that you do not write this code down anywhere else. In future surveys, we will ask you to write in the same code. This process is meant solely to ensure anonymity of your answers.

The researchers and ODOC are only interested in the information about participants as a group. Questions that ask for age and gender, for example, are being collected to better understand how the results of the survey questions relate to participants of certain groups, and not to identify individual participants. Some of the questions being asked may make you remember events that may cause slight discomfort. If you feel as though you need to speak with someone about this, please contact your facility Emergency Staff Services (ESS) or the services available through your Employee Assistance Program at 1-800-433-2320. If you wish to contact a service not provided by your employer, you can call 1-800-273-8255 to speak with someone at a national talk hotline at no charge.

The survey should take about 20 minutes to complete. Participation in this study is voluntary. At any point you can stop taking the survey. You may contact the Human Subjects Research Review Committee at Portland State University at 503-725-4288 (1-877-480-4400) for questions about your rights as a research participant. For other questions about the survey you may contact the Principal Investigator, Dr. Charlotte Fritz, through the Portland State University Department of Psychology at 503-725-3980.

By filling in the following survey, I certify that I am older than 18 years of age and I consent to participate in the survey.

Participant code:

$$
\begin{aligned}
& \text { Third letter of the city you were born in } \\
& \text { Second letter of your mother's maiden name } \\
& \text { First letter of the street you live on } \\
& \text { Second letter of the high school you attended } \\
& \text { Last digit of the year you were born }
\end{aligned}
$$


ONLINE SURVEY: You may also complete the survey online by using this link:

https://portlandstate.qualtrics.com//SE/?SID=SV_1QRwxtE0KyNobWI

Directions: Please read the statements and the questions carefully. Your options for answers will change throughout the survey. Most questions have a number associated with the answer option you agree with the most. Please circle the number that corresponds with the option you agree with the most.

\begin{tabular}{|c|c|c|c|c|c|c|}
\hline \multicolumn{2}{|c|}{$\begin{array}{l}\text { How much has each of the following } \\
\text { contributed to stress you have experienced in } \\
\text { the past month? }\end{array}$} & \multicolumn{4}{|l|}{$\begin{array}{l}\text { Not at } \\
\text { all }\end{array}$} & \multirow{2}{*}{$\begin{array}{c}\begin{array}{c}\text { Very } \\
\text { much }\end{array} \\
5\end{array}$} \\
\hline 1. & $\begin{array}{l}\text { Lack of clear guidelines for job } \\
\text { performance (inconsistent management } \\
\text { practices). }\end{array}$ & 1 & 2 & 3 & 4 & \\
\hline 2. & $\begin{array}{l}\text { Having too little authority to carry out } \\
\text { the responsibilities you are assigned. }\end{array}$ & 1 & 2 & 3 & 4 & 5 \\
\hline 3. & Lack of support from management. & 1 & 2 & 3 & 4 & 5 \\
\hline 4. & Understaffing and resource inadequacy. & 1 & 2 & 3 & 4 & 5 \\
\hline 5. & $\begin{array}{l}\text { Lack of consultation or opportunity to } \\
\text { participate in decision-making. }\end{array}$ & 1 & 2 & 3 & 4 & 5 \\
\hline 6. & Possibility of violence from offenders. & 1 & 2 & 3 & 4 & 5 \\
\hline 7. & Fear of allegations from offenders. & 1 & 2 & 3 & 4 & 5 \\
\hline 8. & $\begin{array}{l}\text { Conflict between having to control and } \\
\text { help offenders. }\end{array}$ & 1 & 2 & 3 & 4 & 5 \\
\hline 9. & $\begin{array}{l}\text { Involvement in major incidents (e.g., } \\
\text { death in custody, overdose, escape). }\end{array}$ & 1 & 2 & 3 & 4 & 5 \\
\hline 10. & $\begin{array}{l}\text { Having to be constantly alert and on } \\
\text { guard. }\end{array}$ & 1 & 2 & 3 & 4 & 5 \\
\hline
\end{tabular}

To what extent do you agree with the following statements? In the past month...

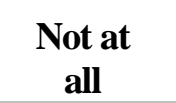

11. I always found new and interesting aspects in my work.

12. It happened more and more often that I talked about my work in a derogatory way.

13. I tended to think less during my work and just execute it mechanically.

14. I experienced my work as a real challenge.

15. Over time, one loses the internal relationship with one's work.

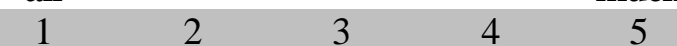

$\begin{array}{lllll}1 & 2 & 3 & 4 & 5\end{array}$

$\begin{array}{lllll}1 & 2 & 3 & 4 & 5 \\ 1 & 2 & 3 & 4 & 5 \\ 1 & 2 & 3 & 4 & 5\end{array}$




\begin{tabular}{|c|c|c|c|c|c|c|}
\hline 16. & $\begin{array}{l}\text { Sometimes I felt really sick about my } \\
\text { work tasks. }\end{array}$ & 1 & 2 & 3 & 4 & 5 \\
\hline 17. & $\begin{array}{l}\text { I could not imagine another occupation } \\
\text { for myself. }\end{array}$ & 1 & 2 & 3 & 4 & 5 \\
\hline 18. & $\begin{array}{l}\text { I got more and more engaged in my } \\
\text { work. }\end{array}$ & 1 & 2 & 3 & 4 & 5 \\
\hline 19. & $\begin{array}{l}\text { There were days that I felt already tired } \\
\text { before I went to work. }\end{array}$ & 1 & 2 & 3 & 4 & 5 \\
\hline 20. & $\begin{array}{l}\text { After my work, I needed more time to } \\
\text { relax than in the past to become fit } \\
\text { again. }\end{array}$ & 1 & 2 & 3 & 4 & 5 \\
\hline 21. & $\begin{array}{l}\text { I could stand the pressure of my work } \\
\text { very well. }\end{array}$ & 1 & 2 & 3 & 4 & 5 \\
\hline 22. & $\begin{array}{l}\text { During my work, I often felt } \\
\text { emotionally drained. }\end{array}$ & 1 & 2 & 3 & 4 & 5 \\
\hline 23. & $\begin{array}{l}\text { After my work, I usually felt still totally } \\
\text { fit for my leisure activities. }\end{array}$ & 1 & 2 & 3 & 4 & 5 \\
\hline 24. & $\begin{array}{l}\text { After my work, I usually felt worn out } \\
\text { and weary. }\end{array}$ & 1 & 2 & 3 & 4 & 5 \\
\hline 25. & When I worked, I usually felt vital. & 1 & 2 & 3 & 4 & 5 \\
\hline 26. & $\begin{array}{l}\text { I could manage the amount of work } \\
\text { well. }\end{array}$ & 1 & 2 & 3 & 4 & 5 \\
\hline 27. & I worked in a dangerous job. & 1 & 2 & 3 & 4 & 5 \\
\hline 28. & $\begin{array}{l}\text { My job has been much more dangerous } \\
\text { than other kinds of jobs. }\end{array}$ & 1 & 2 & 3 & 4 & 5 \\
\hline 29. & $\begin{array}{l}\text { In my job, I stood a good chance of } \\
\text { getting hurt. }\end{array}$ & 1 & 2 & 3 & 4 & 5 \\
\hline 30. & $\begin{array}{l}\text { People I work with were at risk of } \\
\text { getting physically injured on the job. }\end{array}$ & 1 & 2 & 3 & 4 & 5 \\
\hline 31. & $\begin{array}{l}\text { While at work I had to maintain a high } \\
\text { level of alertness due to the potential } \\
\text { for dangerous situations. }\end{array}$ & 1 & 2 & 3 & 4 & 5 \\
\hline 32. & $\begin{array}{l}\text { While at work I have been concerned } \\
\text { that I may be involved in a violent } \\
\text { confrontation. }\end{array}$ & 1 & 2 & 3 & 4 & 5 \\
\hline 33. & $\begin{array}{l}\text { The demands of my work interfered } \\
\text { with my home and family life. }\end{array}$ & 1 & 2 & 3 & 4 & 5 \\
\hline 34. & $\begin{array}{l}\text { The amount of time my job took up } \\
\text { made it difficult to fulfill family } \\
\text { responsibilities. }\end{array}$ & 1 & 2 & 3 & 4 & 5 \\
\hline 35. & $\begin{array}{l}\text { Things I wanted to do at home did not } \\
\text { get done because of the demands my } \\
\text { job put on me. }\end{array}$ & 1 & 2 & 3 & 4 & 5 \\
\hline 36. & $\begin{array}{l}\text { My job produced strain that made it } \\
\text { difficult to fulfill family duties. }\end{array}$ & 1 & 2 & 3 & 4 & 5 \\
\hline
\end{tabular}




\begin{tabular}{|c|c|c|c|c|c|c|}
\hline 37. & $\begin{array}{l}\text { Due to work-related duties, I had to } \\
\text { make changes to my plans for family } \\
\text { activities. }\end{array}$ & 1 & 2 & 3 & 4 & 5 \\
\hline 38. & $\begin{array}{l}\text { The demands of my family or } \\
\text { spouse/partner interfered with work- } \\
\text { related activities. }\end{array}$ & 1 & 2 & 3 & 4 & 5 \\
\hline 39. & $\begin{array}{l}\text { I had to put off doing things at work } \\
\text { because of demands on my time at } \\
\text { home. }\end{array}$ & 1 & 2 & 3 & 4 & 5 \\
\hline 40. & $\begin{array}{l}\text { Things I wanted to do at work didn't } \\
\text { get done because of the demands of my } \\
\text { family or spouse/partner. }\end{array}$ & 1 & 2 & 3 & 4 & 5 \\
\hline 41. & $\begin{array}{l}\text { My home life interfered with my } \\
\text { responsibilities at work such as getting } \\
\text { to work on time, accomplishing daily } \\
\text { tasks, and working overtime. }\end{array}$ & 1 & 2 & 3 & 4 & 5 \\
\hline 42. & $\begin{array}{l}\text { Family-related strain interfered with my } \\
\text { ability to perform job-related duties. }\end{array}$ & 1 & 2 & 3 & 4 & 5 \\
\hline 43. & I had to be on guard to stay safe. & 1 & 2 & 3 & 4 & 5 \\
\hline 44. & $\begin{array}{l}\text { I liked having a wall or something else at } \\
\text { my back so I didn't have to worry about } \\
\text { danger coming from behind me. }\end{array}$ & 1 & 2 & 3 & 4 & 5 \\
\hline 45. & $\begin{array}{l}\text { Bad things may have happened if I had } \\
\text { not constantly been looking out for } \\
\text { danger. }\end{array}$ & 1 & 2 & 3 & 4 & 5 \\
\hline 46. & $\begin{array}{l}\text { I went entire days without worrying } \\
\text { about my safety. }\end{array}$ & 1 & 2 & 3 & 4 & 5 \\
\hline 47. & $\begin{array}{l}\text { I may have put myself and the people } \\
\text { around me in danger if I had not always } \\
\text { been on guard. }\end{array}$ & 1 & 2 & 3 & 4 & 5 \\
\hline 48. & $\begin{array}{l}\text { I maintained awareness of the actions } \\
\text { of others that may have caused me } \\
\text { harm. }\end{array}$ & 1 & 2 & 3 & 4 & 5 \\
\hline 49. & $\begin{array}{l}\text { I always kept an eye out for potential } \\
\text { danger. }\end{array}$ & 1 & 2 & 3 & 4 & 5 \\
\hline 50. & $\begin{array}{l}\text { If I relaxed, I may have made myself } \\
\text { more vulnerable to dangerous } \\
\text { situations. }\end{array}$ & 1 & 2 & 3 & 4 & 5 \\
\hline 51. & $\begin{array}{l}\text { Being aware of my environment was an } \\
\text { important part of staying safe. }\end{array}$ & 1 & 2 & 3 & 4 & 5 \\
\hline
\end{tabular}

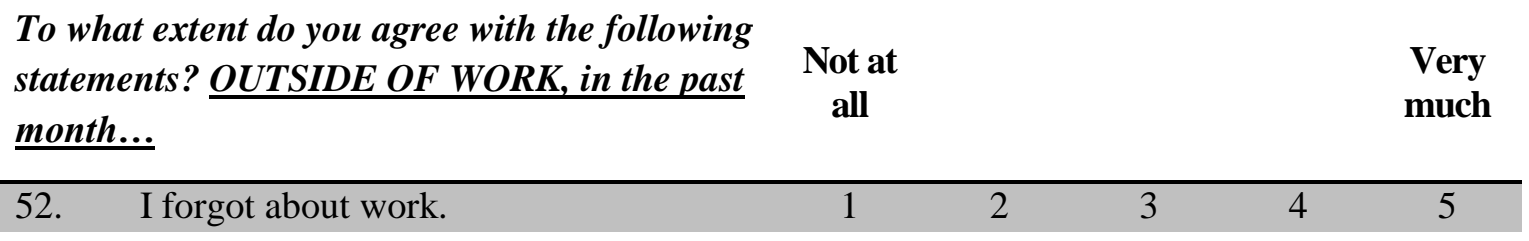




\begin{tabular}{|c|c|c|c|c|c|c|}
\hline 53. & I kicked back and relaxed. & 1 & 2 & 3 & 4 & 5 \\
\hline 54. & I learned new things. & 1 & 2 & 3 & 4 & 5 \\
\hline 55. & $\begin{array}{l}\text { I felt like I could decide for myself } \\
\text { what to do. }\end{array}$ & 1 & 2 & 3 & 4 & 5 \\
\hline 56. & I didn't think about work at all. & 1 & 2 & 3 & 4 & 5 \\
\hline 57. & I did things that were relaxing. & 1 & 2 & 3 & 4 & 5 \\
\hline 58. & I realized what I like about my job. & 1 & 2 & 3 & 4 & 5 \\
\hline 59. & $\begin{array}{l}\text { I considered the negative aspects of my } \\
\text { work. }\end{array}$ & 1 & 2 & 3 & 4 & 5 \\
\hline 60. & I did things together with others. & 1 & 2 & 3 & 4 & 5 \\
\hline 61. & I sought out mental challenges. & 1 & 2 & 3 & 4 & 5 \\
\hline 62. & $\begin{array}{l}\text { It became clear to me what I don't like } \\
\text { about my work. }\end{array}$ & 1 & 2 & 3 & 4 & 5 \\
\hline 63. & I distanced myself from work. & 1 & 2 & 3 & 4 & 5 \\
\hline 64. & I used the time to relax. & 1 & 2 & 3 & 4 & 5 \\
\hline 65. & I did things that challenged me. & 1 & 2 & 3 & 4 & 5 \\
\hline 66. & $\begin{array}{l}\text { I determined for myself how I spent my } \\
\text { time. }\end{array}$ & 1 & 2 & 3 & 4 & 5 \\
\hline 67. & $\begin{array}{l}\text { I thought about the positive aspects of } \\
\text { my job. }\end{array}$ & 1 & 2 & 3 & 4 & 5 \\
\hline 68. & $\begin{array}{l}\text { I was aware of what is negative about } \\
\text { my work. }\end{array}$ & 1 & 2 & 3 & 4 & 5 \\
\hline 69. & I met up with nice people. & 1 & 2 & 3 & 4 & 5 \\
\hline 70. & $\begin{array}{l}\text { I considered the positive aspects of my } \\
\text { job. }\end{array}$ & 1 & 2 & 3 & 4 & 5 \\
\hline 71. & I got a break from the demands of work. & 1 & 2 & 3 & 4 & 5 \\
\hline 72. & I took time for leisure. & 1 & 2 & 3 & 4 & 5 \\
\hline 73. & $\begin{array}{l}\text { I did something to broaden my } \\
\text { horizons. }\end{array}$ & 1 & 2 & 3 & 4 & 5 \\
\hline 74. & $\begin{array}{l}\text { I took care of things the way that I } \\
\text { wanted them done. }\end{array}$ & 1 & 2 & 3 & 4 & 5 \\
\hline 75. & I decided my own schedule. & 1 & 2 & 3 & 4 & 5 \\
\hline 76. & $\begin{array}{l}\text { I enjoyed having people around who are } \\
\text { important to me. }\end{array}$ & 1 & 2 & 3 & 4 & 5 \\
\hline
\end{tabular}

The following questions relate to your sleep habits during the past month. Your answers should indicate the most accurate reply for the majority of days and nights in the past month. Please answer all questions.

77. During the past month, on average, how many hours of actual sleep did you get at night? (This may be different than the number of hours you spend in bed.)

HOURS OF SLEEP PER NIGHT (on average) 


\begin{tabular}{|c|c|c|c|c|c|c|}
\hline & & $\begin{array}{l}\text { Very } \\
\text { bad }\end{array}$ & $\begin{array}{l}\text { Fairly } \\
\text { bad }\end{array}$ & $\begin{array}{l}\text { Neither } \\
\text { good } \\
\text { nor } \\
\text { bad } \\
\end{array}$ & $\begin{array}{l}\text { Fairly } \\
\text { good }\end{array}$ & $\begin{array}{l}\text { Very } \\
\text { good }\end{array}$ \\
\hline \multirow[t]{2}{*}{78.} & $\begin{array}{l}\text { During the past month, how would you rate } \\
\text { your sleep quality overall? }\end{array}$ & 1 & 2 & 3 & 4 & 5 \\
\hline & & $\begin{array}{l}\text { Not } \\
\text { during } \\
\text { the } \\
\text { past } \\
\text { month }\end{array}$ & $\begin{array}{l}\text { Less } \\
\text { than } \\
\text { once } \\
\text { per } \\
\text { week }\end{array}$ & $\begin{array}{c}\text { Once } \\
\text { or } \\
\text { twice } \\
\text { per } \\
\text { week }\end{array}$ & $\begin{array}{c}\text { Three } \\
\text { or } \\
\text { more } \\
\text { times } \\
\text { a } \\
\text { week }\end{array}$ & $\begin{array}{l}\text { Every } \\
\text { day }\end{array}$ \\
\hline 79. & $\begin{array}{l}\text { During the past month, how often have you } \\
\text { taken medicine (prescribed or "over the } \\
\text { counter") to help you sleep? }\end{array}$ & 1 & 2 & 3 & 4 & 5 \\
\hline 80. & $\begin{array}{l}\text { During the past month, how often have you } \\
\text { had trouble staying awake while driving, } \\
\text { eating meals, or engaging in social } \\
\text { activity? }\end{array}$ & 1 & 2 & 3 & 4 & 5 \\
\hline 81. & $\begin{array}{l}\text { How often during the past month did you } \\
\text { get enough sleep to feel rested upon waking } \\
\text { up? }\end{array}$ & 1 & 2 & 3 & 4 & 5 \\
\hline \multicolumn{2}{|c|}{$\begin{array}{l}\text { To what extent did you experience the following } \\
\text { symptoms last month? }\end{array}$} & $\begin{array}{c}\text { Not } \\
\text { during } \\
\text { the } \\
\text { past } \\
\text { month }\end{array}$ & $\begin{array}{c}\text { Less } \\
\text { than } \\
\text { once } \\
\text { per } \\
\text { week }\end{array}$ & $\begin{array}{c}\text { Once } \\
\text { or } \\
\text { twice } \\
\text { per } \\
\text { week }\end{array}$ & $\begin{array}{c}\text { Three } \\
\text { or } \\
\text { more } \\
\text { times } \\
\text { a } \\
\text { week } \\
\end{array}$ & $\begin{array}{l}\text { Every } \\
\text { day }\end{array}$ \\
\hline 82. & Had trouble falling asleep. & 1 & 2 & 3 & 4 & 5 \\
\hline 83. & $\begin{array}{l}\text { Had trouble staying asleep (including waking } \\
\text { up too early). }\end{array}$ & 1 & 2 & 3 & 4 & 5 \\
\hline 84. & Woke up several times during the night. & 1 & 2 & 3 & 4 & 5 \\
\hline 85. & $\begin{array}{l}\text { Woke up after your usual amount of sleep } \\
\text { feeling tired and worn out. }\end{array}$ & 1 & 2 & 3 & 4 & 5 \\
\hline
\end{tabular}

Think about the Officer in Charge (OIC) you have had the most contact with in the last Not at Very month while answering the questions below.

all much

86. I usually know where I stand with my
OIC.




\begin{tabular}{|c|c|c|c|c|c|c|}
\hline 87. & $\begin{array}{l}\text { I usually know how satisfied my OIC } \\
\text { is with me. }\end{array}$ & 1 & 2 & 3 & 4 & 5 \\
\hline 88. & $\begin{array}{l}\text { My OIC understands my job problems } \\
\text { and needs. }\end{array}$ & 1 & 2 & 3 & 4 & 5 \\
\hline 89. & My OIC recognizes my potential. & 1 & 2 & 3 & 4 & 5 \\
\hline 90. & $\begin{array}{l}\text { Regardless of how much formal } \\
\text { authority he/she has built into his/her } \\
\text { position, my OIC would use his/her } \\
\text { power to help me solve problems in } \\
\text { my work. }\end{array}$ & 1 & 2 & 3 & 4 & 5 \\
\hline 91. & $\begin{array}{l}\text { I can count on my OIC to "bail me } \\
\text { out" at his/her own expense. }\end{array}$ & 1 & 2 & 3 & 4 & 5 \\
\hline 92. & $\begin{array}{l}\text { I have enough confidence in my OIC } \\
\text { that I would defend and justify his/her } \\
\text { decision if he/she was not present to } \\
\text { do so. }\end{array}$ & 1 & 2 & 3 & 4 & 5 \\
\hline 93. & $\begin{array}{l}\text { I would characterize my working } \\
\text { relationship with my OIC as extremely } \\
\text { effective. }\end{array}$ & 1 & 2 & 3 & 4 & 5 \\
\hline \multicolumn{2}{|c|}{$\begin{array}{l}\text { To what extent do you agree with the } \\
\text { following statements about your OIC in } \\
\text { general? }\end{array}$} & $\begin{array}{l}\text { Not at } \\
\text { all }\end{array}$ & & & & $\begin{array}{l}\text { Very } \\
\text { much }\end{array}$ \\
\hline 94. & $\begin{array}{l}\text { My OIC makes me feel comfortable } \\
\text { talking to him or her about my } \\
\text { conflicts between work and nonwork. }\end{array}$ & 1 & 2 & 3 & 4 & 5 \\
\hline 95. & $\begin{array}{l}\text { My OIC works effectively with } \\
\text { workers to creatively solve conflicts } \\
\text { between work and nonwork. }\end{array}$ & 1 & 2 & 3 & 4 & 5 \\
\hline 96. & $\begin{array}{l}\text { My OIC demonstrates effective } \\
\text { behaviors in how to juggle work and } \\
\text { nonwork balance. }\end{array}$ & 1 & 2 & 3 & 4 & 5 \\
\hline 97. & $\begin{array}{l}\text { My OIC thinks about how the work in } \\
\text { my department can be organized to } \\
\text { jointly benefit employees and the } \\
\text { agency. }\end{array}$ & 1 & 2 & 3 & 4 & 5 \\
\hline
\end{tabular}

During the past month, how often have you been in a situation where any of your supervisors or coworkers:

Never

Every day

\begin{tabular}{llllllll}
\hline 98. & Put you down or was condescending to you? & 1 & 2 & 3 & 4 & 5
\end{tabular}




\begin{tabular}{|c|c|c|c|c|c|c|}
\hline 99. & $\begin{array}{l}\text { Paid little attention to your statement or showed } \\
\text { little interest in your opinion? }\end{array}$ & 1 & 2 & 3 & 4 & 5 \\
\hline 100. & $\begin{array}{l}\text { Made demeaning or derogatory remarks about } \\
\text { you? }\end{array}$ & 1 & 2 & 3 & 4 & 5 \\
\hline 101. & $\begin{array}{l}\text { Addressed you in unprofessional terms, either } \\
\text { publicly or privately? }\end{array}$ & 1 & 2 & 3 & 4 & 5 \\
\hline 102. & $\begin{array}{l}\text { Ignored or excluded you from professional } \\
\text { camaraderie? }\end{array}$ & 1 & 2 & 3 & 4 & 5 \\
\hline 103. & $\begin{array}{l}\text { Doubted your judgment on a matter over which } \\
\text { you have responsibility? }\end{array}$ & 1 & 2 & 3 & 4 & 5 \\
\hline 104. & $\begin{array}{l}\text { Made unwanted attempts to draw you into a } \\
\text { discussion of personal matters? }\end{array}$ & 1 & 2 & 3 & 4 & 5 \\
\hline
\end{tabular}

You're about halfway through the survey! Thank you for filling out the previous questions. The next set of questions will have a different focus to them. We appreciate your participation.

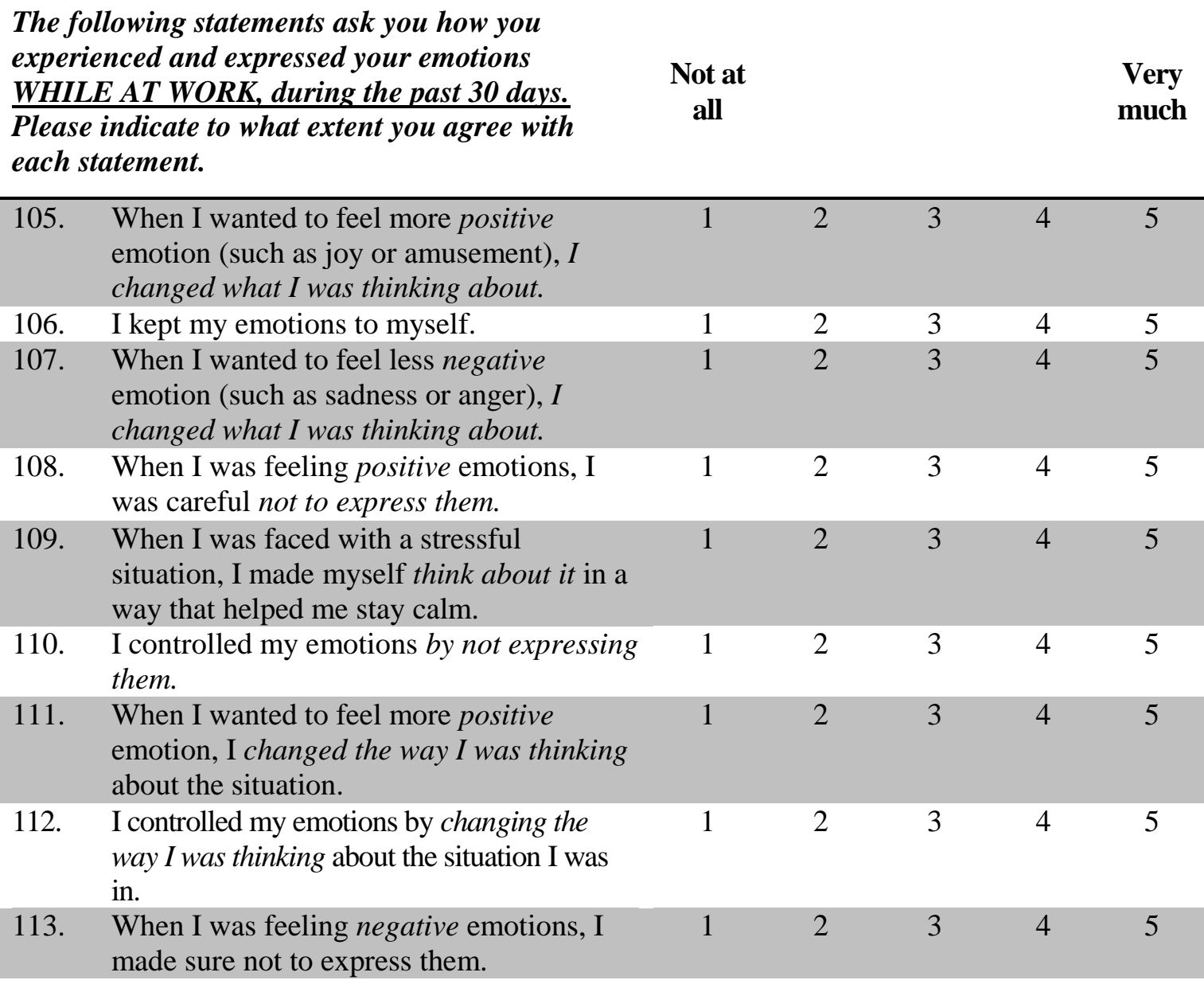



114. When I wanted to feel less negative emotion, I changed the way I was thinking about the situation.

\begin{tabular}{llccccc}
\hline Consider the past month when \\
answering the following questions. & $\begin{array}{c}\text { Very } \\
\text { rarely } \\
\text { or } \\
\text { never }\end{array}$ & $\begin{array}{c}\text { Rarely } \\
\text { (once a } \\
\text { week) }\end{array}$ & $\begin{array}{c}\text { Sometimes } \\
\text { (once a } \\
\text { day) }\end{array}$ & $\begin{array}{c}\text { Often } \\
\text { (several } \\
\text { times a } \\
\text { day) }\end{array}$ & $\begin{array}{c}\text { Several } \\
\text { times } \\
\text { an hour }\end{array}$ \\
\hline $115 . \quad \begin{array}{l}\text { Did your work demand a lot } \\
\text { from you emotionally? }\end{array}$ & 1 & 2 & 3 & 4 & 5 \\
\hline $116 . \quad \begin{array}{l}\text { Were you confronted with things } \\
\text { that affected you emotionally in } \\
\text { your work? }\end{array}$ & 1 & 2 & 3 & 4 & 5 \\
\hline $\begin{array}{l}\text { Did your work put you in } \\
\text { emotionally upsetting situations? }\end{array}$ & 1 & 2 & 3 & 4 & 5 \\
\hline
\end{tabular}

The following questions ask you to indicate what you generally do and feel, when you experience stressful events. Obviously, different events bring out somewhat different responses, but think about what you usually do when you are under a lot of stress.

\begin{tabular}{|c|c|c|c|c|c|c|}
\hline \multicolumn{2}{|c|}{ When I am under stress... } & \multirow{2}{*}{$\frac{\text { Never }}{1}$} & \multirow{2}{*}{$\frac{\text { Rarely }}{2}$} & \multirow{2}{*}{$\frac{\text { Sometimes }}{3}$} & \multirow{2}{*}{$\frac{\text { Usually }}{4}$} & \multirow{2}{*}{$\frac{\text { Always }}{5}$} \\
\hline 118. & $\begin{array}{l}\text { I get upset and let my emotions } \\
\text { out. }\end{array}$ & & & & & \\
\hline 119. & $\begin{array}{l}\text { I get upset, and am really aware } \\
\text { of it. }\end{array}$ & 1 & 2 & 3 & 4 & 5 \\
\hline 120. & I let my feelings out. & 1 & 2 & 3 & 4 & 5 \\
\hline 121. & $\begin{array}{l}\text { I feel a lot of emotional distress } \\
\text { and I find myself expressing } \\
\text { those feelings a lot. }\end{array}$ & 1 & 2 & 3 & 4 & 5 \\
\hline 122. & $\begin{array}{l}\text { I try to get advice from someone } \\
\text { about what to do. }\end{array}$ & 1 & 2 & 3 & 4 & 5 \\
\hline 123. & $\begin{array}{l}\text { I talk to someone to find out } \\
\text { more about the situation. }\end{array}$ & 1 & 2 & 3 & 4 & 5 \\
\hline 124. & $\begin{array}{l}\text { I talk to someone who could do } \\
\text { something concrete about the } \\
\text { problem. }\end{array}$ & 1 & 2 & 3 & 4 & 5 \\
\hline 125. & $\begin{array}{l}\text { I ask people who have had } \\
\text { similar experiences what they } \\
\text { did. }\end{array}$ & 1 & 2 & 3 & 4 & 5 \\
\hline 126. & $\begin{array}{l}\text { I discuss my feelings with } \\
\text { someone. }\end{array}$ & 1 & 2 & 3 & 4 & 5 \\
\hline 127. & $\begin{array}{l}\text { I try to get emotional support } \\
\text { from friends or relatives. }\end{array}$ & 1 & 2 & 3 & 4 & 5 \\
\hline
\end{tabular}




\begin{tabular}{llllll} 
128. $\begin{array}{l}\text { I get sympathy and } \\
\text { understanding from someone. }\end{array}$ & 1 & 2 & 3 & 4 & 5 \\
129. & 1 & 2 & 3 & 4 & 5 \\
$\begin{array}{l}\text { I talk to someone about how I } \\
\text { feel. }\end{array}$ & 1 & 2 & 3 & 4 & 5 \\
$130 . \quad \begin{array}{l}\text { I use alcohol or drugs to make } \\
\text { myself feel better. }\end{array}$ & 1 & 2 & 3 & 4 & 5 \\
$131 . \quad \begin{array}{l}\text { I try to lose myself for a while } \\
\text { by drinking alcohol or taking } \\
\text { drugs. }\end{array}$ & 1 & 2 & 3 & 4 & 5 \\
$132 . \quad \begin{array}{l}\text { I drink alcohol or take drugs, in } \\
\text { order to think about it less. }\end{array}$ & 1 & 2 & 3 & 4 & 5 \\
\hline $\begin{array}{l}\text { I use alcohol or drugs to help } \\
\text { me get through it. }\end{array}$ & 1 & & & & 5
\end{tabular}

\begin{tabular}{|c|c|c|c|c|c|}
\hline $\begin{array}{l}\text { To what extent do you agree with the } \\
\text { following statements about your relationship } \\
\text { with your spouse/partner in the past month? } \\
\text { If you are not currently in a relationship, } \\
\text { think about your last relationship when } \\
\text { responding. }\end{array}$ & $\begin{array}{c}\text { Do } \\
\text { not } \\
\text { agree } \\
\text { at all }\end{array}$ & $\begin{array}{c}\text { Disagree } \\
\text { slightly }\end{array}$ & Neutral & $\begin{array}{l}\text { Agree } \\
\text { slightly }\end{array}$ & $\begin{array}{l}\text { Fully } \\
\text { agree }\end{array}$ \\
\hline 134. We had a good relationship. & 1 & 2 & 3 & 4 & 5 \\
\hline $\begin{array}{l}\text { 135. My relationship with my } \\
\text { spouse/partner was very stable. }\end{array}$ & 1 & 2 & 3 & 4 & 5 \\
\hline 136. Our relationship was strong. & 1 & 2 & 3 & 4 & 5 \\
\hline $\begin{array}{l}\text { 137. My relationship with my } \\
\text { spouse/partner made me happy. }\end{array}$ & 1 & 2 & 3 & 4 & 5 \\
\hline $\begin{array}{l}\text { 138. I really felt like part of the team with } \\
\text { my spouse/partner. }\end{array}$ & 1 & 2 & 3 & 4 & 5 \\
\hline \multirow[t]{2}{*}{ considered, with your relationship? } & $\begin{array}{l}\text { Not } \\
\text { happy } \\
\text { at all }\end{array}$ & & & \multicolumn{2}{|c|}{$\begin{array}{c}\text { Completely } \\
\text { Happy }\end{array}$} \\
\hline & 1 & 2 & 3 & 4 & 5 \\
\hline $\begin{array}{l}\text { To what degree do you agree with the } \\
\text { following statements about yourself in } \\
\text { general? }\end{array}$ & $\begin{array}{c}\text { Do } \\
\text { not } \\
\text { agree } \\
\text { at all } \\
\end{array}$ & $\begin{array}{c}\text { Disagree } \\
\text { slightly }\end{array}$ & Neutral & $\begin{array}{l}\text { Agree } \\
\text { slightly }\end{array}$ & $\begin{array}{l}\text { Fully } \\
\text { agree }\end{array}$ \\
\hline $\begin{array}{l}\text { 140. I don't like to have to think about } \\
\text { work while I'm at home. }\end{array}$ & 1 & 2 & 3 & 4 & 5 \\
\hline 141. I prefer to keep work life at work. & 1 & 2 & 3 & 4 & 5 \\
\hline $\begin{array}{l}\text { 142. I don't like work issues creeping into } \\
\text { my home life. }\end{array}$ & 1 & 2 & 3 & 4 & 5 \\
\hline
\end{tabular}


143. I like to be able to leave work behind $\quad 1 \quad 3 \quad 2 \quad 3 \quad 4 \quad 4 \quad 5$ when I go home.

144. In my job, most of the problems that I experience are completely "out of my hands."

145. I feel powerless to control the outcomes of my work.

146. The same problems keep happening again and again, regardless of what I do.

\begin{tabular}{|c|c|c|c|c|c|c|}
\hline \multicolumn{2}{|c|}{$\begin{array}{l}\text { To what extent do you experience the } \\
\text { following moods in general? }\end{array}$} & \multirow{2}{*}{$\begin{array}{c}\text { Never } \\
1\end{array}$} & \multirow{2}{*}{$\frac{\text { Rarely }}{2}$} & \multirow{2}{*}{$\begin{array}{c}\text { Sometimes } \\
3\end{array}$} & \multirow{2}{*}{$\begin{array}{c}\text { Usually } \\
4\end{array}$} & \multirow{2}{*}{$\begin{array}{c}\text { Always } \\
5\end{array}$} \\
\hline 147. & Scared & & & & & \\
\hline 148. & Afraid & 1 & 2 & 3 & 4 & 5 \\
\hline 149. & Upset & 1 & 2 & 3 & 4 & 5 \\
\hline 150. & Distressed & 1 & 2 & 3 & 4 & 5 \\
\hline 151. & Jittery & 1 & 2 & 3 & 4 & 5 \\
\hline 152. & Nervous & 1 & 2 & 3 & 4 & 5 \\
\hline 153. & Ashamed & 1 & 2 & 3 & 4 & 5 \\
\hline 154. & Guilty & 1 & 2 & 3 & 4 & 5 \\
\hline 155. & Irritable & 1 & 2 & 3 & 4 & 5 \\
\hline 156. & Hostile & 1 & 2 & 3 & 4 & 5 \\
\hline 157. & Frightened & 1 & 2 & 3 & 4 & 5 \\
\hline 158. & Shaky & 1 & 2 & 3 & 4 & 5 \\
\hline 159. & Angry & 1 & 2 & 3 & 4 & 5 \\
\hline 160. & Scornful & 1 & 2 & 3 & 4 & 5 \\
\hline 161. & Disgusted & 1 & 2 & 3 & 4 & 5 \\
\hline 162. & Loathing & 1 & 2 & 3 & 4 & 5 \\
\hline 163. & Lonely & 1 & 2 & 3 & 4 & 5 \\
\hline
\end{tabular}




\begin{tabular}{|c|c|c|c|c|c|c|}
\hline \multicolumn{2}{|c|}{ In the past month, how often have you felt... } & $\begin{array}{c}\text { None } \\
\text { of } \\
\text { the } \\
\text { time }\end{array}$ & $\begin{array}{c}\text { A } \\
\text { little } \\
\text { of } \\
\text { the } \\
\text { time }\end{array}$ & $\begin{array}{c}\text { Some } \\
\text { of } \\
\text { the } \\
\text { time }\end{array}$ & $\begin{array}{c}\text { Most } \\
\text { of } \\
\text { the } \\
\text { time }\end{array}$ & $\begin{array}{c}\text { All } \\
\text { of } \\
\text { the } \\
\text { time }\end{array}$ \\
\hline 164. & $\begin{array}{l}\text { That you were unable to control the important } \\
\text { things in your life? }\end{array}$ & 1 & 2 & 3 & 4 & 5 \\
\hline 165. & $\begin{array}{l}\text { Confident about your ability to handle your } \\
\text { personal problems? }\end{array}$ & 1 & 2 & 3 & 4 & 5 \\
\hline 166. & That things were going your way? & 1 & 2 & 3 & 4 & 5 \\
\hline 167. & $\begin{array}{l}\text { Difficulties were piling up so high that you could } \\
\text { not overcome them? }\end{array}$ & 1 & 2 & 3 & 4 & 5 \\
\hline 168. & So sad nothing could cheer you up? & 1 & 2 & 3 & 4 & 5 \\
\hline 169. & Nervous? & 1 & 2 & 3 & 4 & 5 \\
\hline 170. & Restless or fidgety? & 1 & 2 & 3 & 4 & 5 \\
\hline 171. & Hopeless? & 1 & 2 & 3 & 4 & 5 \\
\hline 172. & That everything was an effort? & 1 & 2 & 3 & 4 & 5 \\
\hline 173. & Worthless? & 1 & 2 & 3 & 4 & 5 \\
\hline
\end{tabular}

There are only a few more sets of questions left. Thank you again for your patience-your responses are important and are intended to help to inform future decisions about your workplace.

\begin{tabular}{|c|c|c|c|c|c|c|}
\hline \multirow{3}{*}{\multicolumn{2}{|c|}{$\begin{array}{l}\text { Over the past month, how often have you experienced } \\
\text { each of the following symptoms? }\end{array}$}} & \multirow{3}{*}{$\begin{array}{c}\text { Not } \\
\text { at } \\
\text { all }\end{array}$} & \multirow{3}{*}{$\begin{array}{c}\begin{array}{c}\text { Once } \\
\text { or } \\
\text { twice }\end{array} \\
2\end{array}$} & \multirow{3}{*}{$\begin{array}{c}\begin{array}{c}\text { Once } \\
\text { or } \\
\text { twice } \\
\text { per } \\
\text { week }\end{array} \\
3\end{array}$} & \multirow{3}{*}{$\begin{array}{c}\text { Most } \\
\text { days }\end{array}$} & \multirow{3}{*}{$\begin{array}{c}\begin{array}{c}\text { Every } \\
\text { day }\end{array} \\
5\end{array}$} \\
\hline & & & & & & \\
\hline & & & & & & \\
\hline Trouble sleeping & & 1 & 2 & 3 & 4 & 5 \\
\hline Headache & & 1 & 2 & 3 & 4 & 5 \\
\hline Acid indigestion or heartburn & & 1 & 2 & 3 & 4 & 5 \\
\hline Eye strain & & 1 & 2 & 3 & 4 & 5 \\
\hline Diarrhea & & 1 & 2 & 3 & 4 & 5 \\
\hline Stomach cramps (Not menstrual) & & 1 & 2 & 3 & 4 & 5 \\
\hline Constipation & & 1 & 2 & 3 & 4 & 5 \\
\hline Ringing in the ears & & 1 & 2 & 3 & 4 & 5 \\
\hline Loss of appetite & & 1 & 2 & 3 & 4 & 5 \\
\hline Dizziness & & 1 & 2 & 3 & 4 & 5 \\
\hline Tiredness or fatigue & & 1 & 2 & 3 & 4 & 5 \\
\hline In the past month, how often were you... & $\begin{array}{l}\text { Not } \\
\text { at all }\end{array}$ & & $\begin{array}{l}\text { nce } \\
\text { la } \\
\text { hile }\end{array}$ & $\begin{array}{l}\text { very } \\
\text { veek }\end{array}$ & $\begin{array}{c}\text { Several } \\
\text { times } \\
\text { per } \\
\text { week }\end{array}$ & $\begin{array}{c}\text { Every } \\
\text { day }\end{array}$ \\
\hline
\end{tabular}




\begin{tabular}{|c|c|c|c|c|c|c|}
\hline 186. & Jumpy or easily startled. & 1 & 2 & 3 & 4 & 5 \\
\hline 187. & $\begin{array}{l}\text { Physically upset by reminders of a } \\
\text { distressing event from your past. }\end{array}$ & 1 & 2 & 3 & 4 & 5 \\
\hline 188. & Irritable or had outbursts of anger. & 1 & 2 & 3 & 4 & 5 \\
\hline 189. & $\begin{array}{l}\text { Unable to have sad or loving } \\
\text { feelings/generally numb. }\end{array}$ & 1 & 2 & 3 & 4 & 5 \\
\hline \multicolumn{4}{|c|}{ In the past month... } & Yes & \multicolumn{2}{|r|}{ No } \\
\hline 190. & \multicolumn{3}{|c|}{$\begin{array}{l}\text { Have you lost control and become physically aggressive, } \\
\text { which could include grabbing, pushing, or shoving, with } \\
\text { an intimate partner, spouse, or significant other? }\end{array}$} & 1 & \multicolumn{2}{|r|}{2} \\
\hline 191. & \multicolumn{3}{|c|}{$\begin{array}{l}\text { Have you been involved in a physical confrontation with } \\
\text { an intimate partner, spouse, or significant other? }\end{array}$} & 1 & \multicolumn{2}{|r|}{2} \\
\hline
\end{tabular}

In the past month...

192. On how many days did you consume alcohol? days

193. When you did drink, on average, how many drinks did you have in a day? drinks*

*(One drink can be one 12 oz. beer or wine cooler, one 5 oz. glass of wine, or $1.5 \mathrm{oz}$. liquor) 
PERCEIVED DANGEROUSNESS AND WELL-BEING

\begin{tabular}{|c|c|c|c|c|}
\hline The & lowing are some questions about your workplace. & Yes & No & $\begin{array}{c}\text { Not } \\
\text { sure/Not } \\
\text { applicable }\end{array}$ \\
\hline 195. & $\begin{array}{l}\text { Do you know how to use your EAP benefit? (Employee } \\
\text { Assistance Program) }\end{array}$ & 1 & 2 & 3 \\
\hline 196. & Do you believe EAP is completely confidential? & 1 & 2 & 3 \\
\hline 197. & Do you know what programs EAP has? & 1 & 2 & 3 \\
\hline 198. & $\begin{array}{l}\text { Do you know who your wellness committee members } \\
\text { are? }\end{array}$ & 1 & 2 & 3 \\
\hline 199. & $\begin{array}{l}\text { Do you feel you can talk to a co-worker about work } \\
\text { stressors? }\end{array}$ & 1 & 2 & 3 \\
\hline 200. & Is there a fitness center at your facility? & 1 & 2 & 3 \\
\hline 201. & Do you ever use the fitness center at your facility? & 1 & 2 & 3 \\
\hline 202. & $\begin{array}{l}\text { Have you participated in at least one wellness activity at } \\
\text { your facility over the last year? }\end{array}$ & 1 & 2 & 3 \\
\hline 203. & $\begin{array}{l}\text { Have you ever volunteered to serve on your wellness } \\
\text { committee? }\end{array}$ & 1 & 2 & 3 \\
\hline 204. & Have you ever felt overwhelmed by events at work? & 1 & 2 & 3 \\
\hline
\end{tabular}

These final questions ask about your background. These questions are not being asked in order to identify you as an individual. Responses will be compiled in order to look at groups of participants, not individual responses.

\begin{tabular}{|c|c|}
\hline 205. & What is your age? \\
\hline 206. & $\begin{array}{l}\text { What is your gender? (Circle one) } \\
\text { a. Male } \\
\text { b. Female }\end{array}$ \\
\hline 207. & $\begin{array}{l}\text { What is your marital status? (Circle one) } \\
\begin{array}{ll}\text { a. Single, never married } & \text { d. Living with a partner } \\
\text { b. Dating someone } & \text { e. Divorced } \\
\text { c. Married } & \text { f. Widowed }\end{array}\end{array}$ \\
\hline 208. & $\begin{array}{l}\text { What is your ethnicity? (Circle all that apply) } \\
\begin{array}{ll}\text { a. White (non-Hispanic) } & \text { e. Native American } \\
\text { b. Hispanic/Latino } & \text { f. Native Alaskan or Pacific Islander } \\
\text { c. African American } & \text { g. Other (please specify: } \\
\text { d. Asian } & \end{array}\end{array}$ \\
\hline 209. & 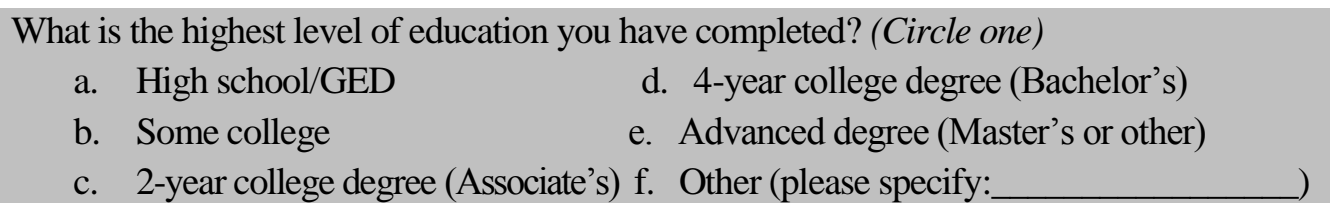 \\
\hline
\end{tabular}


210. How many children do you have that are living with you at least half time?

211. How many minutes to you spend traveling to and from work per day?

212. At which facility do you currently work?

213. What is the security level of inmates you've worked with the most in the past month?
a. Minimum
b. Medium
c. Maximum

214. Which best describes the shift you work?

a. Day shift

b. Swing shit

c. Night shift

215. How long have you been working as a correctional officer? years

216. How long have you been working at your current facility? years

217. Have you ever served on active duty in the U.S. Armed Forces? (Circle one)

a. Yes

b. No

218. On average in the past month, how many hours did you work per week? hours

219. Please indicate whether your current position in DOC is classified as... Circle one)

a. Security staff

b. Non-security staff

\section{Additional comments:}

